\title{
Acoustic Communication in the Pine Engraver Bark Beetle, Ips pini (Coleoptera: Scolytinae)
}

\author{
by
}

Senthurran Sivalinghem

A thesis submitted to the Faculty of Graduate and Postdoctoral Affairs in partial fulfillment of the requirements for the degree of

Master of Science

in

Biology

Carleton University

Ottawa, Ontario

(C) 2011

Senthurran Sivalinghem 
UMI Number: MR87816

All rights reserved

\section{INFORMATION TO ALL USERS}

The quality of this reproduction is dependent upon the quality of the copy submitted.

In the unlikely event that the author did not send a complete manuscript and there are missing pages, these will be noted. Also, if material had to be removed, a note will indicate the deletion.

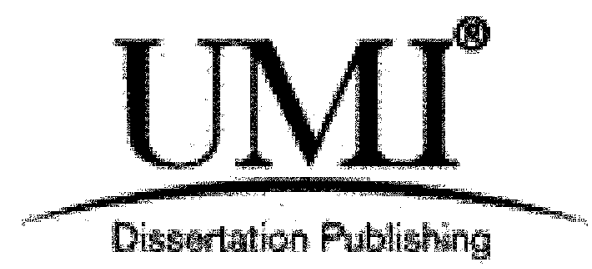

\section{UMI MR87816}

Published by ProQuest LLC 2012. Copyright in the Dissertation held by the Author. Microform Edition (C) ProQuest LLC.

All rights reserved. This work is protected against unauthorized copying under Title 17, United States Code.

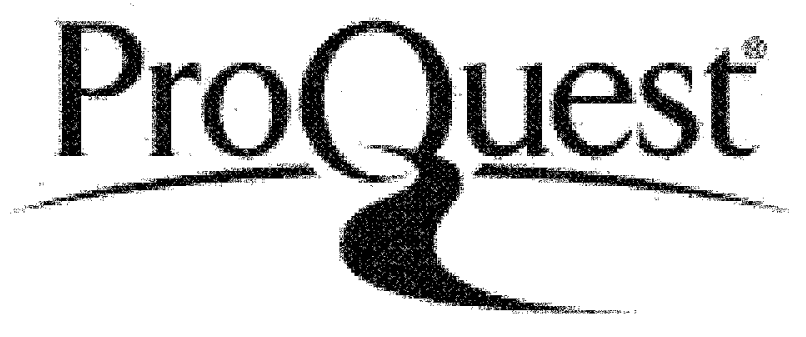

ProQuest LLC

789 East Eisenhower Parkway

P.O. Box 1346

Ann Arbor, MI 48106-1346 


\begin{abstract}
Most species of bark beetles (Coleoptera: Curculionidae: Scolytinae) produce acoustic signals that have been implicated to function in defense, mating, and orientation. Despite the purported importance of acoustic signals, little is known about their specific functions, physical characteristics and transmission properties, or how they are detected. The main objective of this thesis was to use the pine engraver (Ips pini) bark beetle as a model to characterize the acoustic properties of their signals, and describe putative receptor mechanisms. Females produced multi-impulse chirps using a vertex-pronotum stridulatory mechanism during disturbance $(22-27 \mathrm{kHz})$ and male-female pre-mating (10 to $12 \mathrm{kHz}$ ) behavioural conditions. There was significant variation in the temporal and spectral features of the acoustic signals between females, between behavioural conditions, and between populations. Signals were transmitted through air and the phloem substrate. Preliminary anatomical investigations show that receptors may be located in the antennae and lateral margins of the metathorax.
\end{abstract}




\section{Acknowledgement}

This thesis would not have been possible without the support and input from numerous people. First and foremost, I would like to express gratitude to my supervisor, Dr. Jayne Yack, who provided numerous opportunities for my development as a scientist. I am very grateful to Jayne for allowing me to independently pursue my research interest, and for always being available to provide direction and input, throughout all stages of my research, writing, and presentations. I am greatly indebted to Jayne for the time I was allowed to spend in her lab. Second, I would like to thank my committee, Dr. Jeff Dawson, and Dr. John Lewis. I am very thankful to Dr. Jeff Dawson, who was always willing and able to answer questions, explain concepts, and provide insightful advice on a variety of topics. Third, I greatly thank my fellow graduate students at the Yack lab, J-P Fournier, A.J. Fleming, Veronica Bura, Jackie Scott, Sarah Matheson, Ombor Mitra, Laura McMillan, and Amanda Lindeman, for helpful discussions and feedback on analysis and presentations, for their friendship, and for making my time in and outside the lab fun and enjoyable. A.J. Fleming was very helpful when I started working in the lab, and I have enjoyed our many discussions about bark beetles. Veronica Bura was helpful with taking morphological measurements, and putting together some of the figures in this thesis. Some of the images in this thesis were taken by expert photographer J-P Fournier. This research would also not be possible without the assistance from our undergraduate summer students, Karen Wang, Cynthia Shaheen, and Mikhel Sickand, who helped me with some experiments, and collected bark beetles every week. All of the illustrations and many figures in this thesis would not have been possible without Karen's wonderful 
artistry and Photoshop skills. I also thank Dr. Mary Reid at the University of Calgary for collecting and shipping pine engravers to Carleton, and Dr. Myron Smith for helping with cutting down red pine trees and collecting logs for my experiments. I would also like to thank my parents, Sivalinghem and Selva, and all my family and friends for their love and support. Lastly, I thank Carleton University for awarding me the Carleton Graduate Scholarship, and providing travel funds to go to conferences. Funding for this research was provided to Dr. Jayne Yack by grants from the National Science and Engineering Research Council (NSERC Discovery Grant), and from the Ministry of Research and Innovation (Early Research Award). 


\section{Table of Contents}

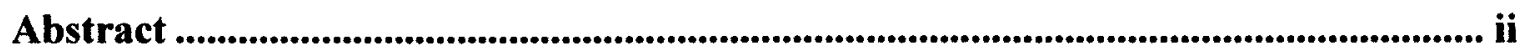

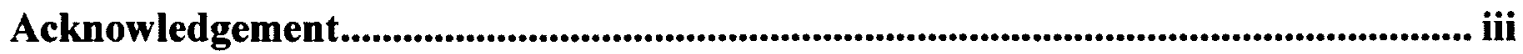

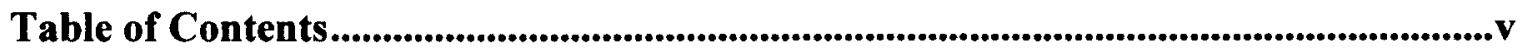

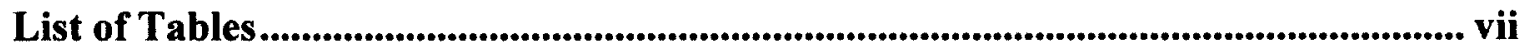

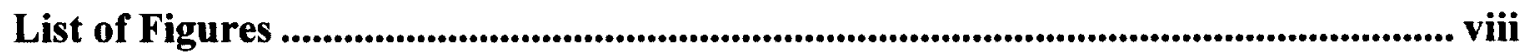

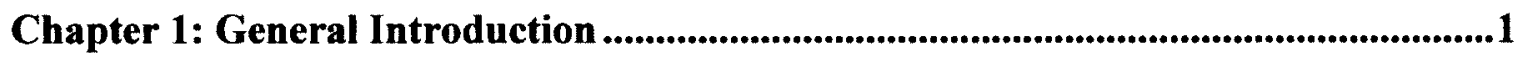

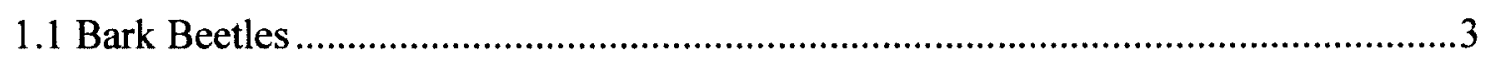

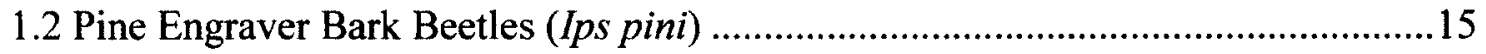

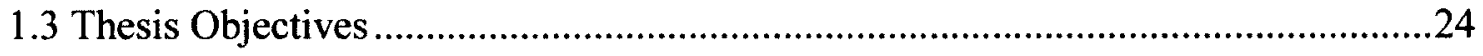

Chapter 2: Acoustic communication in the pine engraver bark beetle, Ips pini (Say)

(Coleoptera: Scolytinae): Signal characterization, variation, and function................27

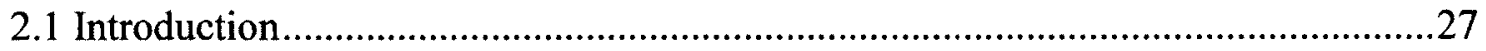

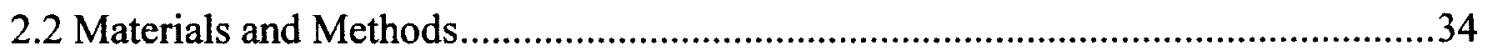

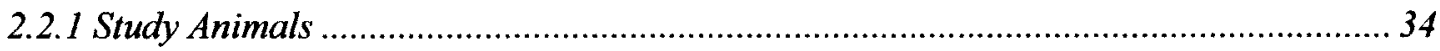

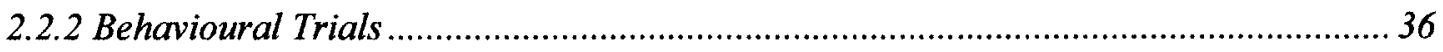

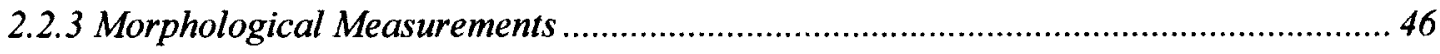

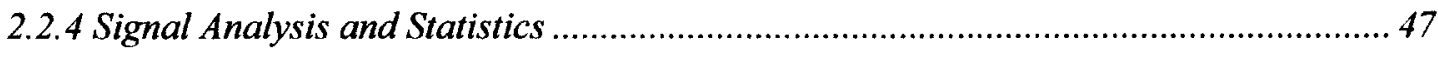

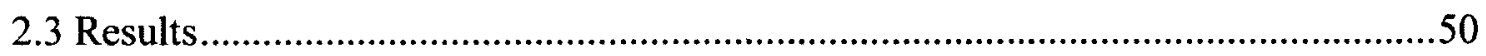

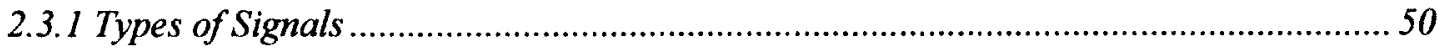

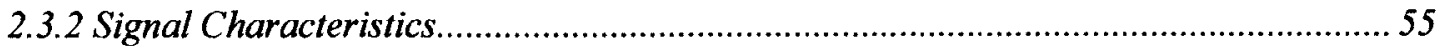

2.3.3 Comparing Signal Characteristics between Behavioural Conditions ........................ 73

2.3.4 Comparing Signal Characteristics between Populations ........................................... 76 
2.4 Discussion

Chapter 3: Acoustic communication in Ips pini: Putative acoustic receptors and the central nervous system ..............................................................................................................98

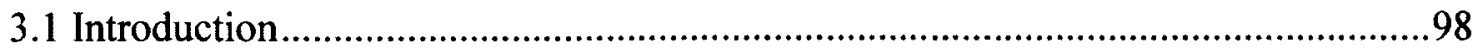

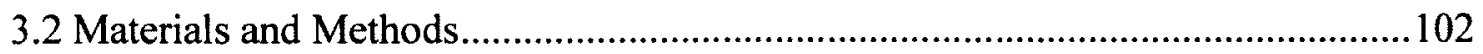

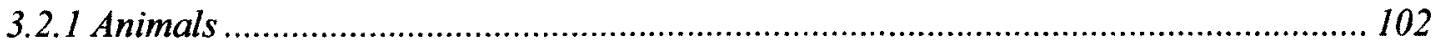

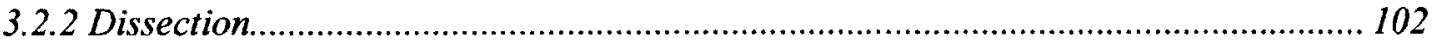

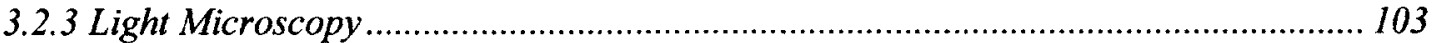

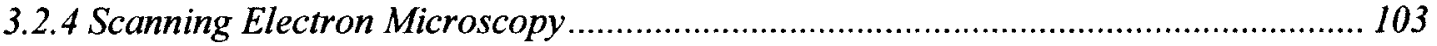

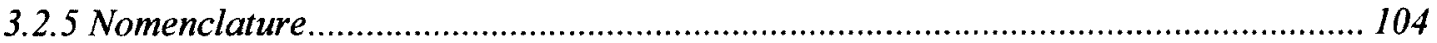

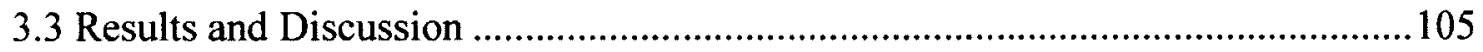

3.3.1 External Morphology of Ips pini........................................................................ 105

3.3.2 Anatomy of the Central Nervous System of Ips pini................................................ 113

Chapter 4: General Discussion .........................................................................................................125

References..............................................................................................................................131 


\section{List of Tables}

Table 1.1. Summary of bark beetle acoustics literature................................................................7

Table 1.2. Occurrence of stridulatory organs in the North America Ips species...............22

Table 2.1. Results from Swaby and Rudinsky (1976) showing temporal characteristics of

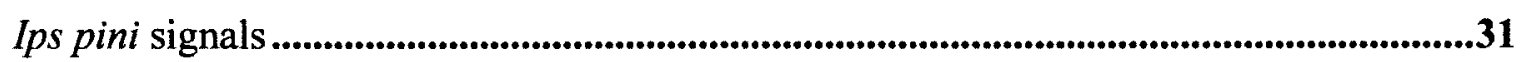

Table 2.2. Summary of female Ips pini acoustic signal characteristics................................56

Table 2.3. Raw data of female phenotypic characteristics for stepwise regressions ........61

Table 2.4. Raw data of female acoustic signal characteristics for stepwise regressions ..62

Table 2.5. Results from a stepwise multiple regression analysis examining correlations between disturbance signal characteristics and female phenotypic traits.............................63

Table 2.6. Within-female coefficient of variation ....................................................................64

Table 2.7. Between-female coefficient of variation..............................................................65

Table 2.8. Results from a Kurskal-Wallis comparison of signals characteristics between behavioural conditions.......................................................................................................................74

Table 2.9. Results from a Mann-Whitney $U$ comparison of signal characteristics between Alberta and Ontario females......................................................................................................77 


\section{List of Figures}

Figure 1.1. Mating behaviour of the pine engraver (Ips pini) bark beetles .........................18

Figure 1.2. Gallery of pine engraver (Ips pini) adults and larvae.........................................20

Figure 2.1. Lateral view of adult Ips pini male and female..........................................................37

Figure 2.2. Dorsal and ventral view of checkered beetle, Thanasimus dubius ...................38

Figure 2.3. Scanning electron micrographs of Ips pini stridulatory organ .........................39

Figure 2.4. General methodology for recording disturbance and anti-predation signals .40

Figure 2.5. General methodology for recording female pre-mating signals........................45

Figure 2.6. General characteristics of female Ips pini acoustic signals................................52

Figure 2.7. Variation in female I. pini acoustic signals.........................................................53

Figure 2.8. Proportion of interrupted chirps between behavioural conditions ...................54

Figure 2.9. Disturbance signals of Ontario Ips pini female recorded with an Avisoft

microphone ............................................................................................................................................58

Figure 2.10. Disturbance signals of Ontario Ips pini female recorded with a Brüel and Kjær microphone ..................................................................................................................................59

Figure 2.11. Ontario female Ips pini signals during predation event ...................................67

Figure 2.12. Pre-mating signals of Alberta female Ips pini recorded with an Avisoft microphone .............................................................................................................................69

Figure 2.13. Change in female signaling effort with time......................................................71

Figure 2.14. Substrate-borne vibrations signals of Ips pini ...................................................72

Figure 3.1. External morphology of Ips pini antennae ..........................................................106

Figure 3.2. External morphology of Ips pini thoracic legs......................................................111

Figure 3.3. External morphology of putative tympanal structure........................................114 
Figure 3.4. Schematic illustration of Ips pini central nervous system................................117

Figure 3.5. Dorsal view of the brain and suboesophageal ganglion of Ips pini ..............118

Figure 3.6. Lateral view of Ips pini brain, esophagus, and suboesophageal ganglion ...119

Figure 3.7. Dorsal view of the thoracic and abdominal ganglia of Ips pini ......................120 


\section{Chapter 1}

\section{General Introduction}

Numerous insect species across taxa communicate with complex acoustic and vibratory signals. Acoustic signals have been shown to function in a variety of behavioural contexts including, mate attraction and recognition, courtship, predator-prey interactions, and aggression/territoriality (Drosopoulos and Claridge 2006). In theory, signals that function for communication must be efficiently and effectively transmitted, received and processed, and elicit a behavioural response in the intended receiver. This sender-receiver interaction has been extensively demonstrated and studied in several orthopteran, hemipteran, lepidopteran and hymenopteran species (Drosopoulos and Claridge 2006). In contrast, studies of acoustic communication in beetles (Coleoptera) have lagged behind, receiving relatively less attention (Alexander et al. 1963; Arrow 1942; Wessel 2006).

Sound production in beetles has been described in at least 30 families and has evolved multiple times (Wessel 2006). Sounds are produced through a mechanism of stridulation, which is ubiquitous across Coleoptera, where a "file-and-scraper-like" stridulatory organ is scraped together (Alexander et al 1963; Arrow 1942; Wessel 2006). Stridulatory organs consists of two highly sclerotized structures, a "pars stridens" (file), usually composed of a series of transverse ridges, and a "plectrum" (scraper), which can either be a single sclerotized peg, a series of pegs, a single ridge, multiple ridges, tapered edge of an appendage, or tubercles (Wessel 2006). Given the highly sclerotized exoskeletons, where simple movements can cause body parts to strike and elicit 
vibrations, stridulatory organs have evolved on almost every part of the beetle body (Wessel 2006). Axel Michelsen (1965) discussed the synchronization of various rhythmic movements during courtship behaviour in the long-horned beetles (Cerambycidae), and suggested that the 'ritualization' of these movements can lead to different stridulatory organs independently evolving. Miller (1971) later demonstrated that the prothoracic movements during stridulation in a sub-family, Strangalia (Cerambycidae), are comparable to the prothoracic movements during hyperventilation in a non-stridulating primitive sub-family, the Prionines (Cerambycidae). To date, 14 different types of stridulatory mechanisms have been described in beetles (see Wessel 2006 for a comprehensive list), and many are thought to have evolved from movements produced during walking, wing-folding, biting, and struggling behaviours (see discussions in Claridge 1968; Hyder and Oseto 1989; Lyal and King 1996; Masters 1980; Michelsen 1965; Miller 1971).

In contrast to the plethora of studies describing stridulatory structures and mechanisms (Barr 1969; Carisio et al. 2004; Hyder and Oseto 1989; Kasper and Hirschberger 2005; Lyal and King 1996; Schmitt and Traue 1990; Schmitt 1994), very few studies have empirically tested the functions of acoustic signaling in beetles (Buchler et al. 1981; Eisner et al. 1974; Masters 1979 and 1980), and only a few provide adequate descriptions of the signals produced (see Hirschberger 2001; Mankin et al. 2009; Schmitt and Traue 1990). Furthermore, the receptor mechanisms involved in receiving conspecific signals are largely unknown for most beetles. Functional receptor organs, however, has been described in a few species (e.g. tympanal hearing organ in scarab (Dynastinae) and tiger (Cicindelidae) beetles: Forrest et al. 1997; Spangler 1988; Yager 
and Spangler 1995 and 1997; and Johnston's organ in whirligig beetles (Gyrinidae): Bendele 1986; Kolmes 1983). However, in those beetles, "hearing" organs primarily function for detecting the ultrasonic cries of predatory bats (in scarab and tiger beetles) or the water-surface vibrations of preys (in whirligig beetles). Clearly, there remains a need for further research into the characteristics, functions and receptors mechanisms of acoustic communication in different beetle groups.

One large family of beetles that has received relatively little attention in terms of acoustic communication is the bark beetles (Scolytinae), a subfamily of the true weevils (Curculionidae). The main focus of this thesis is to investigate acoustic and vibratory communication in the bark beetles.

\subsection{Bark Beetles}

Bark beetles (Coleoptera: Curculionidae: Scolytinae) are ecologically important parasites of coniferous trees (order, Pinales) mainly in the Pinaceae family. They attack and kill recently damaged and weakened host trees, promoting nutrient and carbon cycling, and can influence the structure, tree species composition, and biodiversity of coniferous forest ecosystems (Kurz et al. 2008; Raffa et al. 2008). In general, adults will parasitize weakened trees, bore into the phloem, mate, build galleries, and lay eggs along the sides. The larvae will mature, feed, excavate tunnels (disrupting water flow in the tree vascular system), pupate, and emerge as adults, causing the eventual deaths of their hosts (Byers 1989; Rudinsky 1962; Sauvard 2007). This life cycle involves complex con and hetero-specific interactions and associations, many of which are not yet fully understood (see Klepzig et al. 2001; Klepzig and Six 2004; Raffa et al. 2008). For example, during 
periods of population eruptions (outbreak conditions), some "aggressive" bark beetle species are capable of attacking healthy trees by overcoming the resinous defenses of their hosts (Raffa and Berryman 1983). Two evolutionary adaptations facilitate with weakening the defenses of healthy hosts: 1) conspecific mass aggregations/attacks; and 2) complex symbiotic association and vectoring of various fungal, and mite species (Bentz et al. 2010; Klepzig et al. 2001; Raffa et al. 2008). During outbreaks, these aggressive bark beetles are considered primary pests, as damage to healthy trees can directly and indirectly alter forest ecosystems, with significant negative environmental and economical impacts (Bentz et al. 2010; Raffa et al. 2008). Understanding the mechanisms of these con- and hetero-specific interactions can provide invaluable insights into bark beetle behavioural and evolutionary ecology, which has applications in conservation biology, forest and pest management, and international environmental policy making.

Host colonization in bark beetles involves both long and short range communication systems. Long-range communication involves chemical cues and pheromones (Byers 2007; Symond and Elgar 2004a and b), whereas short-range communication involves both acoustic signaling and pheromones (Ryker 1988). Chemical communication has been extensively studied (Andersson et al. 2009; Angst and Lanier 1979; Byers 1989 and 2007; Raffa 2001; Rudinsky 1962; Wallin and Raffa 2000). These studies show that host localization, selection and colonization are driven by: 1) primary attraction to host terpenes, and kairomones; and 2) secondary attraction to conspecific aggregation "calling" pheromones (Byers 2007). Aggregation or attractant pheromones are synthesized through the oxidization of host terpenes (Raffa et al. 2008), and can have a duel function for mate attraction, and for inter and intra-species 
competition (as anti-aggregation pheromones), depending on the concentration (Rudinsky et al. 1974 and 1975; Symond and Elgar 2004a and b; Tommeras et al. 1984). These signals are received through hair-like olfactory receptors located on the antennal clubs, and studies show a good match between species-specific pheromone composition, and receptor sensitivity or "tuning" in many species (Mustaparta et al. 1982 and 1985; Pureswaran et al. 2004). Acoustic communication, however, is less understood, and has received relatively little attention compared to research on chemical communication.

\section{Mechanisms of sound production}

Acoustic communication is believed to be widespread across Scolytinae, as stridulatory structures have been documented and described in numerous species across genera (see Barr 1969). To date, studies on acoustics in bark beetles have primarily focused on the mechanisms of sound production, as well as some of the temporal characteristics of signals and how they are associated with different behavioural contexts (see Table 1.1). Three main types of stridulatory mechanisms have been described: 1) vertex-pronotum, where the pars stridens on the vertex of the head is scraped against a plectrum (comprised of multiple ridges) on the ventral anterior of the pronotum; 2) gularprosternum, where the pars stridens on the underside of the head is scraped against a single or multi-ridged plectrum at the anterior edge of the prosternum; and 3) elytralabdominal, where the pars stridens on one of the elytra (usually on the left elytrum) is

scraped by two sclerotized pegs on the $7^{\text {th }}$ abdominal tergite (Barr 1969). Rudinsky and Michael (1973) described a fourth mechanism found in some females of the genus 
Dendroctonus, where a sclerotized peg on the $8^{\text {th }}$ abdominal segment (pygidium), is scraped against a pars stridens on the posterior margin of the last sternite.

The evolutionary origin of these different mechanisms is not yet known. Lyal and King (1996), however, demonstrated that the elytral-abdominal mechanism is common across the family Curculionidae, which includes the sub-family Scolytinae (bark beetles), and suggested that this mechanism likely evolved from abdominal movements during wing-folding- the folding of the thin and transparent flight wings under the elytra. For example, during stridulation, in the beech weevils (Curculionidae: Rhynchaenus), the abdomen is inflated (either by haemolymph pressure, air pressure, or muscular contraction; mechanism is not known) allowing the plectrum to contact the pars stridens, and stridulation is produced by the up and down motion of the abdomen (Claridge 1968). This is similar to the abdominal movements during wing-folding, where the abdominal inflation allows spines on the membranous tergites (i.e. $5^{\text {th }}$ and $6^{\text {th }}$ segments) to contact flight wings, and the up and down motion gradually pulls and folds the wings under the elytra (Claridge 1968). Similar wing-folding behaviour was observed, under a light microscope, in the pine engraver bark beetle, Ips pini (personal observation).

The type of stridulatory mechanism found in bark beetles has a general association with the stridulating sex, the genus, and mating system. For example, the elytral-abdominal mechanism is primarily found in non-host selecting males of monogamous species (e.g. Dendroctonus, Hylesinus, and Leperisinus) (Michael and Rudinsky 1972; Rudinsky and Vallo 1978; Vernoff and Rudinsky 1980), whereas the vertex-pronotum mechanism is usually found in non-host selecting females of 
Table 1.1. Summary of bark beetle (Coleoptera: Curculionidae: Scolytinae) acoustics literature.

\begin{tabular}{|c|c|c|c|c|}
\hline \multirow{2}{*}{ Genus and species } & \multirow{2}{*}{$\begin{array}{c}\text { Stridulating } \\
\text { sex }\end{array}$} & \multicolumn{2}{|c|}{ Stridulatory Mechanism } & \multirow{2}{*}{ References and Notes } \\
\hline & & Location of pars stridens & Location of plectrum & \\
\hline Dendroctonus & & & & See Ryker 1988 \\
\hline \multirow{2}{*}{ D. brevicomis } & Males & $\begin{array}{l}\text { Posterior medial undersurface of the } \\
\text { elytra }\end{array}$ & $\begin{array}{l}\text { Posterior edge the } 7^{\text {th }} \text { abdominal } \\
\text { tergite }\end{array}$ & \multirow{2}{*}{$\begin{array}{l}\text { Rudinsky et al. 1976; Rudinsky } \\
\text { and Michael } 1974\end{array}$} \\
\hline & Females & $\begin{array}{c}\text { Inside wall of posterior margin of } \\
\text { the last sternite }\end{array}$ & $\begin{array}{c}\text { Posterior half of the } 8^{\text {th }} \text { abdominal } \\
\text { segment (pygidium) }\end{array}$ & \\
\hline \multirow{2}{*}{ D. frontalis } & Males & $\begin{array}{l}\text { Posterior medial undersurface of the } \\
\text { elytra }\end{array}$ & $\begin{array}{c}\text { Posterior edge the } 7^{\text {th }} \text { abdominal } \\
\text { tergite }\end{array}$ & \multirow{2}{*}{ Rudinsky and Michael 1974} \\
\hline & Females & $\begin{array}{l}\text { Inside wall of posterior margin of } \\
\text { the last sternite }\end{array}$ & $\begin{array}{l}\text { Posterior half of the } 8^{\text {th }} \text { abdominal } \\
\text { segment (pygidium) }\end{array}$ & \\
\hline \multirow{3}{*}{ D. ponderosae } & Males & $\begin{array}{l}\text { Posterior medial undersurface of the } \\
\text { elytra }\end{array}$ & $\begin{array}{c}\text { Posterior edge the } 7^{\text {th }} \text { abdominal } \\
\text { tergite }\end{array}$ & \multirow{3}{*}{$\begin{array}{l}\text { Michael and Rudinsky 1972; } \\
\text { Rudinsky and Michael 1973; } \\
\text { Ryker and Rudinsky 1976b; } \\
\text { Yandell } 1984\end{array}$} \\
\hline & ingalec & $\begin{array}{l}\text { 1) Posterior medial undersurface of } \\
\text { the elytra }\end{array}$ & Posterior half of the $8^{\text {th }}$ abdominal & \\
\hline & remales & $\begin{array}{l}\text { 2) Inside wall of posterior margin of } \\
\text { the last sternite }\end{array}$ & segment (pygidium) & \\
\hline \multirow{3}{*}{ D. pseudotsugae } & Males & $\begin{array}{l}\text { Posterior medial undersurface of the } \\
\text { elytra }\end{array}$ & $\begin{array}{l}\text { Posterior edge the } 7^{\text {th }} \text { abdominal } \\
\text { tergite }\end{array}$ & \multirow{3}{*}{$\begin{array}{l}\text { Michael and Rudinsky 1972; } \\
\text { Rudinsky et al. } 1973 \text { and 1976; } \\
\text { Rudinsky and Michael 1972; } \\
\text { Rudinsky and Michael 1973; } \\
\text { Rudinsky and Ryker 1976; } \\
\text { Rudinsky 1969; Ryker et al. } 1979\end{array}$} \\
\hline & Females & $\begin{array}{l}\text { 1) Posterior medial undersurface of } \\
\text { the elytra }\end{array}$ & Posterior half of the $8^{\text {th }}$ abdominal & \\
\hline & & $\begin{array}{l}\text { 2) Inside wall of posterior margin of } \\
\text { the last sternite }\end{array}$ & segment (pygidium) & \\
\hline
\end{tabular}




\begin{tabular}{|c|c|c|c|c|}
\hline \multirow{3}{*}{ D. rufipennis } & Males & $\begin{array}{c}\text { Posterior medial undersurface of the } \\
\text { elytra }\end{array}$ & $\begin{array}{l}\text { Posterior edge the } 7^{\text {th }} \text { abdominal } \\
\text { tergite }\end{array}$ & \multirow{3}{*}{$\begin{array}{l}\text { Rudinsky and Michael 1973; } \\
\text { Rudinsky and Michael } 1974\end{array}$} \\
\hline & \multirow[b]{2}{*}{ Females } & & \multirow{2}{*}{$\begin{array}{l}\text { Posterior half of the } 8^{\text {th }} \text { abdominal } \\
\text { segment (pygidium) }\end{array}$} & \\
\hline & & $\begin{array}{l}\text { 2) Inside wall of posterior margin of } \\
\text { the last sternite }\end{array}$ & & \\
\hline \multirow{3}{*}{ D. valens } & Males & $\begin{array}{l}\text { Posterior medial undersurface of the } \\
\text { elytra }\end{array}$ & $\begin{array}{c}\text { Posterior edge the } 7^{\text {th }} \text { abdominal } \\
\text { tergite }\end{array}$ & \multirow{3}{*}{ Ryker and Rudinsky 1976a } \\
\hline & & $\begin{array}{l}\text { 1) Posterior medial undersurface of } \\
\text { the elytra }\end{array}$ & $8^{\text {th }}$ & \\
\hline & Females & $\begin{array}{l}\text { 2) Inside wall of posterior margin of } \\
\text { the last sternite }\end{array}$ & segment (pygidium) & \\
\hline \multicolumn{5}{|l|}{ Hylesinus } \\
\hline H. oleiperda & Males & $\begin{array}{c}\text { Posterior medial undersurface of the } \\
\text { elytra }\end{array}$ & $\begin{array}{c}\text { Posterior edge the } 7^{\text {th }} \text { abdominal } \\
\text { tergite }\end{array}$ & Rudinsky and Vallo 1978 \\
\hline \multicolumn{5}{|l|}{ Hylurgopinus } \\
\hline H. rufipennis & Males & $\begin{array}{l}\text { Posterior medial undersurface of the } \\
\text { elytra }\end{array}$ & $\begin{array}{c}\text { Posterior edge the } 7^{\text {th }} \text { abdominal } \\
\text { tergite }\end{array}$ & Swedenborg et al. 1989 \\
\hline \multicolumn{5}{|l|}{ Hylurgops } \\
\hline \multirow{2}{*}{ H. rugipennis } & Males & $\begin{array}{c}\text { Posterior medial undersurface of the } \\
\text { elytra }\end{array}$ & $\begin{array}{c}\text { Posterior edge the } 7^{\text {th }} \text { abdominal } \\
\text { tergite }\end{array}$ & \multirow{2}{*}{ Oester et al. 1978} \\
\hline & Females & $\begin{array}{l}\text { Posterior medial undersurface of the } \\
\text { elytra }\end{array}$ & Unknown & \\
\hline
\end{tabular}




\begin{tabular}{|c|c|c|c|c|}
\hline Ips & & & & See Barr 1969 \\
\hline I. calligraphus & Females & Vertex of head & $\begin{array}{l}\text { Ventro-anterior portion of the } \\
\text { pronotum }\end{array}$ & $\begin{array}{l}\text { Lewis and Cane 1990; Wilkinson } \\
\text { et al. 1967; Wilkinson } 1962\end{array}$ \\
\hline I. concinnus & $\begin{array}{l}\text { Males and } \\
\text { Females }\end{array}$ & Underside (gula) of the head & Anterior edge of the prosternum & $\begin{array}{l}\text { Barr 1969; Oester and Rudinsky } \\
\text { 1975; Oester and Rudinsky } 1979\end{array}$ \\
\hline I. confusus & Females & Vertex of head & $\begin{array}{l}\text { Ventro-anterior portion of the } \\
\text { pronotum }\end{array}$ & Barr 1969; Lewis and Cane 1992; \\
\hline $\begin{array}{l}\text { I. confuses (pinyon } \\
\text { form) }\end{array}$ & Females & Vertex of head & $\begin{array}{l}\text { Ventro-anterior portion of the } \\
\text { pronotum }\end{array}$ & Barr 1969 \\
\hline I. hoppingi & Females & Vertex of head & $\begin{array}{l}\text { Ventro-anterior portion of the } \\
\text { pronotum }\end{array}$ & Lewis and Cane 1992 \\
\hline I. lecontei & Females & Vertex of head & $\begin{array}{l}\text { Ventro-anterior portion of the } \\
\text { pronotum }\end{array}$ & Lewis and Cane 1992 \\
\hline I. mexicanus & $\begin{array}{l}\text { Males and } \\
\text { Females }\end{array}$ & Underside (gula) of the head & Anterior edge of the prosternum & $\begin{array}{l}\text { Barr 1969; no sounds heard in } \\
\text { males }\end{array}$ \\
\hline I. paraconfusus & Females & Vertex of head & $\begin{array}{l}\text { Ventro-anterior portion of the } \\
\text { pronotum }\end{array}$ & Lewis and Cane 1992 \\
\hline \multirow{2}{*}{ 1. pini } & Females & Vertex of head & $\begin{array}{l}\text { Ventro-anterior portion of the } \\
\text { pronotum }\end{array}$ & \multirow{2}{*}{$\begin{array}{l}\text { Barr 1969; Oester and Rudinsky } \\
\text { 1975; Swaby and Rudinsky 1976; } \\
\text { Males produced 'clicks' }\end{array}$} \\
\hline & males & Unknown & Unknown & \\
\hline I. plastographus & Females & Vertex of head & $\begin{array}{l}\text { Ventro-anterior portion of the } \\
\text { pronotum }\end{array}$ & $\begin{array}{l}\text { Barr 1969; Oester and Rudinsky } \\
1979\end{array}$ \\
\hline
\end{tabular}




\begin{tabular}{|c|c|c|c|c|}
\hline \multirow{2}{*}{ I. tridens tridens } & Females & $\begin{array}{l}\text { Transverse ridges found on the } \\
\text { underside (gula) of the head }\end{array}$ & Unknown & \multirow{2}{*}{$\begin{array}{l}\text { Oester and Rudinsky 1975; Oester } \\
\text { and Rudinsky 1979; Males } \\
\text { produced 'clicks' }\end{array}$} \\
\hline & Males & Unknown & Unknown & \\
\hline \multirow{2}{*}{ I. typographus } & Females & Underside (gula) of the head & Anterior edge of the prosternum & \multirow{2}{*}{$\begin{array}{l}\text { Rudinsky 1979; Males produced } \\
\text { 'clicks' }\end{array}$} \\
\hline & Males & Unknown & Unknown & \\
\hline \multicolumn{5}{|l|}{ Leperisinus } \\
\hline L. californicus & Males & $\begin{array}{l}\text { Posterior medial undersurface of the } \\
\text { elytra }\end{array}$ & $\begin{array}{l}\text { Posterior edge the } 7^{\text {th }} \text { abdominal } \\
\text { tergite }\end{array}$ & Vernoff and Rudinsky 1980 \\
\hline \multirow{2}{*}{ L. fraxini } & Males & $\begin{array}{l}\text { Posterior medial undersurface of the } \\
\text { elytra }\end{array}$ & $\begin{array}{c}\text { Posterior edge the } 7^{\text {th }} \text { abdominal } \\
\text { tergite }\end{array}$ & \multirow{2}{*}{$\begin{array}{l}\text { Rudinsky and Vallo 1979; Females } \\
\text { produced 'clicks' }\end{array}$} \\
\hline & Females & $\begin{array}{l}\text { Posterior medial undersurface of the } \\
\text { elytra }\end{array}$ & Unknown & \\
\hline L. oregonus & Males & $\begin{array}{l}\text { Posterior medial undersurface of the } \\
\text { elytra }\end{array}$ & $\begin{array}{c}\text { Posterior edge the } 7^{\text {th }} \text { abdominal } \\
\text { tergite }\end{array}$ & Vernoff and Rudinsky 1980 \\
\hline \multicolumn{5}{|l|}{ Polygraphus } \\
\hline \multirow{2}{*}{ P. rufipennis } & Males & $\begin{array}{l}\text { Posterior medial undersurface of the } \\
\text { elytra }\end{array}$ & $\begin{array}{l}\text { Posterior edge the } 7^{\text {th }} \text { abdominal } \\
\text { tergite }\end{array}$ & \multirow{2}{*}{$\begin{array}{l}\text { Rudinsky et al. 1978a; Females } \\
\text { scraped their mandibles against } \\
\text { males' declivity }\end{array}$} \\
\hline & Females & Unknown & Unknown & \\
\hline
\end{tabular}




\begin{tabular}{|c|c|c|c|c|}
\hline \multirow{2}{*}{ P. nebulosus } & Males & $\begin{array}{l}\text { Posterior medial undersurface of the } \\
\text { elytra }\end{array}$ & $\begin{array}{c}\text { Posterior edge the } 7^{\text {th }} \text { abdominal } \\
\text { tergite }\end{array}$ & \multirow{2}{*}{$\begin{array}{l}\text { Oester et al. } 1981 \text {; females } \\
\text { produced 'clicks' }\end{array}$} \\
\hline & Females & $\begin{array}{l}\text { Posterior medial undersurface of the } \\
\text { elytra }\end{array}$ & Unknown & \\
\hline \multicolumn{5}{|l|}{ Scolytus } \\
\hline S. mali & $\begin{array}{l}\text { Males and } \\
\text { Females }\end{array}$ & Underside (gula) of the head & Anterior edge of the prosternum & Rudinsky et al. $1978 \mathrm{~b}$ \\
\hline S. multistriatus & $\begin{array}{l}\text { Males and } \\
\text { Females }\end{array}$ & Underside (gula) of the head & Anterior edge of the prosternum & $\begin{array}{l}\text { Jefferies and Fairhurst 1982; no } \\
\text { sounds characterized }\end{array}$ \\
\hline S. scolytus & $\begin{array}{l}\text { Males and } \\
\text { Females }\end{array}$ & Underside (gula) of the head & Anterior edge of the prosternum & $\begin{array}{l}\text { Jefferies and Fairhurst 1982; no } \\
\text { sounds characterized }\end{array}$ \\
\hline
\end{tabular}


polygamous species (e.g. Ips and Gnathotrichus) (see Barr 1969; Swaby and Rudinsky 1976; Wilkinson et al. 1967). The gular-prosternum mechanism, in contrast, has been described in both males and females of both polygamous (e.g. Ips) and monogamous (e.g. Scolytus) species (Oester and Rudinsky 1979; Rudinsky et al. 1978b; but see Rudinsky 1979). Earlier studies generally assumed that stridulation and sound production was limited to the non-host selecting sex (males in monogamous, and females in polygamous species) (Barr 1969). However, subsequent studies have described sounds in hostselecting sex of many species, albeit, the stridulatory mechanism is not known in most cases (Oester and Rudinsky 1975; Rudinsky et al. 1976; Rudinsky and Michael 1973; Ryker and Rudinsky 1976b; Sasakawa and Yoshiyasu 1983). Interestingly, in Dryocoetes autographus, the host-selecting females have two stridulatory organs, a vertex-pronotum and an elytral-abdominal, whereas the males do not produce sounds (Sasakawa and Yoshiyasu 1983). A similar dual stridulatory mechanism has also been described in males of the monogamous minute pine bark beetles, Cryphalus fulvus (Sasakawa and Sasakawa 1981). In C. fulvus, the type of stridulatory organ used depends on the behavioural contexts; males use the vertex-pronotum stridulatory apparatus during male-female interactions, and the elytral-abdominal apparatus during male-male aggressive interactions (see Sasakawa and Sasakawa 1981).

\section{Acoustic Signal Characteristics and Suggested Functions}

Acoustic studies in bark beetles have generally described sound production in three main behavioural contexts: 1) disturbance; 2) male-female pre-copulatory interactions; and 3) intra-sexual rivalry interactions (Ryker 1988). The recorded signals 
from the different conditions have been labeled and categorized using a variety of different terms, but in general, the nomenclature either describes the overall temporal structure of the signal or the proposed function (see Ryker and Rudinsky 1976b). Based on the temporal structure, six general types of signals have been described: 1) simple chirps; 2) double chirps; 3) complex (multi-component) chirps; 4) interrupted chirps; 5) trills; and 6) clicks (Oester et al. 1978 and 1981; Rudinsky et al. 1978a and b; Rudinsky and Vallo1979; Ryker 1988; Rudinsky 1979; Swaby and Rudinsky 1976). However, previous authors have only provided qualitative descriptions of these different signal types, and it is unclear how these signals were categorized. This in turn has led to some confusion in the nomenclature. For example, the "complex" chirps of some Dendroctonus males are composed of multiple components ("sub-chirps"), and the number of components is fairly consistent between chirps (Ryker and Rudinsky 1976b; Ryker 1988). These chirps are also called "interrupted" chirps (Michael and Rudinsky 1972; Ryker and Rudinsky 1976b; Rudinsky and Ryker 1976). However, "interrupted" chirps described in some Ips females do not have multiple components, rather they are single ("simple") chirps with gaps of missing pulses (tooth-strikes), and are structurally different from the "complex" chirps described in Dendroctonus males (Oester and Rudinsky 1978; Swaby and Rudinsky 1976).

In addition to temporal structure, signals are also labeled based on proposed function (Ryker 1988). For example, signals recorded during pre-mating interactions have been labeled as, "attractant" chirps, "agreement" chirps, "greeting" chirps, and "courtship" chirps, depending on when they occurred during the male-female interaction (Ryker and Rudinsky 1976a; Ryker 1988). However, there is a general indistinctness in 
the qualitative descriptions of the different signals (Ryker 1988). For example, in the Douglas-fir beetles, Dendroctonus pseudotsugae, Rudinsky and Ryker (1976), described that males, attracted to female aggregation pheromones, produced "simple" "attractant" chirps, while entering the female galleries, and then switched to "complex" multicomponent chirps during the aggressive (i.e. male biting and scratching) phase of the interaction. Upon being accepted by the females, prior to copulation, males switched back to emitting "simple" chirps, which were labeled as "courtship" signals (Rudinsky and Ryker 1976). In the red turpentine beetles, D. valens, Ryker and Rudinsky (1976a) described "simple" "attractant" chirps produced by males in the presence of female pheromones, to which the females respond with "simple" "agreement" chirps. Once males made contact with females, females produced relatively shorter "simple" chirps, which they labeled as "greeting" chirps (Ryker and Rudinsky 1976a). In both studies, the temporal criteria used to distinguish the different phase of the male-female interaction, and the different acoustic signals were not described.

In addition to the general lack of standard definitions and criteria for distinguishing and categorizing different signal types, several details of the signal characteristics are also not known. To date, studies have described the temporal characteristics (i.e. chirp duration, number of pulses and components per chirp, and pulse rate) of these signals, and have shown significant variation both between chirp types, and between behavioural conditions. However, details of the spectral characteristics (i.e. frequencies and intensities), and the transmission properties (whether air-borne or substrate-borne) of the signals, have not been described, and is not known for any bark beetle species. Furthermore, the functions of these signals are also not known, and have 
only been hypothesized based on the behavioural context in which the signal occurs (Ryker 1988); and to date, nothing is known about the receptor mechanism involved in receiving these signals.

The general goal of this thesis is to investigate the details of acoustic and vibratory communication in a model species, the pine engraver bark beetle, Ips pini (Say), to better describe signal characteristics, understand signal function, and determine potential receptor mechanisms.

\subsection{Pine Engraver Bark Beetles (Ips pini)}

\section{General Life History and Mating System}

Pine engravers, Ips pini (Say), are small (3 to $6 \mathrm{~mm}$ ), reddish-brown to black, cylindrically shaped bark beetles that breed under the bark of various pine (Pinales: Pinaceae: Pinus) and spruce (Picea) trees (Barr 1969; Wood 1982) They are found across North America - from California, Arizona, Oregon, Idaho, British Columbia, and Alberta in the west, to Wisconsin, New York, and Ontario in the east (Barr 1969; Kegley et al. 1997; Wood 1982). In eastern North America, specifically in the Great Lakes region, they primarily colonize red pines (Pinus resinosa; Erbilgin et al. 2002), but can also be found in jack pines ( $P$. banksiana), white pines ( $P$. strobes), and ponderosa pines ( $P$. ponderosa) (Schenk and Benjamin 1969; Thomas 1961). Males and females are identified by their distinct concavity on their posterior elytra, called "declivity" (typical in the genus Ips), which is comprised of four small spines on each side (Wood 1982). In general, males are larger than females, and have an enlarged $3^{\text {rd }}$ declivity spine (from the top), whereas spines 2 and 3 on females are joined at the base (Reid and Roitberg 1995; 
Wood 1982). Pine engravers, specifically in eastern North America, can have up to two generations a year; a late spring/early summer generation consisting of 2-3 broods per individual, and a fall generation consisting of one brood (Thomas 1961). In most populations, the offspring overwinter in the ground as adults, but in warmer and drier regions, they can overwinter under bark as pupae or larvae (Kegley et al. 1997; Schenk and Benjamin 1969; Schmitz 1972; Thomas 1961).

In late spring, during periods of warm and dry temperatures, large adult males will emerge from natal trees and embark on risky and physiologically costly flights to disperse and colonize recently dead or weakened host trees (Anderson 1948; Erbilgin and Raffa 2000; Gries et al. 1990; Herms et al. 1991; Raffa and Dahlsten 1995; Raffa 2001; Schenk and Benjamin 1969; Schmitz 1972; Stamps et al. 2005; Thomas 1961). However, when the population size reaches outbreak levels, primarily as a result of poor slash management and natural environmental damages, (i.e. droughts, forest fires, and storm damage) colonization can turn into attacks on live healthy trees (Gara et al. 1999; Six et al. 2002; Steed and Wagner 2004). The mechanisms involved in localizing and choosing a particular host tree are not fully understood, and may involve complex multi-modal sensory processing (i.e. chemical, visual, and acoustics stimuli). Regardless, studies show host monoterpenes (i.e. $\alpha$-pinene, $\beta$-pinene and myrcene) and kairomones (i.e. $\beta$ phellandrene) to play an important role during host localization and selection (Byers 2004; Huber et al. 2001; Mustaparta et al. 1977 and 1979; Sallé and Raffa 2007; Wallin and Raffa 2000).

Upon landing on a suitable tree, males will burrow through the outer bark, excavate a circular nuptial chamber in the phloem layer, and emit attractant pheromones, 
ipsdienol (2-methyl-6-methylene-2,7-octadien-4-ol) and lanierone (2-hydroxy-4,4,6trimethyl-2,5-cyclohexadien-1-one), which attracts both females and males (Miller et al 1996; Pureswaran et al. 2000; Robertson and Roitberg 1998; Robins and Reid 1997; Sallé and Raffa 2007; Seybold et al. 1992; Teale et al. 1991) (Fig 1.1). The function and benefits of aggregation during attacks on unhealthy trees remains unclear, as reproductive success in I. pini decreases with increasing densities (Robins and Reid 1997). However, Aukema and Raffa (2004) hypothesized that attractant pheromones of large males primarily evolved for mate attraction, which smaller satellite males exploit during localization of suitable hosts (also see Raffa 2001).

Ips pini have a polygynous mating system (Kirkendall 1983; Reid and Roitberg 1994; Schmitz 1972; Thomas 1961), which is typical in the genus Ips (Kirkendall 1983). Male pine engraver bark beetle will form harems within a few days, attracting 2-3 females (up to 8 in some populations) per reproductive bout, after which, emission of attractants ceases (Schenk and Benjamin 1969; Reid and Roitberg 1994; Swaby and Rudinsky 1976). Females will land on colonized logs and scout the different entrance holes, showing preference for larger males (Schmitz 1972; Reid 1992). Access to nuptial chambers is usually blocked by males with their declivity, and during entrance, a period of jostling occurs where females repeatedly push against the male elytral declivity with their frons, while occasionally biting and scraping male elytral spines with their mandibles, and acoustically signaling (Schmitz 1972) (Fig 1.1).

Upon admittance into male nuptial chambers, females continue their jostling and biting behaviour, which can last for several hours, after which, copulation ensues, lasting 


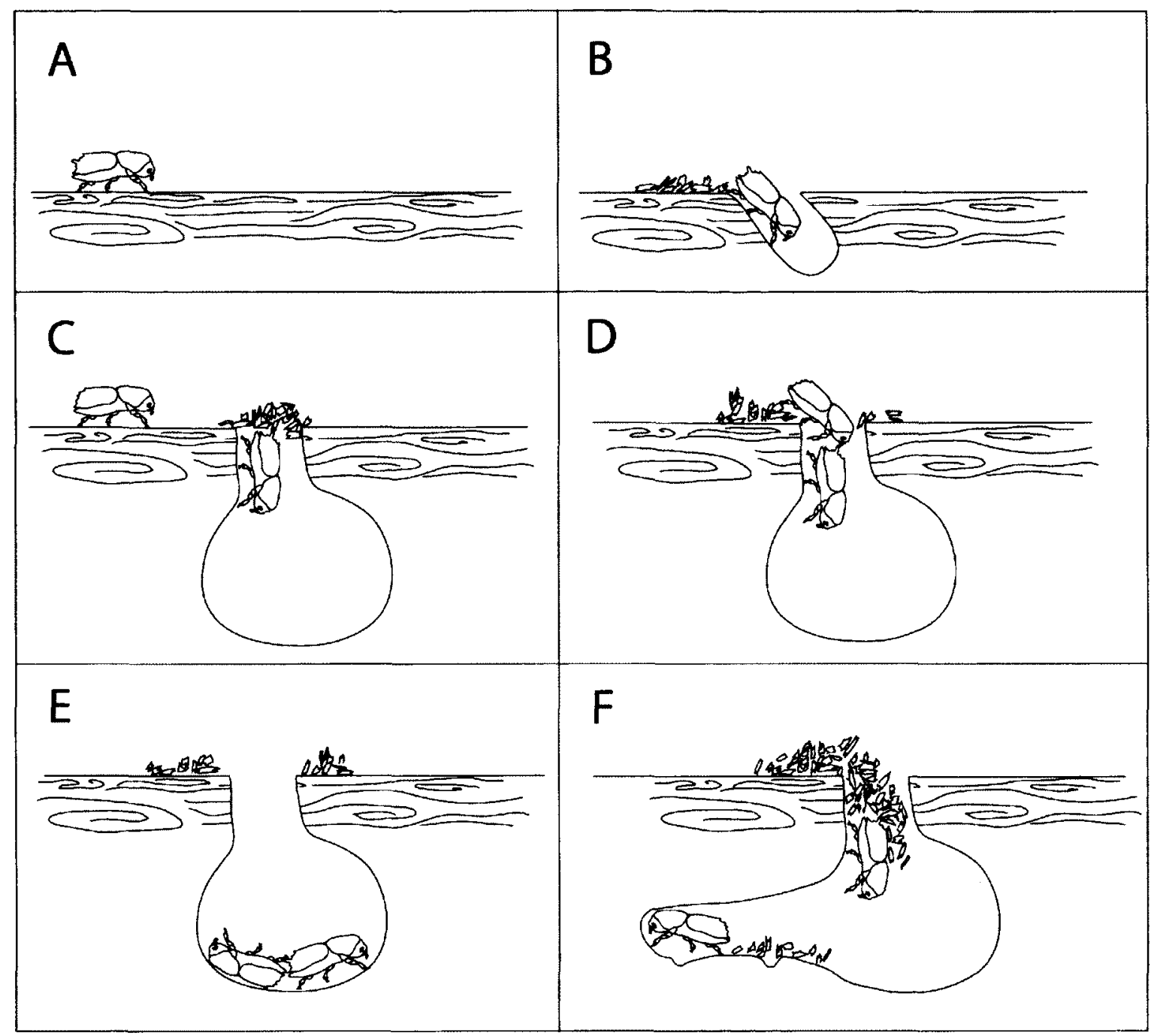

Figure 1.1. Mating behaviour of the pine engraver bark beetles, Ips pini. A and B) Adult males will burrow through the outer bark and build a circular nuptial chamber in the phloem layer. C) Males will block entrance to nuptial chamber with their elytral declivity. Females will localize males using pheromones in the frass. D) Upon localizing males, females will dig through the frass, and attempt to gain entrance into male nuptial chambers by repeatedly pushing against the male declivity and stridulating. Only stridulating females are admitted. E) Inside the nuptial chamber, males will copulate with females. Males will copulate with each females multiple times during oviposition period. F) Mated females will excavate egg galleries, while males remain in the nuptial chamber, blocking the entrance and helping with frass removal. (Illustration credit: Karen Wang). 
10 to 45 seconds (Schmitz 1972) (Fig 1.1). Mated females will excavate egg galleries (5 to $25 \mathrm{~cm}$ long), that radiate out from the nuptial chamber, parallel to the grain of the wood, and lay eggs in equally spaced niches cut along the side (Reid and Roitberg 1994; Robins and Reid 1997; Schmitz 1972; personal observation) (Fig 1.2). During the oviposition period, males will repeatedly copulate with females, in the nuptial chamber (Schmitz 1972), and actively help with frass (wood debris and feces) removal (Lissemore 1997; Robertson 1998; Reid and Roitberg 1994), and defense against predators (Reid and Roitberg 1994). Most eggs are laid within two to three weeks, but can take several weeks (Robertson 1998; Robertson and Roitberg 1998; Reid and Roitberg 1994; Schmitz 1972). Males will reside with females throughout the oviposition period (Reid and Roitberg 1994), and residence time is positively correlated with reproductive success (Reid and Roitberg 1994; Robertson and Roitberg 1998; Robertson 1998). Larger males, however, will abandon mates and brood earlier than smaller males, both in the lab (Reid and Roitberg 1995), and in the field (Robertson 1998), albeit, siring more and larger offspring (Reid and Roitberg 1995). Larger males are more likely to establish multiple broods during a breeding season (Robertson and Roitberg 1998). Once egg-laying ceases, both males and females will leave their breeding sites to find new mating opportunities (Reid and Roitberg 1994; Robertson 1998).

\section{Acoustic communication in Ips pini}

Of the 27 North American species of the genus Ips, the pine engraver bark beetles are one of only 17 species that has been shown to communicate acoustically (Table 1.2). 

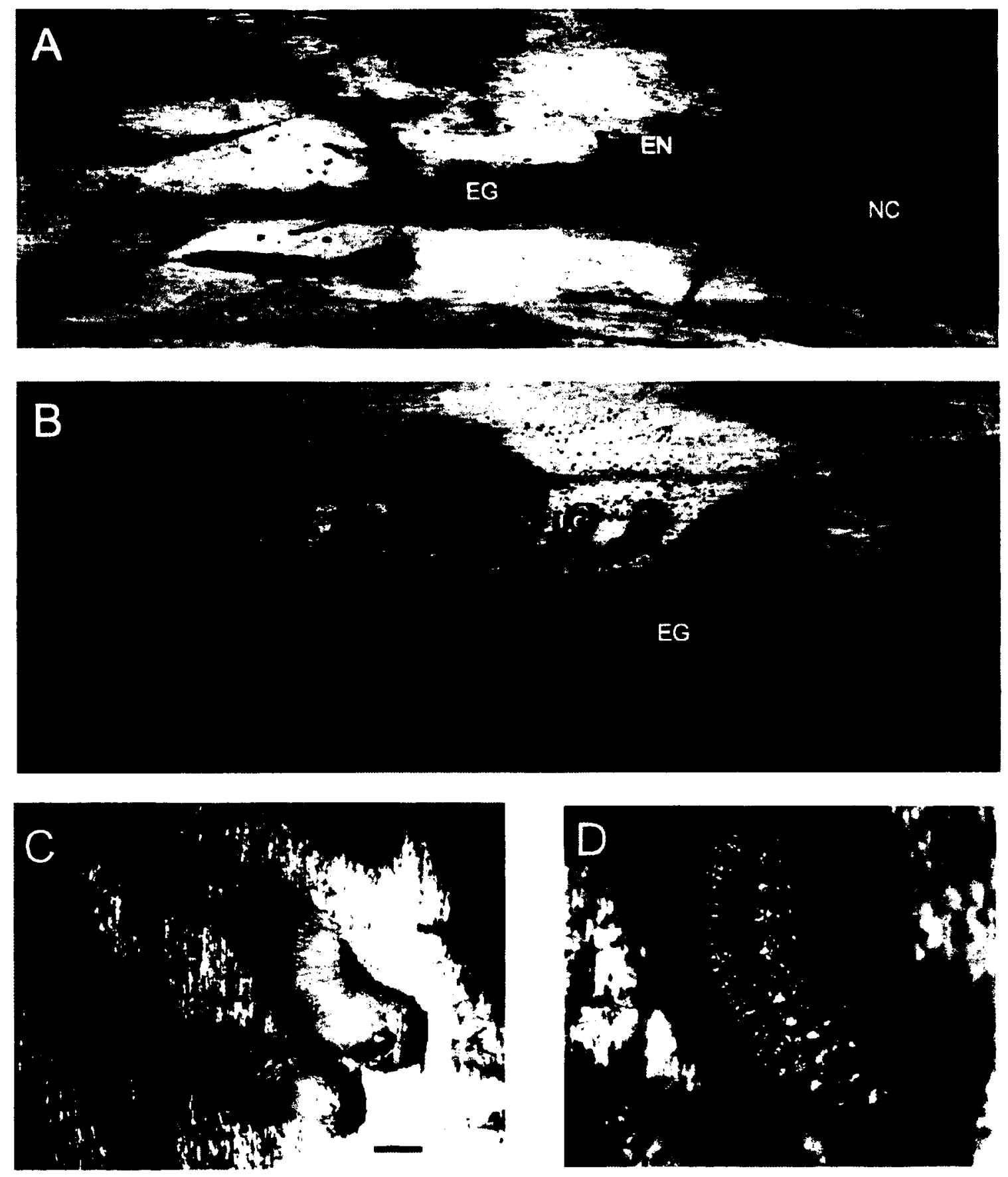

Figure 1.2. A) Typical Ips pini gallery showing the male initiated nuptial chamber $(N C)$, the female excavated egg gallery $(E G)$ through the phloem, along the grain of the wood, and a single egg niche $(E N)$ cut along the side. Scale bar $=1 \mathrm{~cm}$. B) $I$. pini larvae will tunnel galleries $(L G)$ that radiate away, usually perpendicular, from female egg galleries $(E G)$. Scale bar $=1 \mathrm{~cm}$. C) Larval galleries rarely intersect. Scale bar $=1000 \mu \mathrm{m}$. D) $I$. pini larvae are white, legless, and have light-brown heads. Scale bar $=500 \mu \mathrm{m} . E N=\mathrm{Egg}$ Niche; $E G=$ Egg Gallery; $L G=$ Larval Gallery; $N C=$ Nuptial Chamber. (Photo credit: Senthurran Sivalinghem). 
To date, only two studies have described acoustic signals in Ips pini (Oester and Rudinsky 1975; Swaby and Rudinsky 1976). Oester and Rudinsky (1975) described "clicks" produced by males during "aggressive" male-male interaction, and suggested that "clicks" probably functioned for maintaining gallery dominance or defending territory. However, the mechanism of click production, and function of clicks remains unknown, and it is unclear how they distinguished "clicks" from incidental sounds produced while walking and/or digging. Swaby and Rudinsky (1976) later demonstrated that female Ips pini produced acoustic signals through stridulation of a pars stridens ("file"), located on the vertex of the head, against a plectrum, located on the ventral anterior side of the pronotum (the vertex-pronotum stridulatory apparatus: see Barr 1969). Sound production in females were recorded during physical (handling) disturbance, during male-female pre-mating (i.e. during gallery entrance), and supposed female-female "aggressive" interactions; these signals were labeled "stress", "attraction", and "rivalry" chirps, respectively (Swaby and Rudinsky 1976). In the context of malefemale pre-mating interaction, Swaby and Rudinsky (1976) suggested that females attempting to enter male nuptial chambers stridulated (producing attraction signals) once they made physical contact with male elytral declivity, and noted that stridulation was necessary to gain entrance into male nuptial chambers. This was also described in other Ips species, particularly Ips calligraphus (Wilkinson et al. 1967), and I. confusus (Barr 1969). Swaby and Rudinsky (1976) described the temporal (i.e. chirp duration, number of pulses, and pulse rate) characteristics of the acoustic signals, and showed significant temporal differences between the different signals; specifically pulse rate differences between "stress" and "attraction" signals. They also described the frequency bandwidths 
Table 1.2. Occurrence of stridulatory organs in the North America Ips species (adapted and modified from Barr 1969).

\begin{tabular}{|c|c|c|c|c|}
\hline Group & Species & Type of stridulatory Organ & Stridulating Sex & Host Tree Genus \\
\hline \multirow{2}{*}{ I } & I. concinnus & Gula-prosternal & Both & Picea \\
\hline & I. mexicanus & Gula-prosternal & Both & Pinus \\
\hline \multirow{2}{*}{ II } & I. emarginatus & None & $\mathrm{N} / \mathrm{A}$ & Pinus \\
\hline & I. knausi & None & N/A & Pinus \\
\hline \multirow{2}{*}{ III } & I. integer & Unknown & Unknown & Pinus (some Picea) \\
\hline & I. plastographus & Vertex-pronotal & Female & Pinus \\
\hline \multirow{3}{*}{ IV } & I. avulsus & Vertex-pronotal & Female & Pinus \\
\hline & 1. bonanseai & Vertex-pronotal & Female & Pinus \\
\hline & I. pini & Vertex-pronotal & Female & Pinus (some Picea) \\
\hline $\mathbf{V}$ & I. perroti & None & $\mathrm{N} / \mathrm{A}$ & Picea \\
\hline \multirow{3}{*}{ VI } & I. hunteri & None & $\mathrm{N} / \mathrm{A}$ & Picea \\
\hline & I. perturbatus & None & $\mathrm{N} / \mathrm{A}$ & Picea \\
\hline & I. woodi & Vertex-pronotal & Female & Pinus \\
\hline VII & I. borealis & None & N/A & Picea \\
\hline \multirow{2}{*}{ VIII } & I. pilifrons & None & $\mathrm{N} / \mathrm{A}$ & Picea \\
\hline & I. tridenst & None‡ & $\mathrm{N} / \mathrm{A}$ & Picea \\
\hline \multirow{7}{*}{ IX } & I. confusus & Vertex-pronotal & Female & Pinus \\
\hline & 1. cribricollis & Vertex-pronotal & Female & Pinus \\
\hline & I. grandicollis & Vertex-pronotal & Female & Pinus \\
\hline & 1. hoppingi & Vertex-pronotal & Female & Pinus \\
\hline & I. lecontei & Vertex-pronotal & Female & Pinus \\
\hline & I. montannus & Vertex-pronotal & Female & Pinus \\
\hline & 1. paraconfusus & Vertex-pronotal & Female & Pinus \\
\hline
\end{tabular}




\begin{tabular}{ccccc}
\hline \multirow{2}{*}{$\mathbf{X}$} & I. calligraphus & Vertex-pronotal & Female & Pinus \\
& I. interstitialis & Unknown & Unknown & Pinus \\
\hline \multirow{2}{*}{$\mathbf{0}$} & I. latidens & Vertex-pronotal & Female & Pinus \\
& I. spinifer & Vertex-pronotal & Female & Pinus \\
\hline
\end{tabular}

†Both males and females produced "clicks" (Oester and Rudinsky 1975).

†Several rudimentary transverse ridges were found on the gula of males and females (possible pars stridens), but no plectrum on the prosternum was identified (Oester and Rudinsky 1978). 
of the signals (ranging from 1 to $27 \mathrm{kHz}$ ), but specific details of the frequency characteristics of the signals were not examined. In general, there are several lapses in the details of their signal descriptions. For example, they described two types of chirps, "uninterrupted" and "interrupted" chirps, which were observed in all behavioural conditions, but details of how these chirps were distinguished, how often and when they occurred, and their possible functions are not known. Furthermore, besides the temporal, and frequency range descriptions of signals, and the general association between context and sound production, no other details of the signals (i.e. frequency and intensity characteristics) were described, and it is not clear exactly how these signals vary between contexts, and how these signals are transmitted to the receiver (e.g. air-borne and/or substrate-borne). Understanding the details of signal characteristics and transmission properties is very important for linking behaviours to specific signals and determining potential receptor mechanisms.

\subsection{Thesis Objectives}

The primary objectives of my thesis are the following:

1) To record and characterize the temporal, and spectral properties of Ips pini airborne signals during different behavioural interactions. (Chapter 2)

2) To determine how signals vary between and within the different behavioural conditions. (Chapter 2)

A sub-objective will be to extend signal characterization to include both eastern (Ontario), and western (Alberta) populations to determine if there are inter-population 
differences in acoustic signals. To date, population variation in acoustic signals has not been described in any species of the Ips genus. Variation in acoustic signals between conspecific populations, however, has been demonstrated in the Douglas-fir beetles (Dendroctonus pseudotsugae; Ryker et al. 1979), and in the mountain pine beetles (D. ponderosae; Yandell 1984). In D. ponderosae, for example, significant temporal variation between the three populations studied was found only in male stress and rivalry chirps, but not in the attractant chirps, suggesting that attractant chirps may convey species recognition information in D. ponderosae (Yandell 1984).

3) To record the solid (wood)-borne vibrations of the signals to determine if signals might be communicated through the phloem substrate. (Chapter 2)

4) To test the startling function of Ips pini disturbance signals with their natural predators, Thanasimus dubius. (Chapter 2)

Previous studies have inferred that $I$. pini disturbance signals functioned to startle predators ("startling hypothesis") (Swaby and Rudinsky 1976; also see Lewis and Cane 1990). However, disturbance signals have only been described from recordings using the classic handling method, where the beetles were held between the thumb and forefinger, and the function of these signals remains unknown, and untested with natural predators.

Four specific predictions will be addressed to determine the startling function of $I$. pini disturbance signals: i) females should begin signaling immediately after predator attack; ii) predators will drop signaling females at a higher proportion than non-signaling males; iii) signaling should increase prey handling time, resulting in a longer latency 
from prey seizure to death in predators attacking females compared to non-signaling males; and iv) natural predators are capable of hearing disturbance signals.

5) To identify putative receptor structures in I. pini. (Chapter 3)

Given that sound production is prevalent across Scolytinae, and studies have shown an association between acoustic signaling and pheromone release(Barr 1969; Ryker 1988), indicating that these signals are somehow received and processed by the receivers, it is surprising that, to date, no study has investigated potential receptor mechanisms involved in acoustic reception in any bark beetles.

Identification of receptor organs and determining their functional significance typically involves three systematic approaches: 1) identifying and describing the external morphology of putative areas where potential receptor systems may be located; 2) conducting neurophysiological experiments to determine whether receptor organs are capable of detecting biologically relevant signals; and 3) behavioural and ablation studies to determine whether signal reception mediates adaptive behavioural response (Yack and Fullard 1993). In chapter 3, I will take a first step towards identifying potential receptor mechanisms by, 1) reviewing the external morphology to look for possible receptor organs, and 2) describing the central nervous system (CNS) of I. pini for future neurophysiological studies. 


\section{Chapter 2}

\section{Acoustic communication in the pine engraver bark beetle, Ips pini (Say) (Coleoptera: Scolytinae): Signal characterization, variation, and function}

\subsection{Introduction}

Bark beetles (Coleoptera: Curculionidae: Scolytinae) are integral constituents of North American coniferous forest ecosystems that influence nutrient and carbon/nitrogen cycling, and plant biodiversity (Kurz et al. 2008; Raffa et al. 2008). During periods of population eruption (outbreaks) however, some species are considered highly successful and notorious disturbance agents capable of causing large scale damages to coniferous forests resulting in several billion dollars worth of economic loss (Kurz et al. 2008; Raffa et al. 2008). Their success as effective pests relies heavily on their communication and sensory systems, which mediate complex interactions with conspecifics, and heterospecifics including sympatric bark beetles, host-plants, symbiotic mites and fungi, and predators and parasitoids (Bentz et al. 2010; Byers 1989; Klepzig et al. 2001; Raffa et al. 2008; Rudinsky 1962; Sauvard 2007). This has led to extensive research over the last six decades in bark beetle communication and sensory ecology. However, much of this research has primarily focused on one sensory modality, chemical/pheromone communication, while other modes of communication have received relatively little attention (Dickens et al. 1984; Mustaparta et al. 1977, 1979, 1982 and 1985; Pureswaran et al. 2004; Symond and Elgar 2004a and b).

One of the less understood and largely under-appreciated forms of communication in bark beetles is acoustic (Ryker 1988). In the early 1970s, a set of seminal studies on the Douglas-fir beetles, Dendroctonus pseudotsugae, demonstrated that female 
aggregation pheromones elicited acoustic signaling in males (Rudinsky and Michael 1972), which in turn caused females to cease production of aggregation pheromones and release anti-aggregation pheromones (Rudinsky et al. 1973; Rudinsky 1969). These discoveries led to an increase in bark beetle bioacoustics research throughout the 1970s, up until the mid 1980s (see Ryker 1988). These early studies have demonstrated that many bark beetle species have well developed stridulatory organs (Barr 1969; Jefferies and Fairhurst 1982; Michael and Rudinsky 1972; Rudinsky and Michael 1973; Rudinsky and Vallo 1979; Vernoff and Rudinsky 1980; Wilkinson 1964; Wood 1961), and some have been shown to produce acoustic signals during physical (handling) disturbance, premating, and rivalry behavioural contexts (see Ryker 1988); which have been implicated to function for defense (see Lewis and Cane 1990), species/mate recognition and attraction (see Lewis and Cane 1992; Yandell 1984), courtship (see Michael and Rudinsky 1972; Rudinsky and Ryker 1976; Ryker and Rudinsky 1976a and b), and spacing and territoriality (see Oester and Rudinsky 1975; Rudinsky and Michael 1972; Rudinsky et al. 1973). Despite the large number of acoustic studies, and the ubiquity of acoustic signaling throughout Scolytinae, there is a surprising dearth of information on the physical characteristics and function of these signals, and potential receptor mechanisms.

Early research has provided details on the temporal characteristics (i.e. chirp duration, number of pulses per chirp, chirp rate) of acoustic signals, and has shown variation in signal characteristics between species, between con-specific populations, and between behavioural conditions (Lewis and Cane 1992; Oester and Rudinsky 1978; Rudinsky and Vallo 1979; Ryker et al. 1979; Ryker 1988; Swedenborg et al. 1989; 
Vernoff and Rudinsky 1980; Yandell 1984). Besides these temporal characteristics however, several details of the signals including the spectral and intensity characteristics, correlations between signal characteristics and phenotypic traits, variation between individuals, populations, and behavioural conditions, and how they are transmitted to the receiver (i.e. through air and/or solid wood), are not known for any bark beetle species. Understanding the physical characteristics of acoustic signals, correlations with phenotypic traits, and transmission properties has important implications for understanding how signals vary between different behavioural contexts, possible function and information content in signals, potential receptor mechanisms, and the processing demands on such receptors. Understanding how signal characteristics vary within and between individuals and between conspecific populations is important for understanding its potential role in species recognition, and mate choice (see Gerhardt 1991). It also allows for developing hypotheses about mechanisms of signal divergence, and its role in the evolution of reproductive isolation and speciation (see Dobzhansky 1937; Lande 1982; Mayr 1963; Paterson 1985). The overarching objective of this thesis is to use the pine engraver beetle, Ips pini, as a model system to characterize acoustic signals and determine variation in signal characteristics to gain insight into the proximate and ultimate mechanisms associated with acoustic communication in bark beetles.

\section{Acoustic signals in Ips pini}

The pine engravers, Ips pini (Say) (Coleoptera: Scolytinae), are endemic, transcontinentally distributed bark beetles of North America (Boone et al. 2009) that parasitize weakened or recently dead pine (Pinus) and spruce (Picea) trees (Wood 1982). 
Males will localize weakened host-plants, and construct a circular nuptial chamber in the phloem layer, while emitting the aggregation pheromones to attract females; males will sequentially mate with up to 3-4 females per reproductive bout (Miller et al 1996; Seybold et al. 1992; Thomas 1961). Upon localizing a preferred male, females will attempt to gain admittance into male nuptial chambers by pushing against male elytral declivity (which males use to block entrance into nuptial chambers), and acoustically signaling; males do not have a stridulatory organ seen in females (i.e. the vertexpronotum stridulatory mechanism) (Reid and Roitberg 1994; Reid 1992; Schmitz 1972).

To date, only one study has examined the physical characteristics of female Ips pini acoustic signals (Swaby and Rudinsky 1976). Acoustic signals were recorded during physical (handling) disturbance ("stress/disturbance" signals), male-female pre-mating ("attractant" signals), and supposed female-female rivalry ("rivalry" signals) interactions. Swaby and Rudinsky (1976) described female signals as "multi-pulsed chirps" with frequency bandwidths ranging from 1 to $27 \mathrm{kHz}$, with intense frequencies between 1 and $18 \mathrm{kHz}$. However, specific details of the frequency characteristics of the signals have not been examined. They also characterized the temporal features (i.e. chirp duration, number of pulses, and pulse rate) of the signals, and showed significant variation in pulse number and rates between 'disturbance', 'attractant', and 'rivalry' chirps (see Table 2.1). Besides these temporal analyses, no further descriptions were provided, and several details of the signals that have potential important implications for function and transmission have not been examined.

In addition, details of how female signaling patterns change with time, specifically during female gallery entrance, from pre-entrance into male 
Table 2.1. Results from Swaby and Rudinsky (1976) showing the temporal characteristics of female Ips pini acoustic signals.

Comparisons of temporal features were made between different behavioural contexts.

\begin{tabular}{ccccccc}
\hline \multirow{2}{*}{ Condition } & \multicolumn{2}{c}{$\begin{array}{c}\text { Number of Pulses per } \\
\text { Chirp }\end{array}$} & \multicolumn{2}{c}{ Chirp Duration (sec) } & \multicolumn{2}{c}{ Pulse Rate (\#/sec) } \\
\cline { 2 - 7 } & Average & Range & Average & Range & Average & Range \\
\hline Disturbance & $153.6^{(\mathbf{a})}$ & $103-216$ & $0.81^{(\mathbf{c})}$ & $0.012-0.058$ & $1890.36^{(\mathbf{d})}$ & $1621.2-2190.5$ \\
\hline $\begin{array}{c}\text { Male-Female } \\
\text { Interaction }\end{array}$ & $124.7^{(\mathbf{a}, \mathbf{b})}$ & $15-376$ & $0.106^{(\mathbf{c})}$ & $0.012-0.495$ & $1231.2^{(\mathbf{e})}$ & $241-4560$ \\
\hline $\begin{array}{c}\text { Female-Female } \\
\text { Rivalry } \\
\text { Interaction }\end{array}$ & $83.1^{(\mathbf{b})}$ & $22-268$ & $0.075^{(\mathbf{c})}$ & $0.017-0.189$ & $1205.11^{(\mathbf{e})}$ & $314.3-2440.7$ \\
\hline \hline
\end{tabular}

* Letters in brackets indicate grouping of averages at $\mathrm{p}<0.05$.

**Details of frequency and intensity characteristics of acoustic signals were not described. 
nuptial chambers to post-entrance, are not known, and may have important implications for signal function. Furthermore, Swaby and Rudinsky (1976) noted two general types of chirps, 1) "Interrupted" chirps, described as chirps with brief gaps or interruption of silence, and 2) "Uninterrupted" chirps. Besides these qualitative descriptions of the two chirp types, variation in their characteristics, occurrence, and potential functional implications are not known, and should be further studied.

\section{Chapter Two Objectives}

\section{Main objective 1: Record and characterize airborne signals}

The first main objective of this study is to record and characterize the temporal and spectral (i.e. frequency and intensity) qualities of female Ips pini air-borne signals during physical (handling) disturbance, predation, and female gallery entrance. A specific goal is to record and characterize the acoustic signals of females from two geographically separated populations (i.e. Alberta and Ontario populations). Two sub-objectives will be to: i) determine whether signal parameters correlate with female phenotypic traits; and ii) determine changes in female signaling during male-female gallery entrance interactions.

\section{Main objective 2: Determine variation in signal characteristics}

The second main objective of this study is to examine variation in signal characteristics. Specifically, the goal is to examine how the temporal and spectral features of the signals vary: i) within and between females (within-populations); ii) between behavioural conditions (within-populations); and iii) between conspecific populations. Understanding these variations is important for developing hypotheses about how natural and sexual 
selection may shape the characteristics of signals and the potential roles these signals play during species recognition, and mate choice.

\section{Main objective 3: Determine transmission properties of acoustic signals}

The third main objective of this study is to record and characterize possible solid (wood)-borne vibratory components of Ips pini acoustic signals. To date, studies have only recorded the air-borne component bark beetle acoustics (Ryker 1988), and it is not known whether these beetles can communicate using substrate-borne vibrations. The goal is to generally determine whether acoustic signals can be transmitted through their natural phloem substrate.

\section{Main objective 4: Test functional significance of disturbance signals}

The fourth main objective of this study is to test the "startling function" hypothesis of Ips pini disturbance signals. Bark beetle disturbance signals, produced when handled, were hypothesized by previous researchers to have anti-predation functions (Ryker 1988). However, to date, this hypothesis has only been tested in one species, Ips calligraphus (Lewis and Cane 1990). Lewis and Cane (1990) demonstrated that the predator, Thanasimus dubius, released signaling I. calligraphus females at a higher proportion than non-signaling males, and suggested that disturbance signals were deimatic, and temporarily startled predators. Besides this sole study, the hypothesized "startling function" of disturbance signals remains untested for many bark beetle species. In this study, the fourth main objective was to test the "startling" hypothesis of Ips pini disturbance signals with their natural predator, red-bellied checkered beetles, Thanasimus 
dubius. If acoustic signals function for startling predators, then it is predicted that: 1) females should begin signaling immediately after predator attack; 2) predators will lose grip and release signaling females at a higher proportion than non-signaling males; 3 ) signaling should increase prey handling time, resulting in a longer latency from prey seizure to prey death in predators attacking females compared to those attacking nonsignaling males; and 4) natural predators are capable of hearing disturbance signals.

\subsection{Materials and Methods}

\subsubsection{Study Animals}

Alberta population of pine engraver bark beetles, Ips pini (Say), were collected (by Dr. Mary Reid; University of Calgary) at Bragg Creek (Calgary, Alberta, Canada; UTM 11U 663675 5647331; Latitude/Longitude $=50.954325 \mathrm{~N} / 114.66958 \mathrm{E}$ ) in September 2009, and April 2010, and shipped to Carleton University (Ottawa, Ontario, Canada). I. pini were collected using 12-funnel Lindgren traps (Contech Enterprises Inc., Victoria, British Columbia, Canada), baited with two I. pini attractant lures, ipsdienol, and lanierone (Contech Enterprises Inc, Victoria, British Columbia, Canada). Lindgren funnel traps were hung on branches of 120-year old stand of lodgepole pine trees (Pinus contorta; one trap per tree).

The Ontario populations of I. pini were collected (by myself, Dr. Jayne Yack, and students in Dr. Jayne Yack's laboratory; Carleton University) at the Herbert's Corner site (Carleton University Forest A, Ottawa, Ontario, Canada; Latitude/Longitude $=$ $45^{\circ} 10^{\prime} 51.22^{\prime \prime} \mathrm{N} / 75^{\circ} 36^{\prime} 29.39^{\prime \prime} \mathrm{W}$ ), and at the Central Experimental Farm Arboretum (Ministry of Agriculture and Agri-Food Canada (AAFC), Ottawa, Ontario, Canada; 
Latitude/Longitude $=45^{\circ} 23^{\prime} 28.39^{\prime \prime} \mathrm{N} / 75^{\circ} 42^{\prime} 19.46^{\prime \prime} \mathrm{W}$ ) between April and August 2011 . Ontario I. pini were collected using various 8, 12 or 16- funnel Lindgren traps (Contech Enterprises Inc., Victoria, British Columbia, Canada), baited with ipsdienol and lanierone (Contech Enterprises Inc, Victoria, British Columbia, Canada). Lindgren funnel traps were hung on branches of primarily red pine (Pinus resinosa) trees, but also on white ( $P$. strobes), and jack pine ( $P$. banksiana) trees; one funnel trap per tree. Traps were hung so that the base of the collecting jar was $\sim 1 \mathrm{~m}$ above the ground. Beetles were checked and collected 2 to 3 times a week at Herbert's Corner site, and 4 to 7 times a week at the Central Experimental Farm Arboretum.

In the lab, species was determined by the presence of four elytral declivity spines (Wood 1982) (Fig 2.1). Males were distinguished from females by the presence of an enlarged $3^{\text {rd }}$ declivity spine (from the top; Wood 1982) (Fig 2.1). Females were distinguished by their middle two spines ( 2 and 3 ) joined at the base, and by the presence of acoustic signals when held close to the ear. Voucher specimens were also sent to Dr. Hume Douglas (Carleton University), who confirmed species and gender. Separated males and females were put in plastic containers covered with moist paper towels and kept in the fridge at $5^{\circ} \mathrm{C}$ (for a maximum of two weeks) until used in one of the procedures described below. The mating status and relatedness of pine engraver beetles were not known. All collected beetles were adults, as only adults emerge from natal trees and start flying in the spring (Schenk and Benjamin 1969; Thomas 1961).

Checkered beetles, Thanasimus dubius (Coleoptera: Cleridae: Thanasimus), common predators of I. pini (Aukema and Raffa 2004), were also collected from traps at the Herbert's Corner site, and at the Arboretum. Thanasimus dubius were identified by 
their reddish-brown heads, and two grayish-white "zigzag" patterned bands on the elytra (Fig 2.2). Individual predators were placed in separate plastic containers covered with moist paper towels and kept in the fridge until later use during predation trials (see below). Some predators were kept in $90 \%$ ethanol as voucher specimens for species identification.

\subsubsection{Behavioural Trials}

\section{Disturbance Trials}

Disturbance signals were recorded for both Alberta $(\mathrm{N}=19)$ and Ontario $(\mathrm{N}=26)$ females. Males lack the vertex-pronotum stridulatory mechanism (Fig 2.3), and failed to produce acoustic signals in preliminary trials. Females were held by the abdomen, between the thumb and index (or middle) finger to allow free movement of the head, and signals were recorded $1 \mathrm{~cm}$ from the microphone; similar to previously described method for recording disturbance signals (Fig 2.4) (Swaby and Rudinsky 1976). After each trial, Alberta females were weighed (Sartorius, CP224 S, Goettingen, Germany), and preserved in $90 \%$ ethanol for later morphological measurements (see below).

Disturbance signals were recorded using an ultrasound sensitive condenser microphone (Avisoft CMPA-P48/CM16, Berlin, Germany; flat frequency response (< $\pm 3 \mathrm{~dB}$ change) between $10-150 \mathrm{kHz}$ ). Signals from the microphone was recorded onto a 

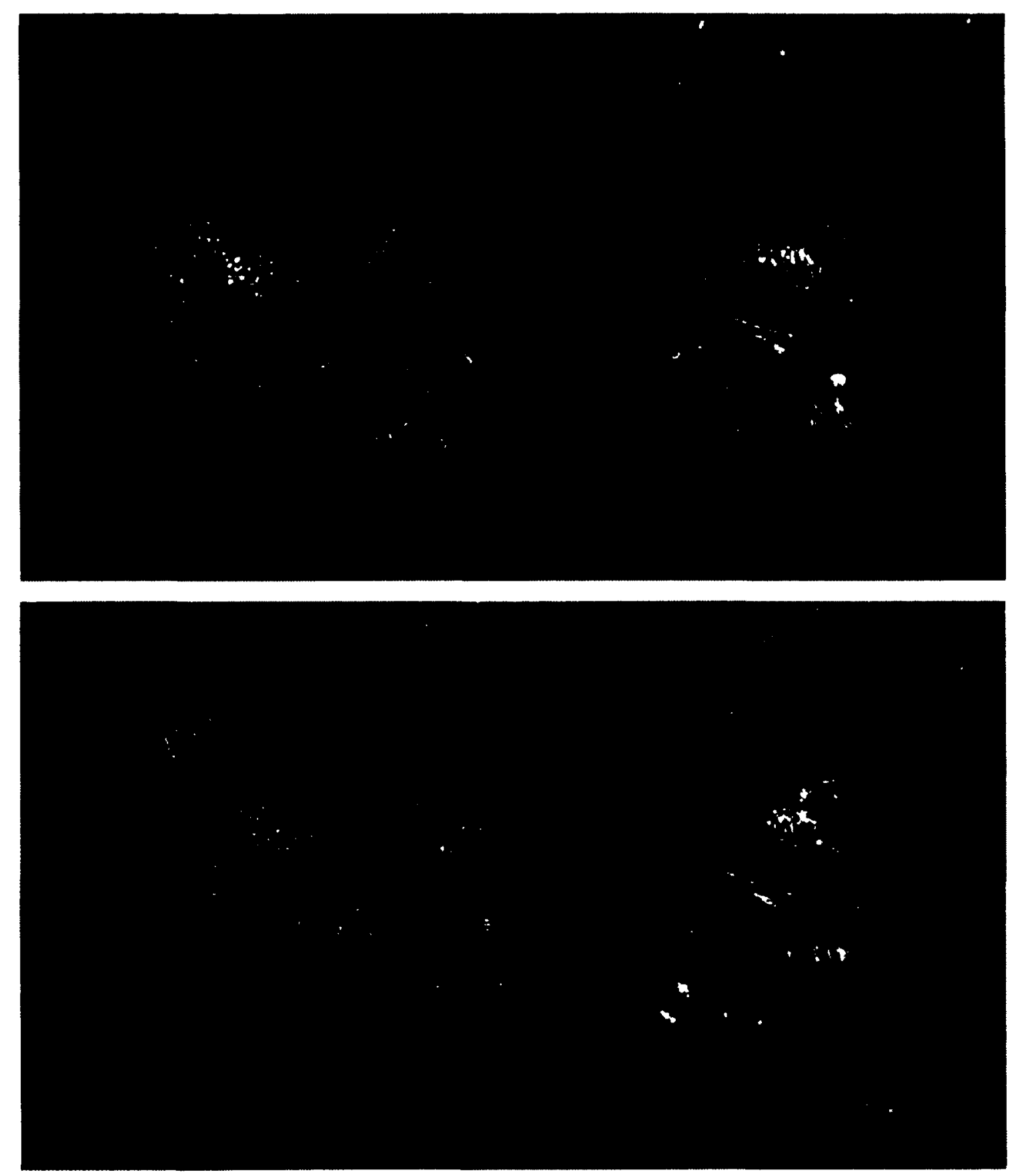

Figure 2.1. Lateral view of (A) adult female and (B) male pine engraver bark beetle, Ips pini. Females were distinguished by their middle two elytral declivity spines ( 2 and 3 ; black arrows) joined at the base, and by the presence of sounds when lightly squeezed. Males were distinguished by their enlarged $3^{\text {rd }}$ declivity spine (black square); males do not produce sounds. Scale bars $=500 \mu \mathrm{m}$. (Photo credit: Senthurran Sivalinghem). 


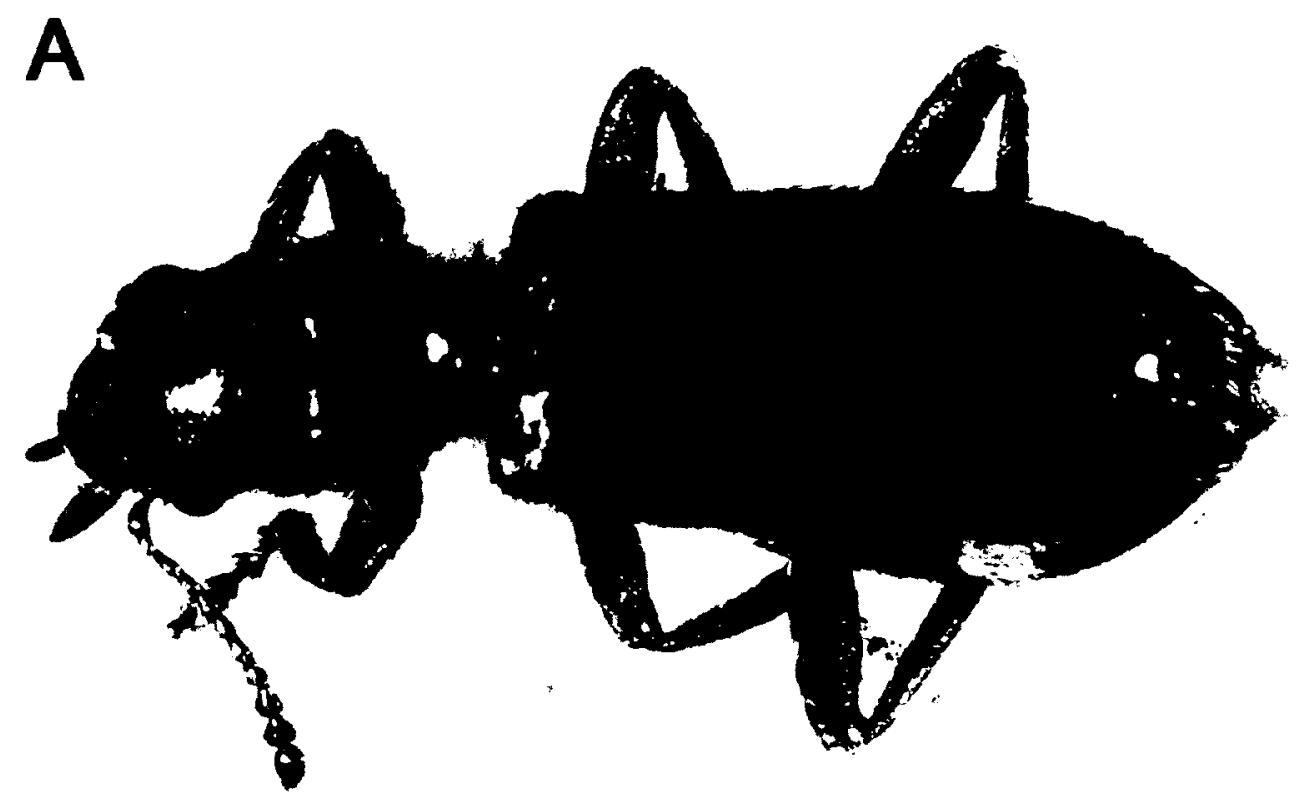

B

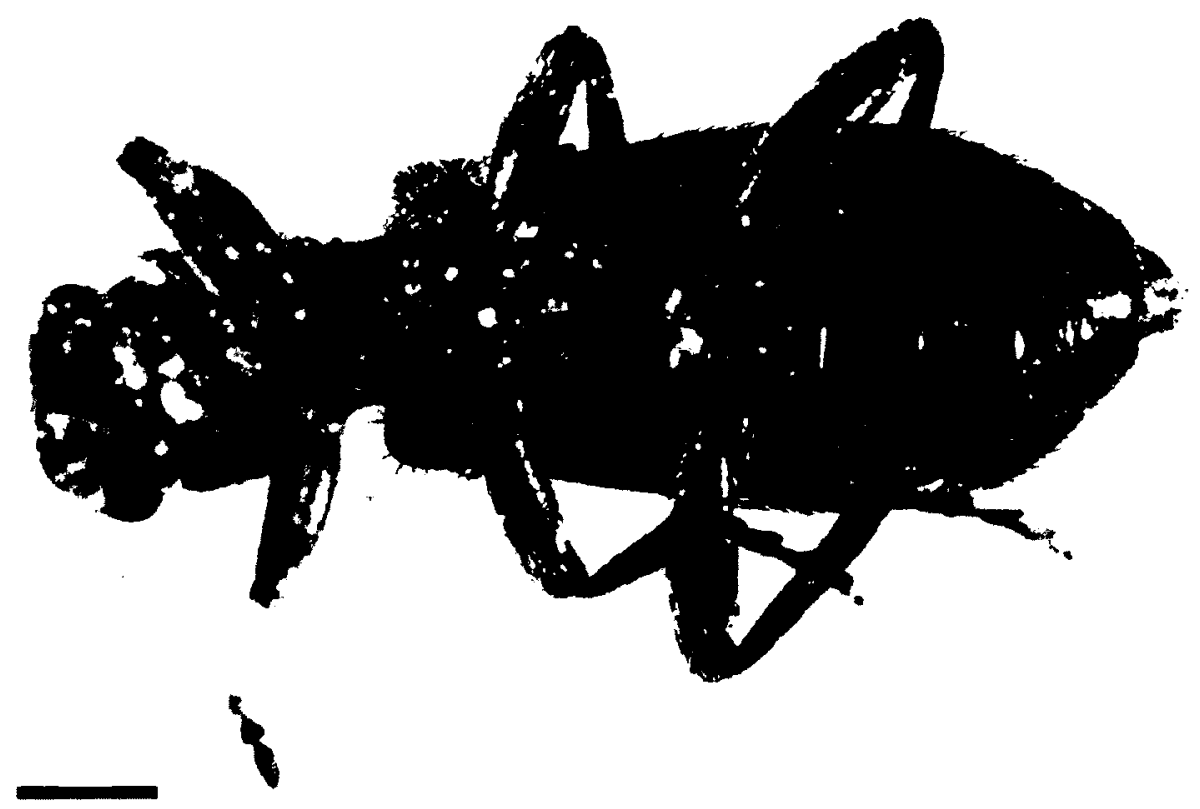

Figure 2.2. Dorsal (A) and ventral (B) view of checkered beetles, Thanasimus dubius (Coleoptera: Cleridae: Thanasimus), primary predators of $I$. pini. Scale bars $=1000 \mu \mathrm{m}$. (Photo credit: Senthurran Sivalinghem). 

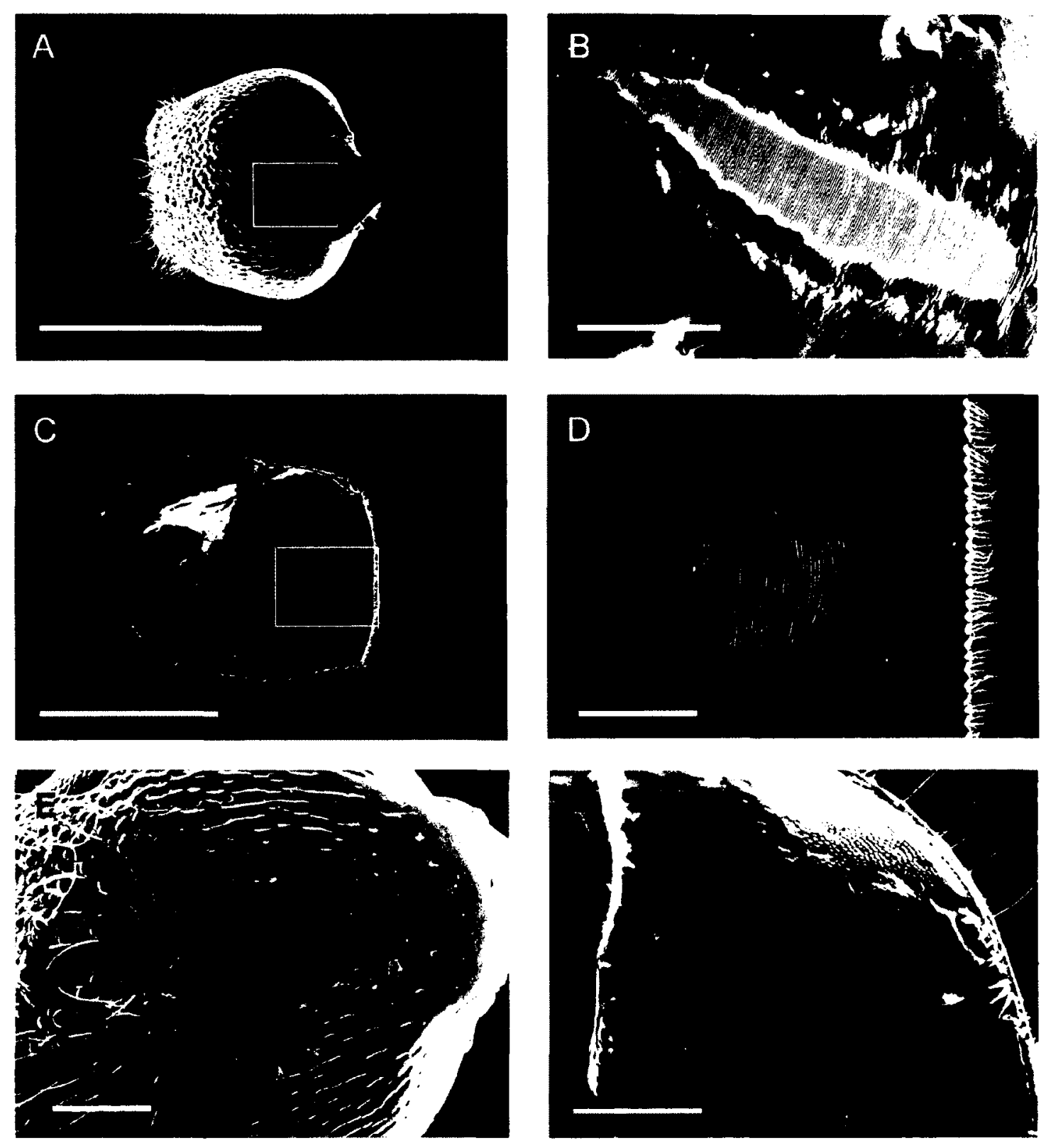

Figure 2.3. Scanning electron micrographs (SEM) of female and male, Ips pini, head and pronotum. (A) Vertex of female head. White rectangle highlights the location of the pars stridens. Scale bar $=1 \mathrm{~mm}$. (B) Female pars stridens. Scale bar $=50 \mu \mathrm{m}$. (C) Ventral surface of female pronotum. White rectangle highlights the location of the plectrum. Scale bar $=1 \mathrm{~mm}$. (D) Female plectrum. Scale bar $=100 \mu \mathrm{m}$. (E) Vertex of male head with no pars stridens. Scale bar $=200 \mu \mathrm{m}$. (F) Ventral surface of male pronotum with no plectrum. Scale bar $=200 \mu \mathrm{m}$. (Photo credit: Senthurran Sivalinghem; Dr. Jianqun Wang assisted with the scanning electron microscope). 

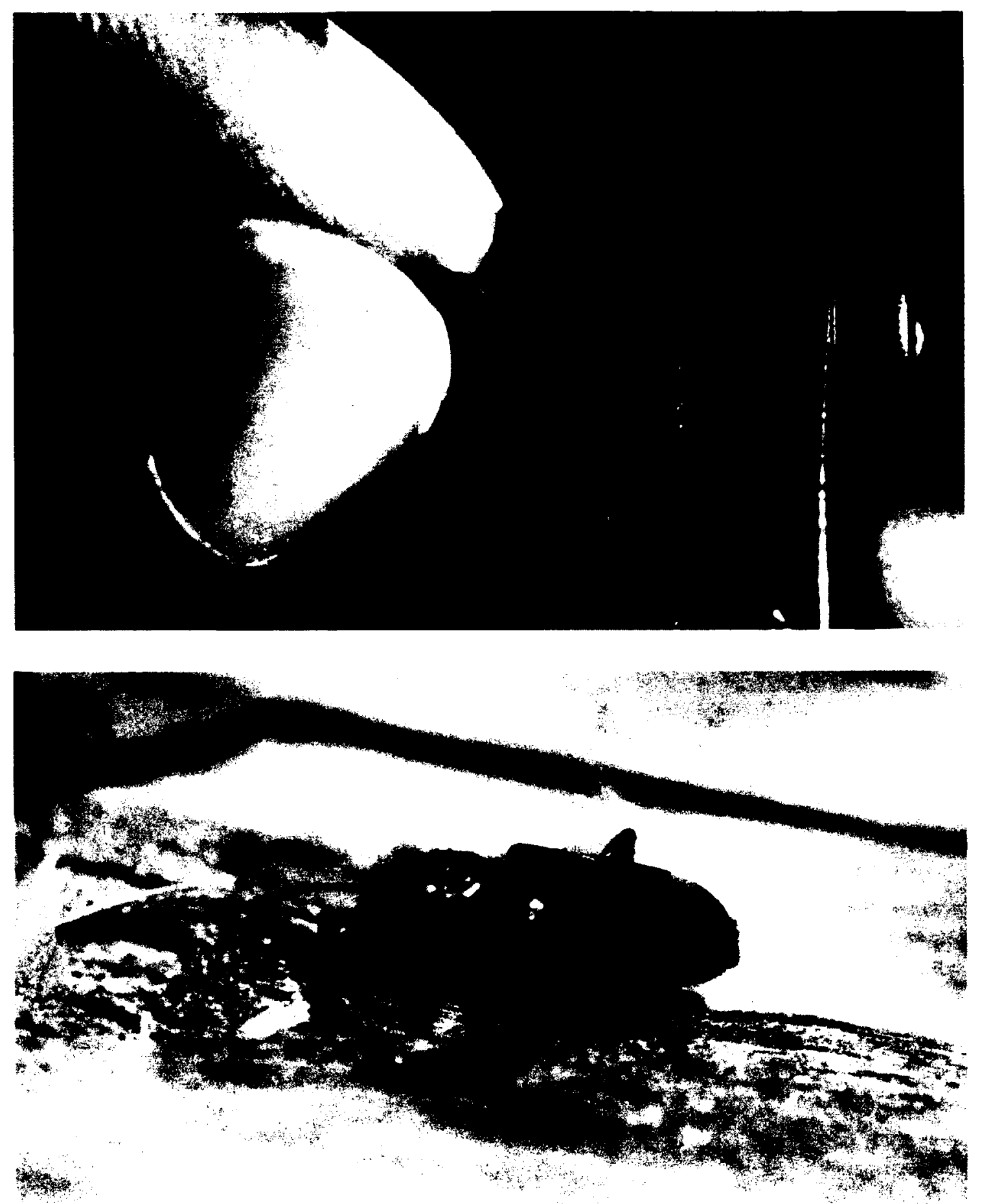

Figure 2.4. General methodology for recording female disturbance (A) and antipredation (B) signals. (A) Female I. pini were held by the abdomen, $1 \mathrm{~cm}$ away from the microphone, and light pinching elicited "disturbance" chirps. (B) Female and male I. pini were placed near their primary predators, Thanasimus dubius, in a Petri dish; predators were starved for 48 hours. Recording microphone was placed $1 \mathrm{~cm}$ above the bark beetles (not shown) (Photo credit: Jean-Paul Fournier, with assistance from Senthurran Sivalinghem). 
Fostex data recorder (FR-2 Field Memory Recorder, Boonton, NJ) set at a sampling rate of $192 \mathrm{kHz}$, where they were stored for later analysis. To ensure that the microphone was accurately covering the frequency spectrum, a subset of females was recorded with a 1/4" free-field Brüel and Kjær microphone (Type 4939, Nærum, Denmark; flat frequency response between $5 \mathrm{~Hz}-100 \mathrm{kHz}$ with protective grid off). Brüel and Kjær microphone recordings were amplified with a conditioning amplifier (Nexus, Type 7749, Denmark). Comparisons between microphones showed that recordings from the Avisoft microphone were not missing any frequency components of the signals (see Fig 2.9 and 2.10). However, the Avisoft microphone was more sensitive, and so recordings with this microphone were used for all temporal and frequency analysis.

Sound pressure levels (dB SPL) of disturbance signals were also obtained from a separate set of Alberta $(\mathrm{N}=5)$ and Ontario $(\mathrm{N}=6)$ females. Signals were recorded $1 \mathrm{~cm}$ from a 1/4" free-field Brüel and Kjær microphone $(100 \mathrm{mV} / \mathrm{Pascal}$, with protective grid off) amplified with a conditioning amplifier (Nexus; see above). Using a digital oscilloscope (Tektronix TDS 2002, $60 \mathrm{MHz}, 1 \mathrm{GS} / \mathrm{s}$ U.S.A.), the peak-to-peak voltage amplitude difference $(\Delta$ voltage $(\mathrm{mV}))$ of five individual chirps was measured for each female. The $\Delta$ voltages were averaged for each female, and converted into Pascal $(\mathrm{Pa})$, which was then converted to SPL (dB) using the formula:

$$
S P L(d B)=20\left(\log _{10}\left(\frac{P a}{20\left(10^{-6}\right)}\right)\right)(\text { Bradbury and Vehrencamp 1998) }
$$

The average dB SPL was calculated for both Alberta and Ontario females. All disturbance trials were conducted in a sound-proof chamber (Model C-14A MR, Eckel Industries of Canada, Morrisburg, Ontario, Canada) at temperatures of $20-22^{\circ} \mathrm{C}$. 


\section{Predation Trials}

Disturbance signals were previously suggested to function for anti-predation. However, to date, signals produced during predation events have not been described, and it is not known whether these signals are comparable to those recorded during handling experiments. To corroborate that signals produced during disturbance trials (described above) are similar to signals produced during predator attacks, predation trials were conducted with Ontario I. pini females $(\mathrm{N}=20)$, and compared to disturbance signals of Ontario females (above). In each trial, a single female was placed near the mandibles of a checkered beetle, Thanasimus dubius, which had been food deprived for 48 hours (Fig 2.4). Acoustic signals produced during attacks were recorded with the Avisoft ultrasound sensitive condenser microphone (see above), placed $\sim 1 \mathrm{~cm}$ above the beetles, and signals were stored using the Fostex data recorder (see above). All predation trials were conducted in a glass petri dish (diameter $=9 \mathrm{~cm}$ and height $=2 \mathrm{~cm}$ ). To ensure that the recorded frequencies were not affected by reverberation of the glass surface of the Petri dish, the bottom was covered with a $2 \mathrm{~mm}$ thick cork sheet. Signals were compared for peak frequencies, and frequency range at $10 \mathrm{~dB}$ below peak intensity.

To test the startling function hypothesis of disturbance signals, separate behavioural trials were conducted on Ottawa males $(\mathrm{N}=8)$ and females $(\mathrm{N}=9)$, and videotaped on a high definition digital camera recorder (Sony Handycam HDR$\mathrm{HC} 5 / \mathrm{HC}$, California, U.S.A.). In each trial, the start time was determined as the moment the predator made contact with the prey, and trials were recorded until the prey stopped all struggling head and leg movements, at which point the prey was considered dead. For all predation events, the time from prey seizure to prey death was measured. All trials 
were also observed for the number of times predators released their prey. The latency to chirp (time between predator attack and first chirp) was then measured for all female bark beetles. All trials were conducted on a glass Petri dish (described above), inside a soundproof chamber (see above).

\section{Male-Female Pre-mating Interaction Trials}

To prepare for mating trials, red pine logs $(-40$ to $50 \mathrm{~cm}$ in length) from felled trees were collected at the Herbert's Corner site (see above). All logs were sealed on each end with paraffin wax within $24 \mathrm{~h}$ of being cut, to prevent dehydration, and stored in a walk-in fridge $\left(5^{\circ} \mathrm{C}\right)$ at Carleton University. Prior to conducting mating trials, each log was inoculated with approximately $12-15$ males. Individual males were placed in manually drilled holes (diameter $=\sim 0.5 \mathrm{~cm}$ ), spaced $\sim 8$ to $10 \mathrm{~cm}$ apart. A $1.5 \mathrm{~mL}$ microcentrifuge (eppendorf) tube (with the conical base cut off) was placed over the hole, using sticky-tack, to prevent escaping. All males were given $48 \mathrm{~h}$ to build nuptial chambers prior to introducing females. Males that did not bore through the holes were replaced. Inoculated logs were kept at room temperature $\left(22\right.$ to $\left.24^{\circ} \mathrm{C}\right)$ in an insect rearing facility.

On the day of recording, an inoculated log was brought into the sound-proof chamber (see above), and placed horizontally on a table, propped up by wooden blocks on each end (Fig 2.5). The eppendorf covering the entrance hole was removed, and females were introduced near the entrance hole. Females placed near the entrance holes dug through the boring dust (frass), and entered the holes (Fig 2.5), upon which, they started signaling; presumably after making contact with male elytral declivity blocking 
the entrance to the nuptial chamber (Barr 1969; Swaby and Rudinsky 1976). Both Alberta $(\mathrm{N}=32)$ and Ontario $(\mathrm{N}=10) I$. pini were recorded with the Avisoft microphone (see above). The microphone was placed at a $\sim 45^{\circ}$ angle, $1 \mathrm{~cm}$ away from the entrance hole, and all recorded signals were stored using a Fostex data recorder (see above) for later analysis.

Given that males are polygynous, and can mate with up to four females per reproductive bouts, a sub-set of Alberta males $(N=14)$ that allowed admittance to the first females were given a second female 24 hours later, and the pre-mating signals of second females were recorded to compare with first females (above). Mating trials were recorded until acoustic signals were no longer heard to determine how signaling changes with time. To account for first-females that gained entry into nuptial chambers, but were later rejected or pushed out by males, after each first-female mating trial, the eppendorf was replaced to trap rejected females overnight; none of the first-females that were allowed admittance was found in the eppendorf traps after 24 hours.

\section{Substrate-borne Vibrations during Male-Female Interactions}

Substrate-borne vibrations transmitted through the phloem layer were also recorded simultaneously with air-borne vibrations for a subset of Alberta females $(\mathrm{N}=$ 31). To record vibrations, $a \sim 0.5 \mathrm{~cm}^{2}$ piece of bark was cut out $1 \mathrm{~cm}$ from the entrance hole, and glass micro-beads (Polytec P-Retro 500, Tustin, CA) were placed onto the exposed phloem layer. Vibrations were recorded using a laser Doppler vibrometer (Polytec PDV 100, Waldbronn, Germany); the laser was reflected off the embedded glass 


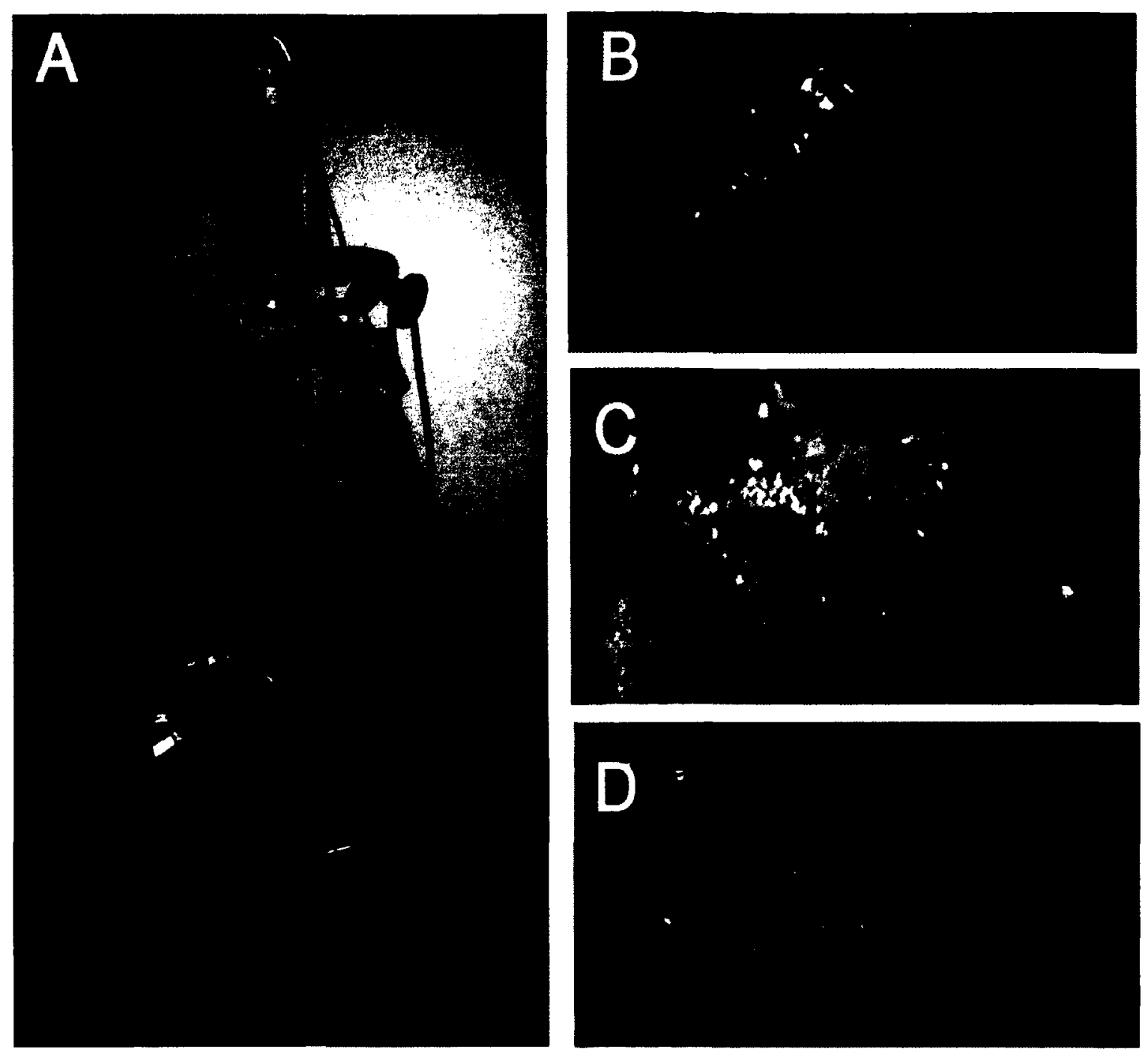

Figure 2.5. General methodology for recording female pre-mating acoustic signals. (A) Red pine logs that were inoculated with males, 48 hours prior to recording, were placed horizontally on two blocks of wood under a laser Doppler vibrometer. B) A recording microphone was placed at a $\sim 45^{\circ}$ angle $1 \mathrm{~cm}$ from the entrance hole to capture air-borne vibrations. To record substrate-borne vibrations, a $1 \mathrm{~cm}^{2}$ piece of bark was removed $\sim 1$ $\mathrm{cm}$ from the entrance hole to expose the phloem underneath, and a laser beam reflected off glass beads embedded in the phloem was used to record vibrations (image not shown). C) During pre-mating trials, females placed near the entrance hole dug through the surrounding frass and entered. D) Females usually started signaling after entering into the hole, presumably after making contact with male. (Photo credit: Senthurran Sivalinghem (A), and Jean-Paul Fournier (B-D)). 
micro-beads. The laser vibrometer was set at a velocity of $20 \mathrm{~mm} / \mathrm{s}$ with high-pass filter off, and low-pass filter at $22 \mathrm{kHz}$. Vibratory signals were stored onto a Marantz solid state data recorder (PMD 671, D\&M Professional, Itasca, IL) at a sampling rate of 44.1 $\mathrm{kHz}$. All trials were videotaped on a high definition digital camera recorder (see above).

\subsubsection{Morphological Measurements}

Using a light microscope (Olympus SZX12, Tokyo, Japan) equipped with a camera (Zeiss AxioCam MRc5, 1.4 megapixels, 1388 x 1040, Oberkochen, Germany), the dorsal and ventral images of Alberta females $(\mathrm{N}=19)$ from the disturbance trials (see above) were taken. The length and width of the pronotum, prosternum, and elytra were measured. All measurements were obtained using Image J (version 1.42q, National Institutes of Health, U.S.A.). These females were then prepared for scanning electron microscopy (SEM) - the pronotum and head was first separated from the rest of the body, and then the head was separated from the pronotum with an insect pin. All specimens were mounted on aluminum stubs so that the pars stridens on the head and the plectrum on the pronotum were in view. Specimens were double-coated with gold-palladium (Hummer VII SEM Sputtering System, Anatech Ltd., Alexandria, VA) prior to imaging. Female pars stridens and plectrum were examined and photographed using a variable pressure scanning electron microscope (Tescan Vega II XMU, Czech Republic). The length of the pars stridens and plectrum were measured. An estimation of the number of ridges on each part of the stridulatory organ was also made by first measuring the total length of the structure $\left(T_{0}\right)$, and then the length of five consecutive ridges (on the middle part of the structure) $\left(T_{1}\right)$, and using the formula $\left(5^{*} T_{0}\right) / T_{1}$. Individual ridges, for the 
most part of the structure, were fairly evenly spaced. However, it was apparent that the inter-ridge gaps were larger towards the posterior and anterior ends of the pars stridens and plectrum; this was not accounted for in the measurements. Therefore, the measured values of number of ridges were not absolute.

\subsubsection{Signal Analysis and Statistics}

Non-parametric statistics were used for all comparisons as some of the data were not normally distributed. Using Broughton (1963), a chirp was defined as "the shortest sound which appears unitary to the human observer's unaided ear" (Fig 2.6). Female chirps fall into two broad categories: 1) Interrupted chirps; and 2) Uninterrupted chirps (Fig 2.7). To test the hypothesis that "interruptions" in chirps were an effect of experimenter handling of the beetles, the proportion (\%) of "interrupted" chirps during disturbance, predation, male-first female, and male second female trials were measured. For each female in each condition, proportions were calculated by dividing the number of "interrupted" chirps out of the first 20 chirps. In trials where females produced less than 20 chirps (i.e. some predation trials), proportions were calculated out of total number of chirps produced. The proportions of "interrupted" chirps were averaged for each condition. Proportions of Alberta and Ontario females during disturbance and male-first female pre-mating trials were pooled together.

A Kruskal-Wallis test was used to compare the proportion of "interrupted" chirps between disturbance $(N=47)$, predation $(N=20)$, male-first female $(N=43)$, and malesecond female $(\mathrm{N}=14)$ trials. A Mann-Whitney $U$ post-hoc test was used to determine 
difference between groups. To control for Type I error, alpha values were adjusted using a Bonferroni correction:

$$
p=\frac{0.5}{\left(\frac{k(k-1)}{2}\right)}, \text { where } \mathrm{k}=\text { number of conditions. }
$$

In the four behavioural conditions (i.e. disturbance, predation, male-first female, and male-second female interaction conditions) described in the above sections, the acoustic signals of each female (from both populations; see above) was averaged for chirp duration (sec), number of pulses per chirp, pulse rate $(\# / \mathrm{sec})$, peak frequency $(\mathrm{kHz})$, signal amplitude $(\mathrm{dB})$, frequency bandwidth at $-10 \mathrm{~dB}$, and if any, the second and third frequency peaks $(\mathrm{kHz})$. For each female, averages were calculated from five randomly selected "uninterrupted" chirps. Substrate-borne vibrations from Alberta females during the male-female interactions $(\mathrm{N}=31)$ were also measured and averaged for peak frequency $(\mathrm{kHz})$, and duration $(\mathrm{sec})$. For each female, averages were calculated from five randomly selected signals.

To determine how air-borne signals varied between behavioural conditions, a Kruskal-Wallis test was used to compare the temporal and spectral difference in acoustic signals between disturbance $(\mathrm{N}=19)$, male-first female $(\mathrm{N}=32)$, and male second female $(N=14)$ conditions, for Alberta females, and between disturbance $(N=26)$, predation $(\mathrm{N}=20)$, and male-first female $(\mathrm{N}=10)$ for Ontario females. A Mann-Whitney $U$ post-hoc test, with Bonferroni correction, was used to determine difference between groups.

To find out whether air-borne signal characteristics were correlated with female morphometrics, a stepwise regressions analysis was used to compare signal 
characteristics of Alberta females (used during disturbance trials above; $N=19$ ) with female weight, body size measurements (see morphological measurements above), and length and number of ridges on both the pars stridens and plectrum.

To determine within-population variation in signal features, the coefficient of variation (CV) (both within and between individuals) of chirp durations, number of pulses, pulse rates, and peak frequencies were calculated for disturbance and male-first female pre-mating signals. To calculate within-individual $\mathrm{CV}$, the average and standard deviation (SD) for each signal parameter of each female was first obtained. Withinindividual CV was calculated using the formula:

$$
C V(\%)=\left(\frac{S D}{\text { Average }}\right) \times 100
$$

To calculate between-individual $\mathrm{CV}$, the averages of each female calculated above were averaged, and the SD of between female averages was obtained. Betweenindividual CV was calculated using the formula above. A Mann-Whitney $U$ test was also used to compare between-population differences in temporal and spectral characteristics of disturbance ( $\mathrm{N}=19$ and 26 , Alberta and Ontario respectively) and male-first female pre-mating $(\mathrm{N}=32$ and 10, Alberta and Ontario respectively) signals.

To determine how female signaling changes with time, during male-female premating interactions, each 6.5 min mating trial was divided into 30 second (or $0.5 \mathrm{~min}$ ) intervals. In each $30 \mathrm{sec}$ interval, female "signaling effort" was measured as the total number of chirps produced during that interval. a Mann-Whitney $U$ test was used to compare female signaling effort, during the first 30 second interval, between first $(\mathrm{N}=$ 33) and second $(\mathrm{N}=14)$ females. A pair-wise Wilcoxon Signed Ranks test was used to 
compare changes in signaling effort between the first 30 second interval, and the second 30 second interval for both first $(\mathrm{N}=33)$ and second $(\mathrm{N}=14)$ females.

In the predation trials, a Mann-Whitney $U$ test was used to compare the latency from prey capture to prey death between predators that were given female prey items $(\mathrm{N}$ $=9)$, and predators that were given male prey items $(\mathrm{N}=8)$.

All signal analysis was done using Raven Bioacoustics Research Program (Pro 1.4 Beta version, Cornell Laboratory of Ornithology, Ithaca, NY, USA). The number of pulses per chirp, however, was measured using the Avisoft Bioacoustics Sound Analysis and Synthesis Laboratory program (Avisoft-SAS Lab Pro, version 4.53, Berlin, Germany). In Raven, all power spectra were produced using a 4096-samples Fast Fourier Transform (FFT) Hanning window with a 3dB filter bandwidth setting at $1079 \mathrm{~Hz}$. All statistical analysis was done on SPSS (v13.0).

\subsection{Results}

\subsubsection{Types of Signals}

Female pine engraver, Ips pini, produced "squeak-like" chirps that corresponded with repeated head movements. Signals were produced during both posterior and anterior movements of the head (personal observation). A 'chirp' was defined as "the shortest sound which appears unitary to the human observer's unaided ear" (from Broughton 1963) (Fig 2.6). Each chirp was composed of multiple pulses that varied in amplitude (Fig 2.6). A 'pulse' was defined as "one complete transient wave train" (from Broughton 1963) (Fig 2.6). Female signals in all behavioural conditions were classified into two broad categories: 1) "Uninterrupted Chirps", defined as simple chirps with pulses that 
occurred continuously throughout the entirety of the chirp (Fig 2.7); and 2) "Interrupted Chirps", defined as simple chirps with one or more gaps lacking pulses (Fig 2.7). There was considerable variation in the length and number of interruptions between interrupted chirps within an individual. Females also produced "Clicks" (Fig 2.7). Clicks usually occurred as a single pulse, but in some occasions were comprised of up to five fairly evenly spaced consecutive pulses (Fig 2.7). It was difficult to distinguish "clicks" from incidental sounds produced by digging or chewing; therefore no further analysis was done on these signals.

Interrupted chirps were previously described by Swaby and Rudinsky (1976) for I. pini, but their functional significance was not known. To test the hypothesis that these interrupted chirps may not have any functional significance, and are likely caused by some obstruction to the stridulatory mechanism, the proportions of interrupted chirps (out of the first 20 chirps; see methods) during disturbance, predation, male-first female, and male-second female interactions were compared. The underlying prediction was that handling the beetles (during disturbance trials) would cause increased obstruction to the stridulatory mechanism, and thus would result in increased occurrence (proportions) of interrupted chirps. A Kruskal-Wallis test, comparing the proportion (\%) of interrupted chirps during disturbance, predation, male-first female, and male-second female trials, showed a significant difference between the four condition $\left(\chi^{2}=36.37, \mathrm{df}=3, \mathrm{p}<\right.$ 0.001 ), with a mean rank of 83.41 for disturbance, 27.95 for predation, 56.45 for malefirst female, and 57.32 for male-second female trials (Fig 2.8). A Mann-Whitney $U$ posthoc test, with a Bonferroni correction $(p=0.5 / 6=0.0083)$, showed that there was significantly more interrupted chirps in the disturbance trials $(\% \pm \mathrm{SD}=34.97 \pm 2.9)$ than 

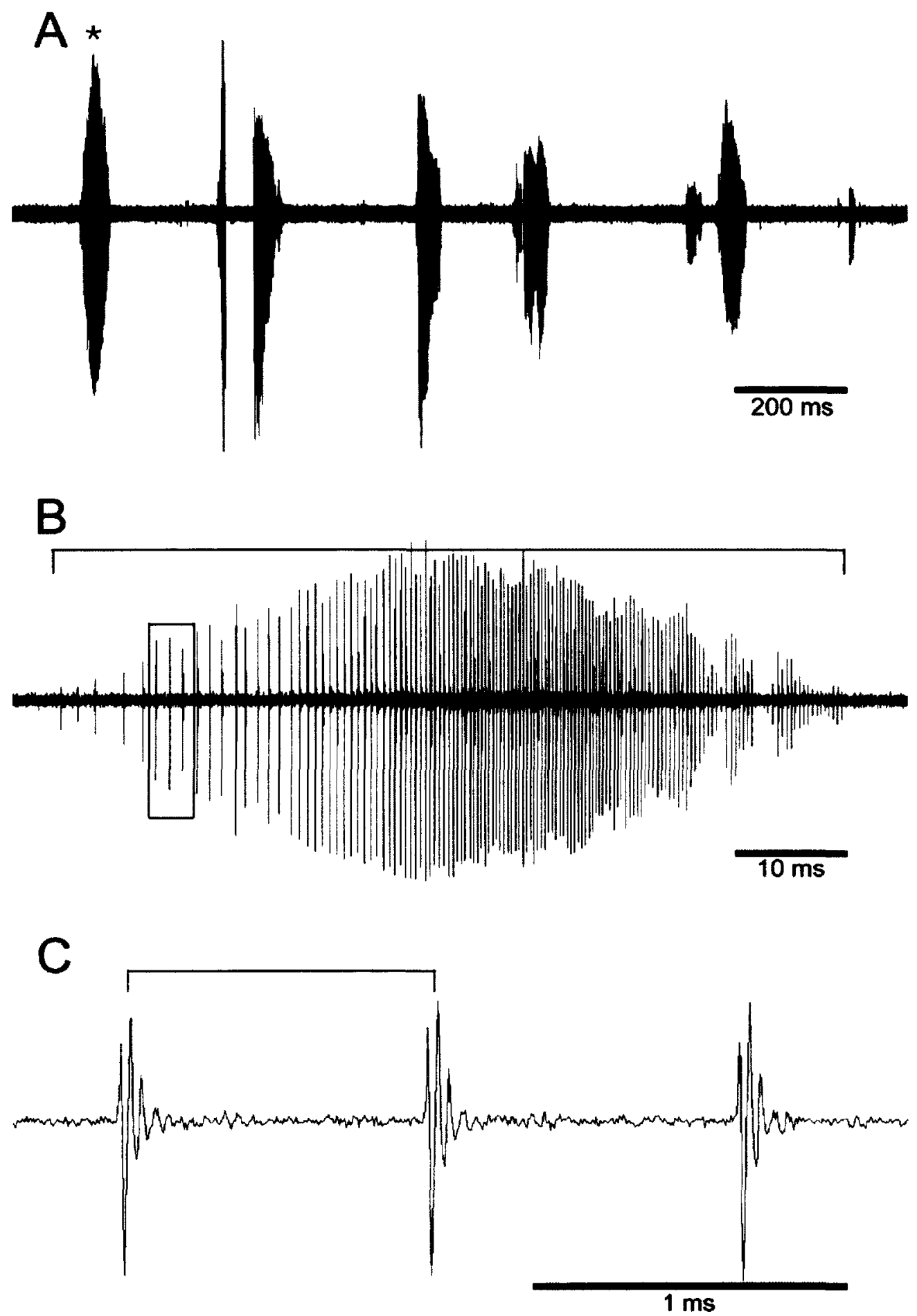

Figure 2.6. General characteristics of female Ips pini acoustic signals. (A) The shortest female sound that appeared unitary to the unaided ear was considered a chirp (indicated by red asterisk). B) Each chirp was composed of multiple pulses. C) Each pulse was a complete transient wave train. Chirp duration was measured as the time interval between the first and last pulse within a chirp, and pulse rate was measured as the number of pulses over chirp duration. 
A

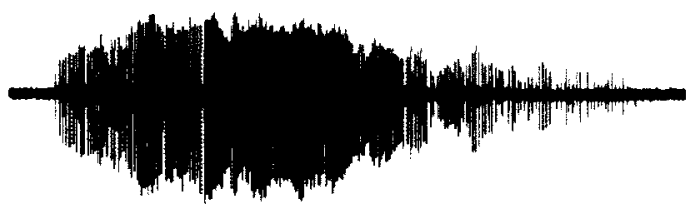

C

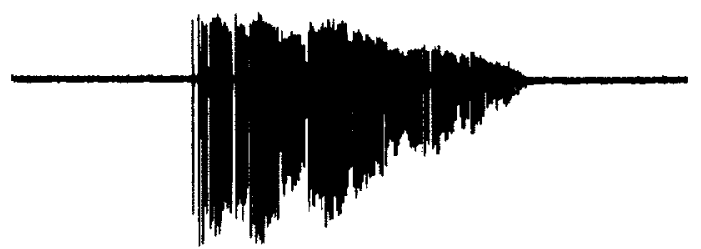

E

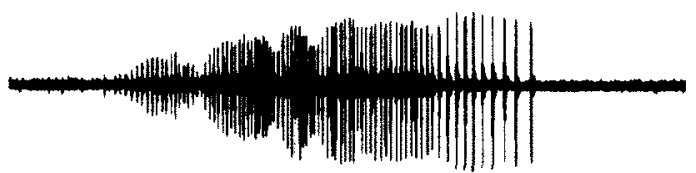

G

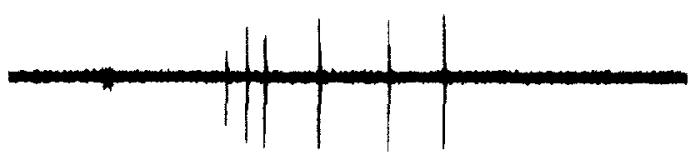

I

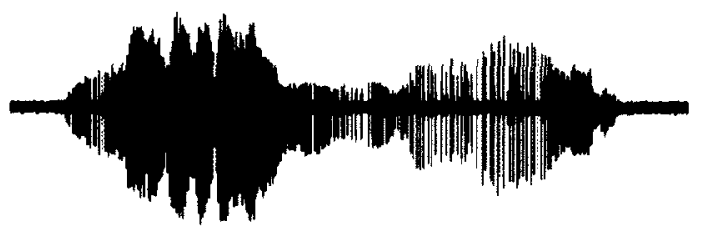

B
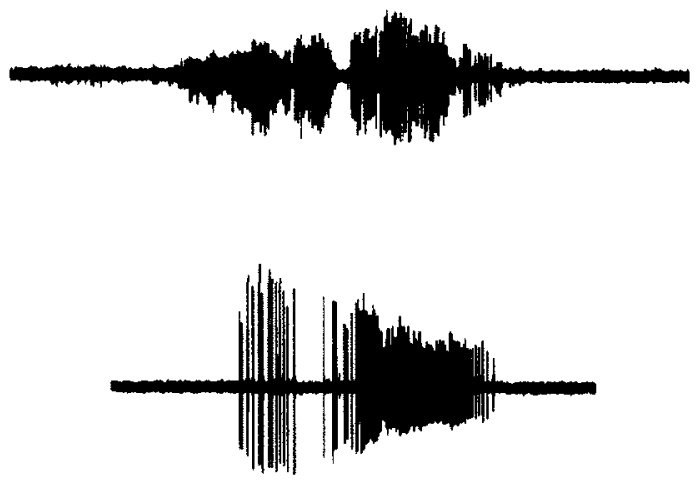

F

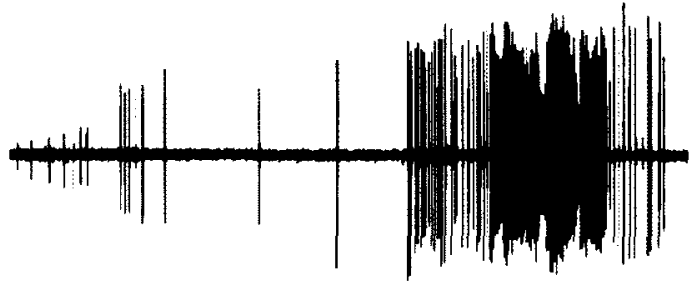

H

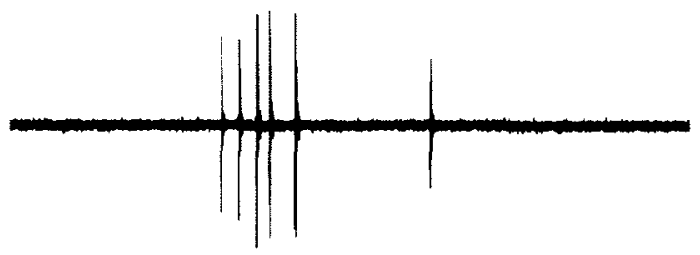

$J$

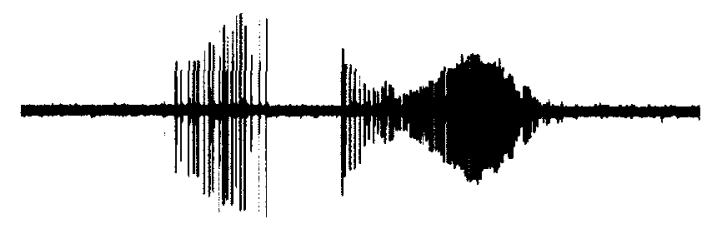

$20 \mathrm{~ms}$

Figure 2.7. Variation in female $I$. pini acoustic signals. All chirp types were categorized as either "Uninterrupted" (A, C, E and I) or "Interrupted" (B, D, F and J) chirps. (G and H) "Clicks" consisted from 1 to 5 consecutive pulses. 


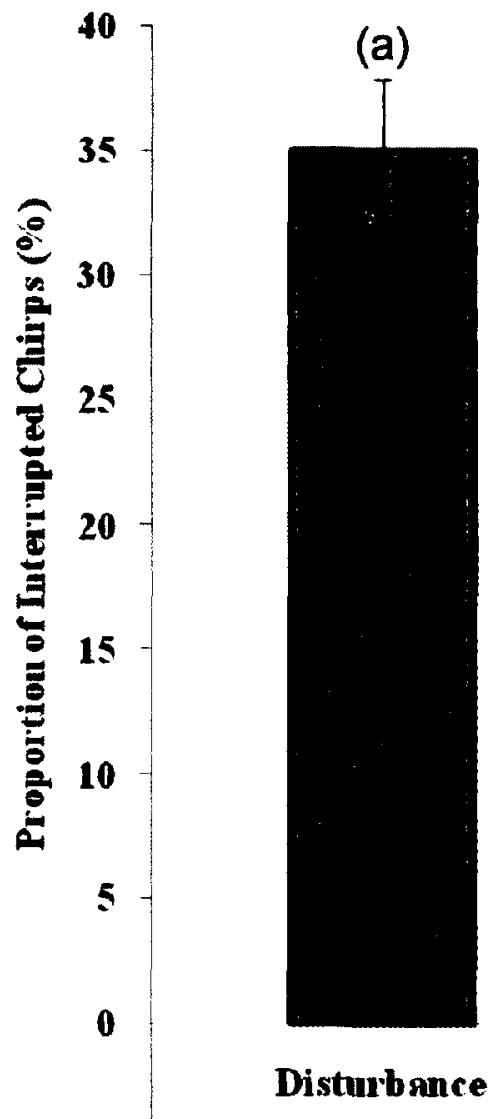

(c)

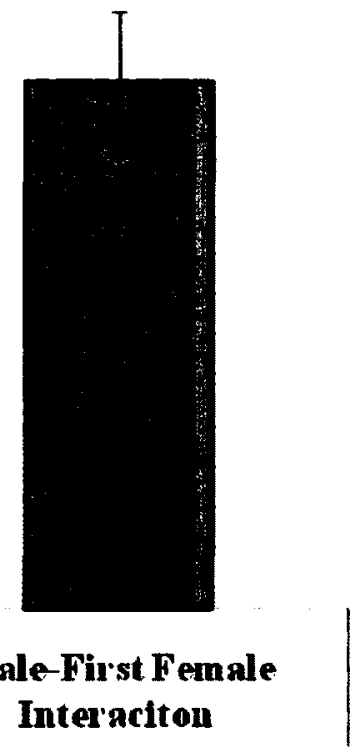

(c)

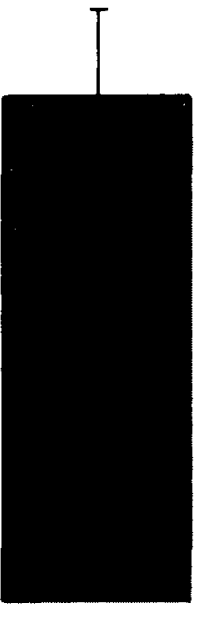

Male-Second Female Interaction

\section{Behaviour'al Context}

Figure 2.8. Proportion of interrupted chirps in disturbance, predation, male-first female, and male-second female behavioural context. Proportions were calculated by dividing the number of interrupted chirps out of the first 20 chirps. Letters in brackets indicate grouping of averages, at $\mathrm{p}<0.0083$ (Bonferroni correction; see text), based on a Kruskal-Wallis test. 
in the predation $(7.61 \pm 2 ; U=86.00, \mathrm{p}<0.001)$, male-first female $(21.07 \pm 2.8 ; U=$ $532.00, \mathrm{p}<0.001)$, and male-second female $(20 \pm 3.6 ; U=168, \mathrm{p}=0.007)$ trials. Predation trials, however, had significantly less interrupted chirps than male-first female $(U=198.00, \mathrm{p}=0.001)$, and male-second female trials $(U=65.00, \mathrm{p}=0.008)$. There was no difference in proportions between the male-first female and male-second female interactions trials $(p=0.801)$. Given that interrupted chirps were rare, and may not have any functional significance, all further comparisons and analysis were done on uninterrupted chirps.

\subsubsection{Signal Characteristics}

\section{Disturbance Signals}

Light pinching of the female abdomen elicited disturbance chirps (Figs. 2.9 and 2.10). A summary of temporal and spectral characteristics of all signals is provided in Table 2.2. Most females did not readily produce disturbance chirps when handled, and many required repeated physical stimulation. Disturbance signals of both Alberta and Ontario females had fairly broad frequency bandwidths (at $-10 \mathrm{~dB}$ ), with peak frequencies and harmonics in the ultrasonic range ( $>20 \mathrm{kHz}$ ) (see Table 2.2) (Figs. 2.9 and 2.10). Peak frequency bandwidth (at -10dB) of Alberta females ranged from 16 to $26 \mathrm{kHz}$, whereas Ontario females had a range between 18 and $37 \mathrm{kHz}$. However, there were large frequency components extending from as low as $10 \mathrm{kHz}$ to well above $85 \mathrm{kHz}$ (Figs. 2.9 and 2.10).

A stepwise multiple regressions analysis showed that disturbance chirps of Alberta females were correlated with female phenotypic traits (Tables 2.3, 2.4, and 2.5). 
Table 2.2. Temporal and spectral characteristics of Alberta and Ottawa female Ips pini acoustic signals.

\begin{tabular}{|c|c|c|c|c|c|c|}
\hline Population & Condition & Chirp Type (N)† & $\begin{array}{c}\text { Chirp Duration } \\
\text { (sec) }\end{array}$ & $\begin{array}{c}\text { Number of } \\
\text { Pulses per Chirp }\end{array}$ & $\begin{array}{c}\text { Pulse Rate } \\
\text { (\#/sec) }\end{array}$ & $\begin{array}{c}\text { Peak } \\
\text { Frequency } \\
(\mathbf{k H z})\end{array}$ \\
\hline & & & Average ( \pm SE) & Average $( \pm$ SE) & Average $( \pm \mathrm{SE})$ & Average $( \pm \mathrm{SE})$ \\
\hline \multirow{6}{*}{$\begin{array}{c}\text { Alberta } \\
\text { (Ips pini) }\end{array}$} & \multirow{2}{*}{ Disturbance } & $\begin{array}{l}\text { Uninterrupted } \\
\text { (19) }\end{array}$ & $0.105(0.009)$ & $103.06(7.22)$ & $190.06(35.75)$ & $22.66(0.49)$ \\
\hline & & Interrupted (13) & $0.162(0.025)$ & $104.77(8.77)$ & $766.63(55.58)$ & $22.42(0.25)$ \\
\hline & \multirow{2}{*}{$\begin{array}{l}\text { Male-1st Female } \\
\text { Interaction }\end{array}$} & $\begin{array}{c}\text { Uninterrupted } \\
(\mathbf{3 2})\end{array}$ & $0.120(0.006)$ & $91.23(5.87)$ & $751.98(33.37)$ & $12.06(0.43)$ \\
\hline & & Interrupted (22) & $0.158(0.012)$ & $86.90(8.78)$ & $583.16(50.96)$ & $13.09(0.78)$ \\
\hline & \multirow{2}{*}{$\begin{array}{l}\text { Male-2nd Female } \\
\text { Interaction }\end{array}$} & $\begin{array}{c}\text { Uninterrupted } \\
\text { (14) }\end{array}$ & $0.121(0.016)$ & $79.01(10.0)$ & $670.88(41.84)$ & $11.41(0.78)$ \\
\hline & & Interrupted (10) & $0.198(0.052)$ & $82.64(12.18)$ & $591.87(91.13)$ & $10.75(1.47)$ \\
\hline \multirow{4}{*}{$\begin{array}{l}\text { Ottawa } \\
\text { (Ips pini) }\end{array}$} & \multirow{2}{*}{ Disturbance } & $\begin{array}{c}\text { Uninterrupted } \\
\text { (26) }\end{array}$ & $0.124(0.008)$ & $136.85(8.63)$ & $\begin{array}{l}1169.28 \\
(57.97)\end{array}$ & $27.24(0.82)$ \\
\hline & & Interrupted (25) & $0.162(0.009)$ & $107.09(7.42)$ & $709.02(47.29)$ & $25.75(0.79)$ \\
\hline & Predation & $\begin{array}{c}\text { Uninterrupted } \\
(\mathbf{2 0}) \\
\end{array}$ & $0.122(0.007)$ & $130.22(8.45)$ & $\begin{array}{l}1069.54 \\
(49.85) \\
\end{array}$ & $21.14(1.59)$ \\
\hline & $\begin{array}{l}\text { Male-Female } \\
\text { Interaction }\end{array}$ & $\begin{array}{c}\text { Uninterrupted } \\
\text { (10) }\end{array}$ & $0.158(0.017)$ & $166.6(13.73)$ & $\begin{array}{l}1145.41 \\
(109.23)\end{array}$ & $12.04(0.59)$ \\
\hline
\end{tabular}




\begin{tabular}{|c|c|c|c|c|}
\hline $\begin{array}{l}\text { Signal Amplitude } \\
\text { (dB) }\end{array}$ & $\begin{array}{l}\text { Sound Pressure } \\
\text { Level (dB SPL) }\end{array}$ & $\begin{array}{l}\text { Bandwidth at -10dB } \\
(\mathrm{kHz})\end{array}$ & $\begin{array}{l}\text { 2nd Frequency Peak } \\
(\mathbf{k H z})\end{array}$ & $\begin{array}{l}\text { 3rd Frequency Peak } \\
\qquad(\mathbf{k H z})\end{array}$ \\
\hline Average $( \pm \mathrm{SE})$ & Average $( \pm \mathrm{SE})$ & Average $( \pm \mathrm{SE})$ & Average $( \pm \mathrm{SE})$ & Average $( \pm \mathrm{SE})$ \\
\hline $106.8(0.87)$ & $69.33(1.57) \ddagger$ & $9.07(0.82)+$ & $41.85(5.64)$ & \\
\hline \multicolumn{5}{|l|}{$108.32(1.22)$} \\
\hline $100.18(0.88)$ & & $8.15(0.84) \ddagger$ & $17.24(2.43)$ & $29.39(5.46)$ \\
\hline \multicolumn{5}{|l|}{$99.81(1.19)$} \\
\hline $99.19(1.47)$ & & $5.73(1.15) \ddagger$ & & \\
\hline \multicolumn{5}{|l|}{$103.31(1.89)$} \\
\hline $110.14(0.82)$ & $24.84(0.43) ¥$ & $13.81(1.34) \ddagger$ & $54.23(0.97)$ & $74.44(2.52)$ \\
\hline \multicolumn{5}{|l|}{$107.09(7.42)$} \\
\hline $99.69(1.05)$ & & $4.86(0.82) \ddagger$ & $36.24(0.73)$ & $52.75(1.38)$ \\
\hline $96.67(0.96)$ & & $9.60(1.70) \ddagger$ & & \\
\hline
\end{tabular}

$\uparrow$ Three to five chirps (of each type) were measured and averaged for each individual.

$\ddagger N=5$ females; for each, five chirps were measured and averaged.

$\mathrm{IN}=6$ females; for each, five chirps were measured and averaged. 

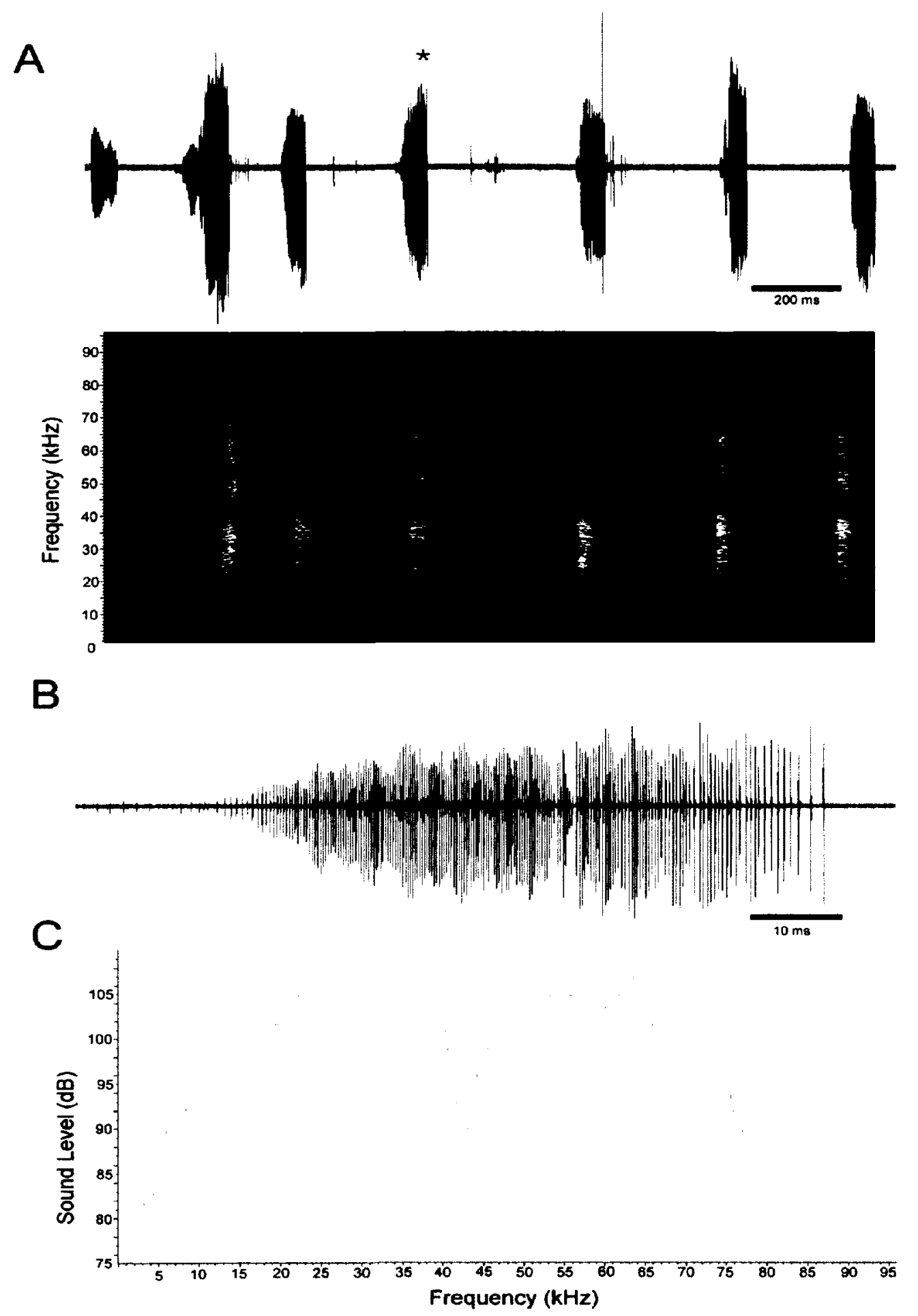

Figure 2.9. Disturbance signals of Ontario Ips pini female recorded with an Avisoft microphone. (A) Oscillogram (top) and spectrogram (bottom) of seven consecutive disturbance chirps recorded from an individual female. (B) An individual chirp from A (denoted by red asterisk) with an expanded time scale to show individual pulses. (C) Power spectrum of the chirp in B. 

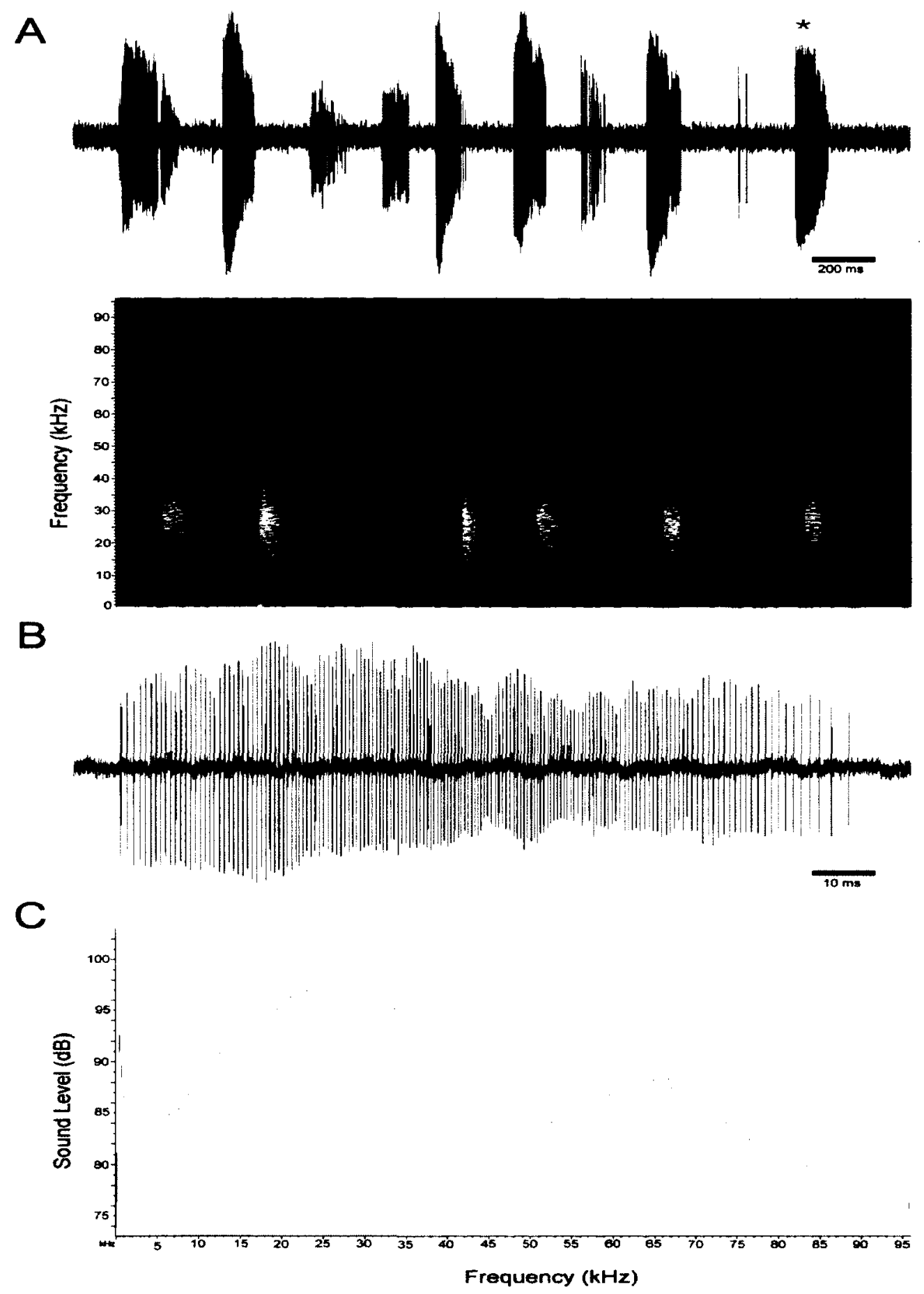

Figure 2.10. Disturbance signals of Ontario Ips pini female recorded with a Brüel and Kjær microphone. (A) Oscillogram (top) and spectrogram (bottom) of nine consecutive disturbance chirps recorded from an individual female. (B) An individual chirp from A (denoted by red asterisk) with an expanded time scale to show individual pulses. (C) Power spectrum of the chirp in B. 
Specifically, chirp duration was positively correlated with female weight $(p=0.021)$ and pronotum width $(p=0.001)$, and negatively correlated with pronotum length $(p=<$ 0.001 ; final model $r^{2}=0.81, F_{3,15}=20.73, p<0.001$ ); the number of pulses was positively correlated with pronotum width $(\mathrm{p}=0.009)$, and negatively correlated with pronotum length $\left(p=0.033\right.$; final model $\left.r^{2}=0.36, F_{2,16}=4.43, p=0.029\right)$; and pulse rate was positively correlated with pronotum length $\left(p=0.003\right.$; final model $r^{2}=0.44, F_{2,16}=$ $6.39, \mathrm{p}<0.009)$, and there was a negative trend with elytra width $(\mathrm{p}=0.056)$ (Table 2.5). Although, peak frequency was positively correlated with elytral width $(p=0.021)$, and negatively correlated with elytral length $(p=0.047)$, the final model was not significant $\left(r^{2}=0.3, F_{3,15}=3.37, p=0.06\right)($ Table 2.5$)$

Both within- and between-female coefficient of variations (CV) showed that disturbance signal parameters were highly variable within populations (Tables 2.6 and 2.7). Based on Gerhardt's (1991) criteria for classifying signal parameters, as either "static" (when coefficient of variation $(\mathrm{CV})<5 \%$; low variation) or "dynamic" (when $\mathrm{CV}>12 \%$; high variation), all temporal characteristics, in both populations, were considered "dynamic" (Table 2.6 and 2.7). Peak frequencies of disturbance signals, however, had the lowest variation both within and between females in both populations. The peak frequencies of disturbance signals in Alberta females were relatively less variable (<12\%; "intermediate") than in Ontario females $(>12 \%$; "dynamic") (Tables 2.6 and 2.7). 
Table 2.3. Raw data of female phenotypic characteristics used for stepwise multiple regressions analysis.

\begin{tabular}{|c|c|c|c|c|c|c|c|c|c|c|c|}
\hline $\begin{array}{l}\text { Female } \\
\text { ID }\end{array}$ & $\begin{array}{c}\text { Pronotum } \\
\text { Length } \\
(\mathbf{m m})\end{array}$ & $\begin{array}{l}\text { Pronotum } \\
\text { width } \\
(\mathrm{mm})\end{array}$ & $\begin{array}{l}\text { Elytra } \\
\text { length } \\
(\mathrm{mm})\end{array}$ & $\begin{array}{l}\text { Elytra } \\
\text { width } \\
(\mathrm{mm})\end{array}$ & $\begin{array}{l}\text { Prosternum } \\
\text { Length } \\
\text { (mm) }\end{array}$ & $\begin{array}{l}\text { Prosternum } \\
\text { width }(\mathrm{mm})\end{array}$ & $\begin{array}{l}\text { Weight } \\
\text { (mg) }\end{array}$ & $\begin{array}{c}\text { Pars } \\
\text { Stridens } \\
\text { Length } \\
(\mu \mathrm{m})\end{array}$ & $\begin{array}{c}\text { Pars } \\
\text { Stridens } \\
\text { \# of } \\
\text { Ridges }\end{array}$ & $\begin{array}{c}\text { Plectrum } \\
\text { Length } \\
(\mu \mathrm{m})\end{array}$ & $\begin{array}{c}\text { Plectrum } \\
\text { \# of } \\
\text { Ridges }\end{array}$ \\
\hline 1 & 1.57 & 1.47 & 2.24 & 1.55 & 0.51 & 1.47 & 50 & 269.38 & 225.61 & 210.04 & 67.49 \\
\hline 2 & 1.41 & 1.27 & 2.09 & 1.38 & 0.6 & 1.32 & 36 & 214.42 & 211.88 & 256.65 & 72.46 \\
\hline 3 & 1.59 & 1.5 & 2.35 & 1.55 & 0.65 & 1.52 & 49 & 177.22 & 195.61 & 300.5 & 92.06 \\
\hline 4 & 1.6 & 1.42 & 2.25 & 1.54 & 0.53 & 1.46 & 49 & 198.13 & 196.56 & 299.39 & 80.96 \\
\hline 5 & 1.57 & 1.38 & 2.04 & 1.43 & 0.49 & 1.39 & 42 & 208.72 & 278.29 & 285.1 & 72.07 \\
\hline 6 & 1.51 & 1.41 & 2.27 & 1.57 & 0.51 & 1.46 & 56 & 268.01 & 262.75 & 315.5 & 91.66 \\
\hline 7 & 1.79 & 1.52 & 2.19 & 1.65 & 0.5 & 1.57 & 62 & 191.21 & 203.85 & 318.06 & 97.56 \\
\hline 8 & 1.55 & 1.41 & 2.16 & 1.49 & 0.47 & 1.45 & 40 & 216.26 & 231.54 & 315.1 & 90.44 \\
\hline 9 & 1.58 & 1.37 & 2.18 & 1.46 & 0.69 & 1.41 & 44 & 265.5 & 258.77 & 286.75 & 67.5 \\
\hline 10 & 1.54 & 1.41 & 2.2 & 1.52 & 0.5 & 1.43 & 47 & 227.93 & 256.1 & 298.1 & 76.79 \\
\hline 11 & 1.72 & 1.49 & 2.37 & 1.58 & 0.49 & 1.55 & 63 & 238.72 & 248.67 & 290.87 & 89.11 \\
\hline 12 & 1.68 & 1.54 & 2.3 & 1.54 & 0.52 & 1.55 & 52 & 288.57 & 260.91 & 356.93 & 91.38 \\
\hline 13 & 1.82 & 1.55 & 2.32 & 1.59 & 0.53 & 1.58 & 60 & 272.08 & 276.5 & 278.07 & 83.06 \\
\hline 14 & 1.46 & 1.34 & 2.1 & 1.39 & 0.46 & 1.38 & 41 & 157.88 & 183.16 & 264.79 & 78.43 \\
\hline 15 & 1.54 & 1.56 & 2.29 & 1.62 & 0.53 & 1.58 & 60 & 282.85 & 260.93 & 269.72 & 83.71 \\
\hline 16 & 1.47 & 1.37 & 2.13 & 1.45 & 0.49 & 1.37 & 42 & 238.66 & 230.37 & 264.23 & 76.77 \\
\hline 17 & 1.62 & 1.44 & 2.14 & 1.46 & 0.4 & 1.46 & 46 & 238.4 & 281.8 & 230.8 & 82.84 \\
\hline 18 & 1.66 & 1.48 & 2.37 & 1.53 & 0.48 & 1.51 & 56 & 237.9 & 220.69 & 264.69 & 77.21 \\
\hline 19 & 1.57 & 1.46 & 2.24 & 1.5 & 0.52 & 1.49 & 49 & 228.05 & 231.76 & 259.53 & 86.57 \\
\hline
\end{tabular}


Table 2.4. Raw data of female acoustic signal characteristics used for stepwise multiple regressions analysis.

\begin{tabular}{c|ccc|c}
\hline $\begin{array}{c}\text { Female } \\
\text { ID }\end{array}$ & $\begin{array}{c}\text { Avg. } \\
\text { Chirp } \\
\text { Duration } \\
\text { (sec) }\end{array}$ & $\begin{array}{c}\text { Avg. } \\
\text { Number } \\
\text { of } \\
\text { Pulses }\end{array}$ & $\begin{array}{c}\text { Avg. } \\
\text { Pulse } \\
\text { Rate } \\
\text { (\#/sec) }\end{array}$ & $\begin{array}{c}\text { Avg. Peak } \\
\text { Frequency } \\
\text { (kHz) }\end{array}$ \\
\hline 1 & 0.16 & 127.2 & 910 & 23.55 \\
2 & 0.07 & 65.6 & 940.6 & 22.05 \\
3 & 0.13 & 126.8 & 999.33 & 20.55 \\
$\mathbf{4}$ & 0.11 & 112.2 & 1019.69 & 21 \\
5 & 0.08 & 96.8 & 1072.18 & 21.6 \\
6 & 0.18 & 165.8 & 898.47 & 22.2 \\
7 & 0.07 & 78.2 & 1203.99 & 27.15 \\
$\mathbf{8}$ & 0.07 & 61.6 & 842.43 & 21.75 \\
9 & 0.07 & 51.33 & 742.2 & 23.5 \\
10 & 0.09 & 103.4 & 1098.28 & 27.9 \\
11 & 0.08 & 87.6 & 1074.18 & 21.45 \\
12 & 0.13 & 163.4 & 1278.26 & 25.95 \\
13 & 0.07 & 74.4 & 1147.99 & 21.3 \\
14 & 0.09 & 101.8 & 1098.67 & 21.15 \\
15 & 0.2 & 120.2 & 665.47 & 23.25 \\
16 & 0.08 & 80.2 & 929.69 & 21.75 \\
17 & 0.09 & 99.4 & 1067.72 & 21.75 \\
18 & 0.1 & 125.2 & 1180.39 & 20.55 \\
19 & 0.11 & 117 & 1021.49 & 22.05 \\
\hline
\end{tabular}


Table 2.5. Results from a stepwise regressions analysis examining correlations between signal characteristics, of Ips pini disturbance signals, to female weight, length and width of pronotum, elytra, and prosternum, and length and number of ridges of the pars stridens and the plectrum. Data shows the final variables (predictor variables) that correlated with the chirp characteristic (criterion variable) (based on $\beta, t$, and $\mathrm{p}_{1}$ values), and the overall significance of the final model $\left(\mathrm{r}^{2}, \mathrm{~F}\right.$, and $\left.\mathrm{p}_{2}\right)$.

\begin{tabular}{|c|c|c|c|c|c|c|c|c|}
\hline $\begin{array}{l}\text { Criterion } \\
\text { Variable } \\
\end{array}$ & Predictor Variable & Beta $(\boldsymbol{\beta})$ & $\mathbf{t}$ & p1 & $\mathbf{r} 2$ & $\mathbf{F}$ & $d f$ & p2 \\
\hline \multirow{3}{*}{ Duration } & Weight & 0.55 & 2.59 & 0.021 & \multirow{3}{*}{0.81} & \multirow{3}{*}{20.73} & \multirow{3}{*}{3,15} & \multirow{3}{*}{$<0.001$} \\
\hline & Pronotum Length & -1.32 & -7.17 & $<0.001$ & & & & \\
\hline & Pronotum Width & 0.92 & 4.09 & 0.001 & & & & \\
\hline \multirow{2}{*}{$\begin{array}{l}\text { Number of Pulses } \\
\text { per chirp }\end{array}$} & Pronotum Length & -0.73 & -2.34 & 0.033 & \multirow{2}{*}{0.36} & \multirow{2}{*}{4.43} & \multirow{2}{*}{2,16} & \multirow{2}{*}{0.029} \\
\hline & Pronotum Width & 0.93 & 2.98 & 0.009 & & & & \\
\hline \multirow{3}{*}{ Pulse Rate } & Pronotum Length & 0.93 & 3.97 & 0.003 & \multirow{3}{*}{0.44} & \multirow{3}{*}{6.39} & \multirow{3}{*}{2,16} & \multirow{3}{*}{0.009} \\
\hline & & & & & & & & \\
\hline & Elytra Width & -0.54 & -2.34 & 0.056 & & & & \\
\hline \multirow{3}{*}{ Peak Frequency } & Elytra Length & -0.66 & -2.15 & 0.047 & \multirow{3}{*}{0.3} & \multirow{3}{*}{3.37} & \multirow{3}{*}{2,16} & \multirow{3}{*}{0.06} \\
\hline & & & & & & & & \\
\hline & Elytra Width & 0.79 & 2.56 & 0.021 & & & & \\
\hline
\end{tabular}


Table 2.6. Within-female variability of acoustic features of Ips pini disturbance and pre-mating signals.

\begin{tabular}{|c|c|c|c|c|c|c|}
\hline Population & Condition & $\mathbf{N}$ & Signal Parameter & $\begin{array}{c}\text { Mean CV } \\
(\%)\end{array}$ & Range & Type $\dagger$ \\
\hline \multirow{8}{*}{$\begin{array}{l}\text { Alberta } \\
\text { Females }\end{array}$} & \multirow{4}{*}{ Disturbance } & \multirow{4}{*}{18} & Chirp Duration & 38.44 & $18.28-66.95$ & Dynamic \\
\hline & & & Number of Pulses per Chirp & 43.05 & $1.86-35.58$ & Dynamic \\
\hline & & & Pulse Rate & 24.32 & $21.67-62.06$ & Dynamic \\
\hline & & & Peak Frequency & 9.6 & $8.95-40.88$ & Intermediate \\
\hline & \multirow{4}{*}{$\begin{array}{l}\text { Male-Female Pre-Mating } \\
\text { Interaction }\end{array}$} & \multirow{4}{*}{32} & Chirp Duration & 39.5 & $13.35-74.13$ & Dynamic \\
\hline & & & Number of Pulses per Chirp & 50.4 & $0-58.20$ & Dynamic \\
\hline & & & Pulse Rate & 30.78 & $10.28-101.75$ & Dynamic \\
\hline & & & Peak Frequency & 28.52 & $6.45-72.41$ & Dynamic \\
\hline \multirow{8}{*}{$\begin{array}{l}\text { Ontario } \\
\text { Females }\end{array}$} & \multirow{4}{*}{ Disturbance } & \multirow{4}{*}{26} & Chirp Duration & 32.92 & $8.35-92.79$ & Dynamic \\
\hline & & & Number of Pulses per Chirp & 31.72 & $2.49-45.19$ & Dynamic \\
\hline & & & Pulse Rate & 21.23 & $8.73-81.0$ & Dynamic \\
\hline & & & Peak Frequency & 14.45 & $8.29-60.0$ & Dynamic \\
\hline & \multirow{4}{*}{$\begin{array}{l}\text { Male-Female Pre-Mating } \\
\text { Interaction }\end{array}$} & \multirow{4}{*}{10} & Chirp Duration & 33.53 & $13.5-54.08$ & Dynamic \\
\hline & & & Number of Pulses per Chirp & 35.56 & $4.85-46.86$ & Dynamic \\
\hline & & & Pulse Rate & 21.79 & $22.76-62.27$ & Dynamic \\
\hline & & & Peak Frequency & 32.35 & $13.75-36.05$ & Dynamic \\
\hline
\end{tabular}

† Gerhardt's (1991) CV criteria was used to classify signal properties as static or dynamic; CV < $5=$ Static; CV >12 Dynamic; CV between 5 and $12=$ Intermediate. 
Table 2.7. Between-female variability of acoustic features of Ips pini disturbance and pre-mating signals.

\begin{tabular}{|c|c|c|c|c|c|}
\hline Population & Condition & $\mathbf{N}$ & Signal Parameter & CV (\%) & Type $\dagger$ \\
\hline \multirow{4}{*}{$\begin{array}{l}\text { Alberta } \\
\text { Females }\end{array}$} & \multirow[b]{2}{*}{ Disturbance } & \multirow[b]{2}{*}{18} & Chirp Duration & 37.41 & Dynamic \\
\hline & & & $\begin{array}{c}\text { Number of Pulses per Chirp } \\
\text { Pulse Rate } \\
\text { Peak Frequency }\end{array}$ & $\begin{array}{c}28.05 \\
14.23 \\
9.68\end{array}$ & $\begin{array}{c}\text { Dynamic } \\
\text { Dynamic } \\
\text { Intermediate }\end{array}$ \\
\hline & \multirow[b]{2}{*}{$\begin{array}{c}\text { Male-Female Pre-Mating } \\
\text { Interaction }\end{array}$} & \multirow[b]{2}{*}{32} & Chirp Duration & 28.63 & Dynamic \\
\hline & & & $\begin{array}{c}\text { Number of Pulses per Chirp } \\
\text { Pulse Rate } \\
\text { Peak Frequency }\end{array}$ & $\begin{array}{c}36.38 \\
25.1 \\
20.07\end{array}$ & $\begin{array}{l}\text { Dynamic } \\
\text { Dynamic } \\
\text { Dynamic }\end{array}$ \\
\hline \multirow{5}{*}{$\begin{array}{l}\text { Ontario } \\
\text { Females }\end{array}$} & \multirow[b]{2}{*}{ Disturbance } & \multirow[b]{2}{*}{26} & Chirp Duration & 31.64 & Dynamic \\
\hline & & & $\begin{array}{c}\text { Number of Pulses per Chirp } \\
\text { Pulse Rate } \\
\text { Peak Frequency } \\
\end{array}$ & $\begin{array}{l}32.15 \\
25.28 \\
15.29 \\
\end{array}$ & $\begin{array}{l}\text { Dynamic } \\
\text { Dynamic } \\
\text { Dynamic }\end{array}$ \\
\hline & \multirow{3}{*}{$\begin{array}{c}\text { Male-Female Pre-Mating } \\
\text { Interaction }\end{array}$} & \multirow{3}{*}{10} & Chirp Duration & 34.23 & Dynamic \\
\hline & & & $\begin{array}{c}\text { Number of Pulses per Chirp } \\
\text { Pulse Rate }\end{array}$ & 26.06 & Dynamic \\
\hline & & & Peak Frequency & 15.38 & Dynamic \\
\hline
\end{tabular}

$\overline{\dagger \text { Gerhardt's (1991) CV criteria was used to classify signal properties as static or dynamic; CV < }=\text { Static; }}$ CV > 12 Dynamic; CV between 5 and $12=$ Intermediate. 


\section{Predation}

While being grasped by the mandibles of one of their natural predators, Thanasimus dubius, both male and female I. pini exhibited similar struggling behaviours characterized by erratic leg movements, while nodding their heads up and down, with their mandibles opened wide; the up and down motion during head nodding occasionally elicited chirps in females (Fig 2.11). Similar to the disturbance trials (above), females did not readily produce chirps during attacks, and most females stopped signaling after a few chirps; but were still struggling to get free. Signals produced during predation events had an average peak frequency around $21 \mathrm{kHz}$ (Table 2.2), with fairly broad frequency bandwidths ranging from as low as $10 \mathrm{kHz}$ to well over $85 \mathrm{kHz}$ (Fig. 2.11). However, unlike disturbance signals, which had two to three broad band frequency peaks, signals during predation events, were comprised of multiple relatively narrow band frequency peaks (see Fig. 2.11). The dominant peak frequency bandwidth (at -10dB) ranged from 22 to $27 \mathrm{kHz}$.

A separate set of experiments was conducted (and videotaped) to test the startling function hypothesis of acoustic signals during predation events (see methods). To test the first prediction - that signal onset should correspond with predator attack - the latency to signal was measured for female I. pini. Of the nine females, six produced acoustic signals during predation events; all females were checked for sound production prior to trials, and were shown to produce sounds. Females on average had a latency of $14.5 \pm 3.84$ seconds $(\mathrm{N}=6)$ between predator attack and the onset of signaling. To test the second prediction - predators will drop signaling females at a higher proportion than nonsignaling males - the number of times predators dropped prey items was observed. None 
A
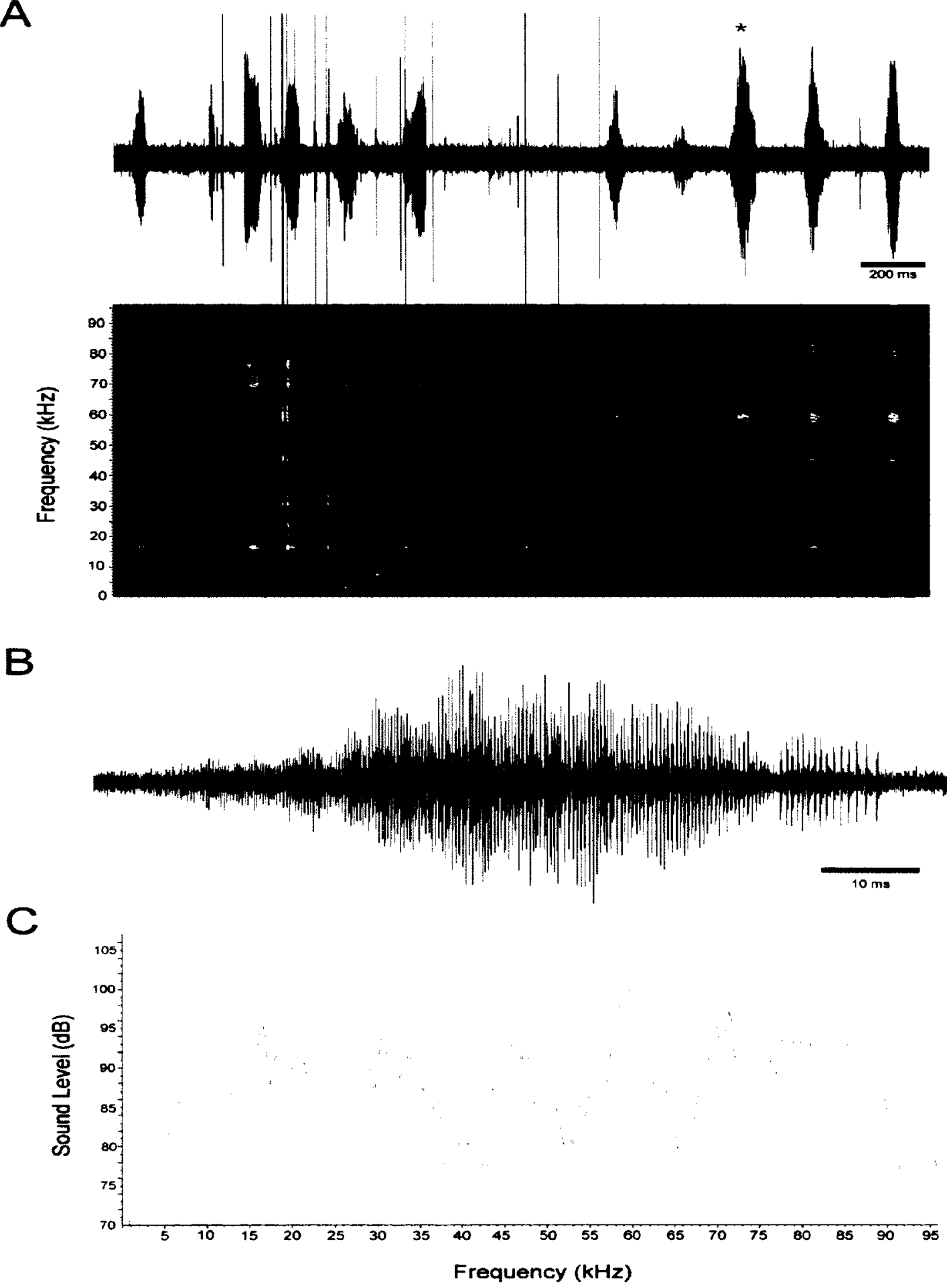

Figure 2.11. Female Ips pini signals during a predation event. (A) Oscillogram (top) and spectrogram (bottom) of 11 consecutive chirps recorded from an individual female from Ontario. (B) An individual chirp from A (denoted by red asterisk) with an expanded time scale to show individual pulses. (C) Power spectrum of the chirp in B. 
of the predators, during behavioural trials, released their prey. To test the third prediction - signaling should increase prey handling time - A Mann-Whitney $U$ test was used to compare the latency from prey seizure to prey death between predators attacking I. pini males, and those attacking females. Results showed no significant different between predators attacking I. pini males $(135.13 \pm 29.41 \mathrm{sec})$, and those attacking females $(134.44 \pm 19.52 \mathrm{sec})(U=32.5, \mathrm{p}=0.743)$. Pine engraver males and females were essentially defenseless against the checkered beetles, Thanasimus dubius, and all prey was eventually consumed by their predators.

\section{Male-Female Pre-Mating Signals}

All females admitted into male nuptial chambers produced acoustic signals; all non-signaling females were rejected. Pre-mating signals of both Alberta and Ontario females had fairly broad frequency bandwidths, with peak frequencies in the sonic range $(<20 \mathrm{kHz})$ (Table 2.2). The peak frequency bandwidth (at -10dB) of Alberta females ranged from 6 to $15 \mathrm{kHz}$; Ontario female signals ranges from 6 and $16 \mathrm{kHz}$. However, pre-mating signals of both Alberta and Ontario females had frequency components ranging from as low as $5 \mathrm{kHz}$ to above $30 \mathrm{kHz}$ (e.g. Fig 2.12). Pre-mating signals of second females (Alberta; see methods), during male-second female trials, were spectrally similar to first females (Alberta), with peak frequency in the sonic range, and a peak frequency bandwidth ranging from 6 to $11 \mathrm{kHz}$ (Table 2.2).

Both within- and between-female coefficient of variations (CV) showed that premating signal parameters were highly variable within populations (Table 2.6 and 2.7). All temporal features of pre-mating signals, in both populations, were highly variable 
A
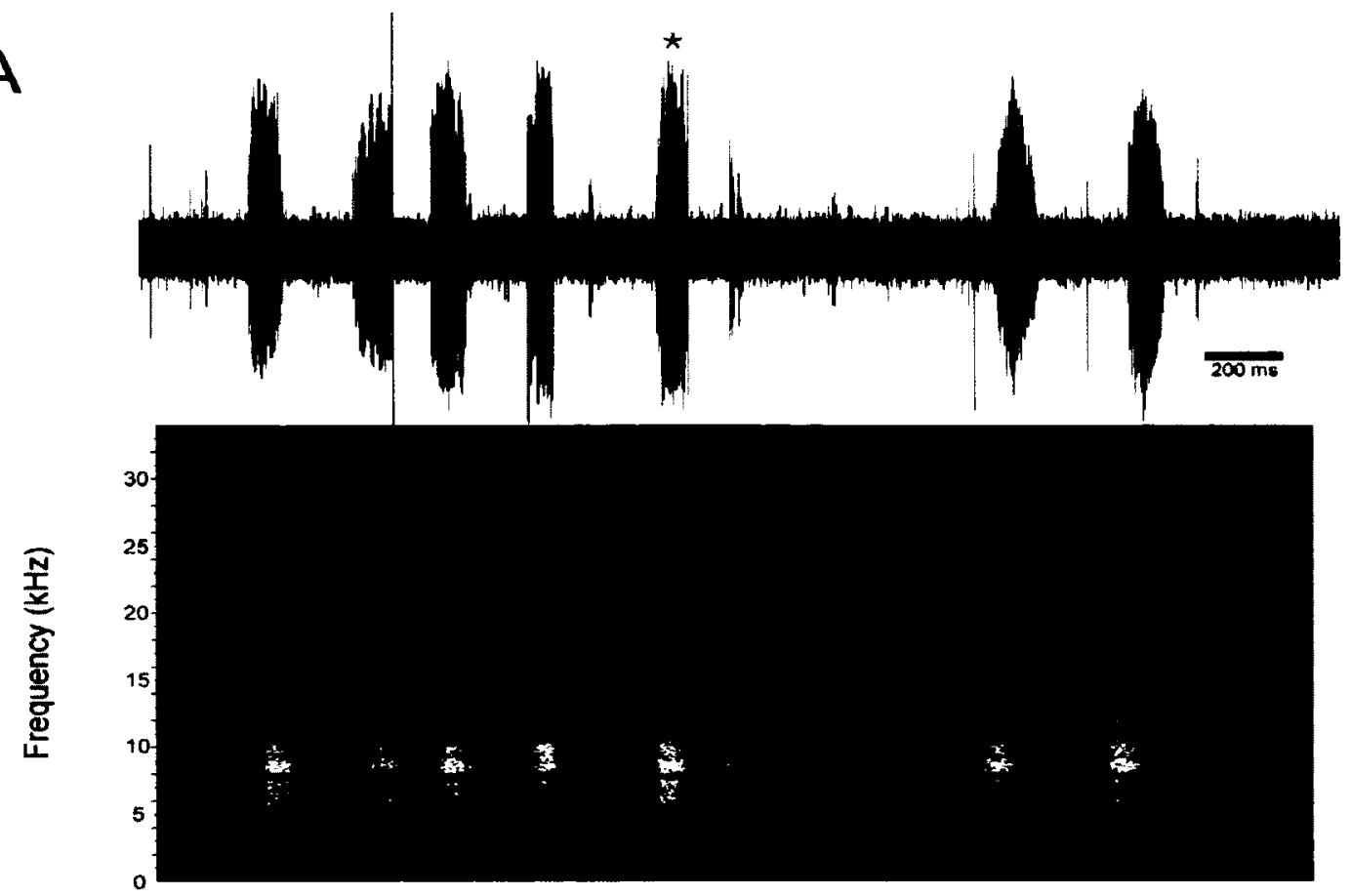

B

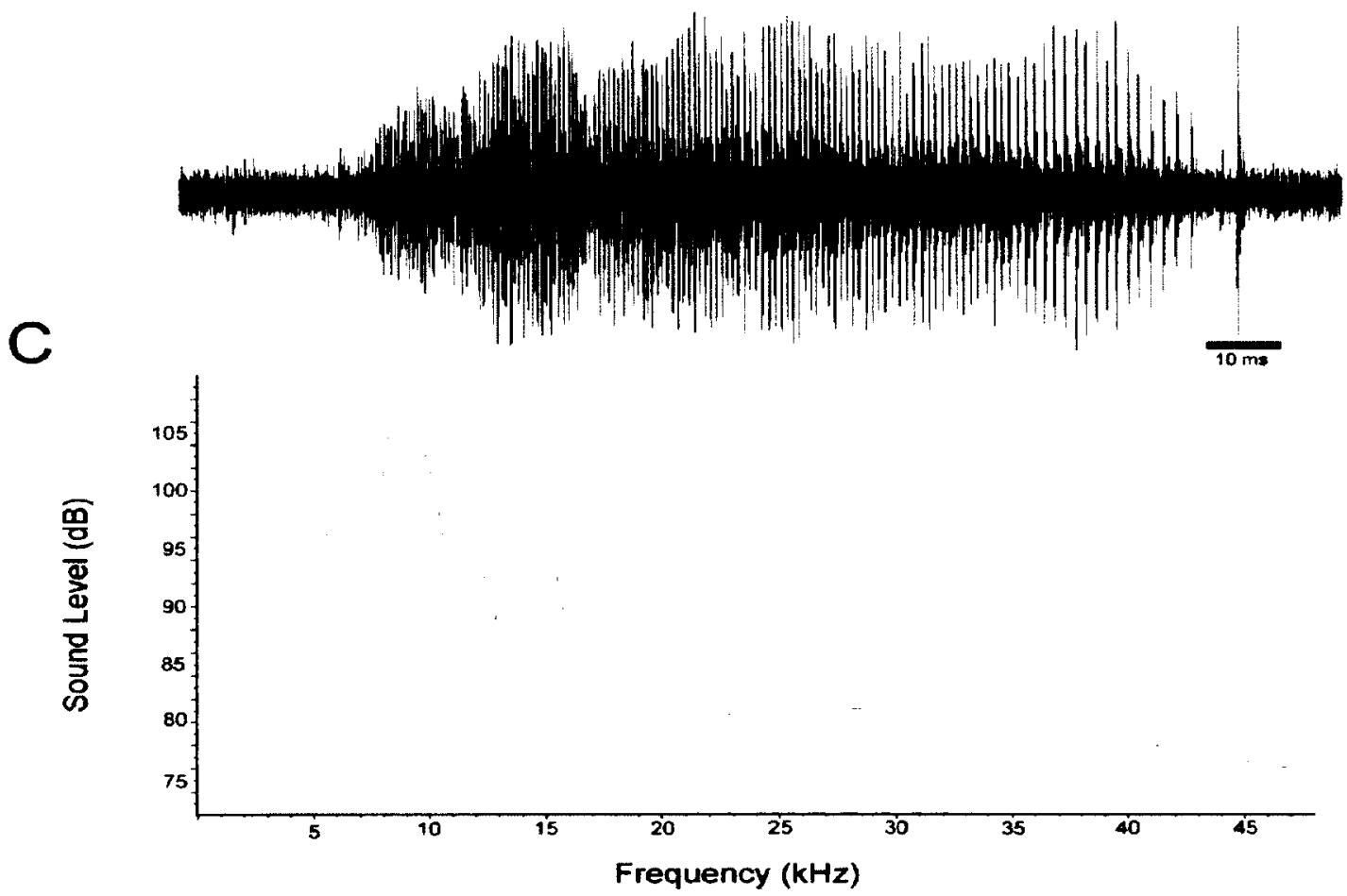

Figure 2.12. Pre-mating signals of female Ips pini recorded with an Avisoft microphone. (A) Oscillogram (top) and spectrogram (bottom) of seven consecutive pre-mating chirps recorded from an individual female from Alberta. (B) An individual chirp from A (denoted by red asterisk) with an expanded time scale to show individual pulses. (C) Power spectrum of the chirp in B. 
(CV < 12\%; "dynamic") both within (Table 2.6) and between (Table 2.7) females. Peak frequencies of pre-mating signals, however, had the lowest variation between females (see Table 2.7).

To determine how female signaling changes overtime during male-female interaction, the signaling "effort" of females was measured for each 30 second interval of the total 6.5 minute mating trials (see methods). The signaling effort of both first and second females decreased with time; females produced fewer chirps with time (Fig. 2.13). A Mann-Whitney $U$ comparison of signaling effort in the first 30 seconds interval between first (29.73 \pm 18.5$)$ and second $(32.71 \pm 14.59)$ females showed no significant difference $(U=203.5, \mathrm{p}=0.522)$. Both first and second females signaled the same amount as they were entering male nuptial chambers. A pair-wise Wilcoxon Signed Ranks comparison between the first 30 seconds interval and the second 30 seconds interval, showed a significant decrease in signaling effort for both first $(z=-4.43, p<$ $0.001)$, and second $(z=-3.05, p=0.002)$ females (Fig. 2.13).

\section{Substrate-borne Vibrations}

Acoustic signals of females (Alberta), during male-female interactions, had both air-borne (described above), and substrate-borne vibratory components. Substrate-borne vibrations (recorded at $1 \mathrm{~cm}$ ) had an average peak frequency of $9.71 \pm 0.51 \mathrm{kHz}$, and an average duration of $0.173 \pm 0.01 \mathrm{sec}$ (Fig. 2.14). Substrate vibrations had a frequency range between 5 to $15 \mathrm{kHz}$ (Fig. 2.14), which was relatively lower compared to the frequency range of Alberta female air-borne component (see above). 


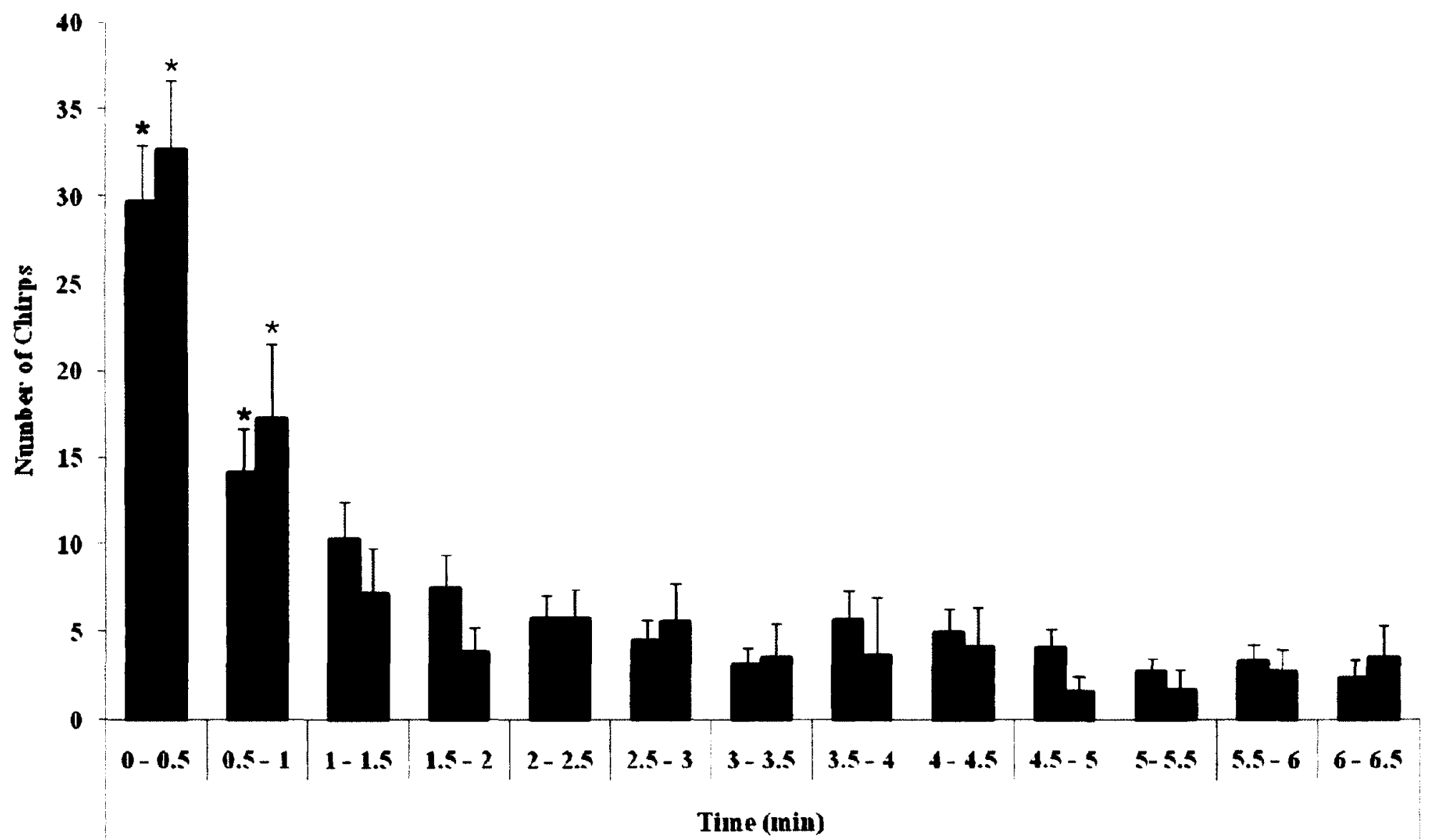

Figure 2.13. Comparing the average signaling effort of female Ips pini in each $30 \mathrm{sec}(0.5 \mathrm{~min})$ time interval during their $6.5 \mathrm{~min}$ premating trials. Female signaling effort was measured as the total number of acoustic signal produced in an interval. Both first (black bars) and second (grey bars) females showed a general decrease in signaling effort; there was no difference in signaling effort between first and second females $(p>0.05)$. Signaling effort showed a significant decrease from first $(0-0.5 \mathrm{~min})$ to second $(0.5-1 \mathrm{~min})$ interval in both first (black asterisk) and second (red asterisk) females. 

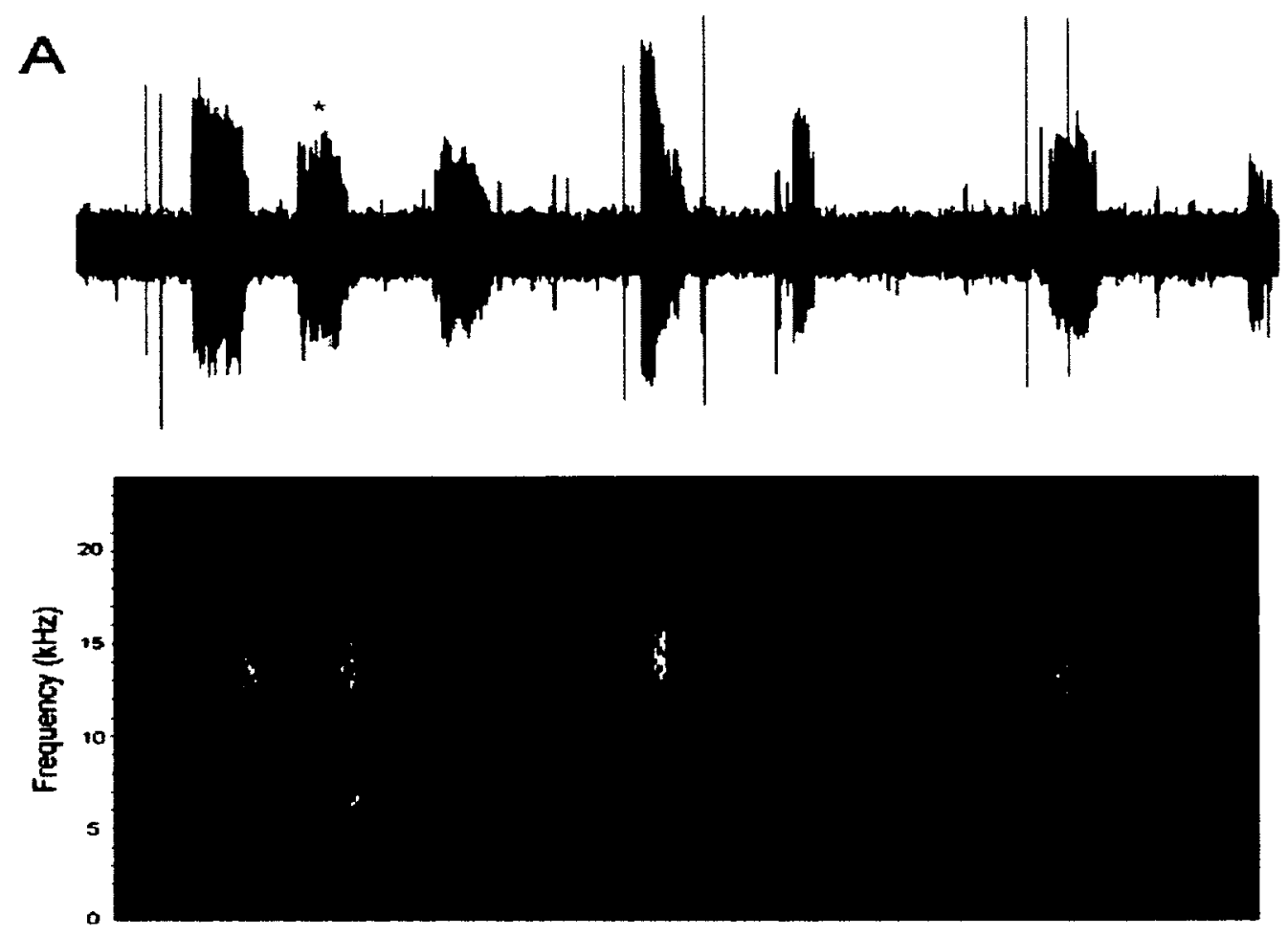

B
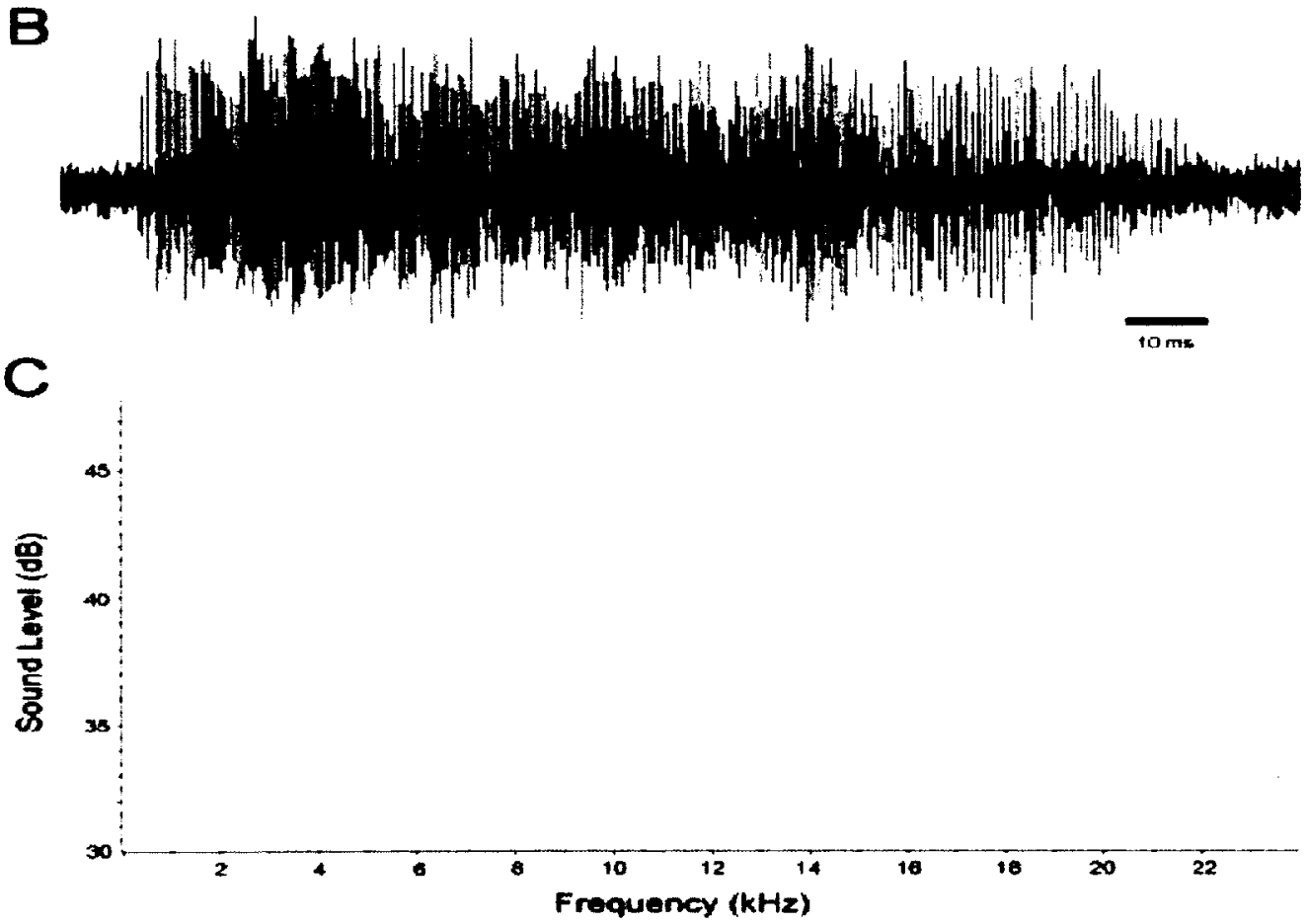

Figure 2.14. Substrate-borne vibrations of Ips pini female during pre-mating interaction. (A) Oscillogram (top) and spectrogram (bottom) of seven consecutive vibrations recorded from an individual female from Alberta. (B) An individual chirp from A (denoted by red asterisk) with an expanded time scale to show individual pulses. (C) Power spectrum of the chirp in B. 


\subsubsection{Comparing Signal Characteristics between Behavioural Conditions}

A Kruskal-Wallis test was used to examine variation in signal characteristics between behavioural conditions for each population. In the Alberta population, a Kruskal-Wallis test showed a significant difference in pulse rate $(p<0.001)$, peak frequency $(p<0.001)$, and signal amplitude intensity $(p<0.001)$ between disturbance, male-first female, and male-second female signals (Table 2.8). Mann-Whitney $U$ posthoc tests, with Bonferroni correction $(p=0.5 / 3=0.017)$, showed that disturbance chirps had significantly lower pulse rates, higher peak frequencies, and higher amplitudes than male-first female $(U=89.00, \mathrm{p}<0.001 ; U=0.01, \mathrm{p}<0.001 ;$ and $U=88.5, \mathrm{p}<0.001$, respectively), and male-second female $(U=15.00, \mathrm{p}<0.001 ; U=0.01, \mathrm{p}<0.001 ;$ and $U$ $=30.00, \mathrm{p}<0.001$, respectively) signals. There was no significant difference in pulse rates $(p=0.23)$, peak frequencies $(p=0.73)$, or signal amplitudes $(p=0.72)$ between male-first female, and male-second female interaction signals.

In the Ontario population, a Kruskal-Wallis test showed a significant difference in peak frequency $(\mathrm{p}<0.001)$, and signal amplitude $(\mathrm{p}<0.001)$ between disturbance, predation, and male-first female pre-mating signals (Table 2.8). Mann-Whitney $U$ posthoc tests, with Bonferroni correction $(p=0.5 / 3=0.017)$, showed that disturbance signals had significantly higher peak frequencies and amplitudes than predation $(U=90.00, \mathrm{p}<$ $0.001 ; U=22.00, \mathrm{p}<0.001$, respectively), and male-first female $(U=0.01, \mathrm{p}<0.001 ; U$ $=0.01, p<0.001$, respectively) signals. Predation signals had significantly higher peak frequencies than male-first female pre-mating signals $(U=2.00, \mathrm{p}<0.001)$. Predation signals also had significantly lower amplitudes $(U=55.5, \mathrm{p}=0.049)$, and higher number 
Table 2.8. Results from a Kruskal-Wallis comparison of temporal and spectral characteristics between disturbance, predation, and male-female pre-mating acoustic signals, for both Alberta and Ontario females.

\begin{tabular}{|c|c|c|c|c|c|c|c|}
\hline Population & Chirp Characteristics & Condition & $\mathbf{N}$ & Mean Rank & df & $x^{2}$ & $\mathbf{p}$ \\
\hline \multirow{15}{*}{$\begin{array}{l}\text { Alberta } \\
\text { Females } \\
\text { (Ips pini) }\end{array}$} & \multirow{3}{*}{ Duration (sec) } & Disturbance & 19 & 26.11 & 2 & & \\
\hline & & Male-First Female Interaction & 32 & 37.75 & 2 & 4.63 & 0.1 \\
\hline & & Male-Second Female Interaction & 14 & 31.5 & 2 & & \\
\hline & \multirow{3}{*}{ Number of Pulses } & Disturbance & 19 & 39 & 2 & & \\
\hline & & Male-First Female Interaction & 32 & 32.97 & 2 & 4.47 & 0.11 \\
\hline & & Male-Second Female Interaction & 14 & 24.93 & 2 & & \\
\hline & \multirow{3}{*}{ Pulse Rate (\#/sec) } & Disturbance & 19 & 50.53 & 2 & & \\
\hline & & Male-First Female Interaction & 32 & 27.84 & 2 & 24.34 & $<0.001$ \\
\hline & & Male-Second Female Interaction & 14 & 21 & 2 & & \\
\hline & \multirow{3}{*}{ Peak Frequency $(\mathbf{k H z})$} & Disturbance & 19 & 56 & 2 & & \\
\hline & & Male-First Female Interaction & 32 & 23.95 & 2 & 39.81 & $<0.001$ \\
\hline & & Male-Second Female Interaction & 14 & 22.46 & 2 & & \\
\hline & \multirow{3}{*}{ Signal Amplitude (dB) } & Disturbance & 19 & 49.96 & 2 & & \\
\hline & & Male-First Female Interaction & 32 & 26.73 & 2 & 21.23 & $<0.001$ \\
\hline & & Male-Second Female Interaction & 14 & 24.57 & 2 & & \\
\hline
\end{tabular}




\begin{tabular}{|c|c|c|c|c|c|c|c|}
\hline \multirow{15}{*}{$\begin{array}{c}\text { Ottawa } \\
\text { Females } \\
\text { (Ips pini) }\end{array}$} & \multirow{3}{*}{ Duration (sec) } & Disturbance & 26 & 26.06 & 2 & \multirow{3}{*}{4.2} & \multirow{3}{*}{0.12} \\
\hline & & Predation & 20 & 26.9 & 2 & & \\
\hline & & Male-First Female Interaction & 10 & 38.05 & 2 & & \\
\hline & \multirow{3}{*}{ Number of Pulses } & Disturbance & 26 & 26.92 & 2 & \multirow{3}{*}{4.42} & \multirow{3}{*}{0.11} \\
\hline & & Predation & 20 & 25.68 & 2 & & \\
\hline & & Male-First Female Interaction & 10 & 38.25 & 2 & & \\
\hline & \multirow{3}{*}{ Pulse Rate (\#/sec) } & Disturbance & 26 & 30 & 2 & \multirow{3}{*}{0.71} & \multirow{3}{*}{0.7} \\
\hline & & Predation & 20 & 26.05 & 2 & & \\
\hline & & Male-First Female Interaction & 10 & 29.5 & 2 & & \\
\hline & \multirow{3}{*}{ Peak Frequency (kHz) } & Disturbance & 26 & 40.04 & 2 & \multirow{3}{*}{33.5} & \multirow{3}{*}{$<0.001$} \\
\hline & & Predation & 20 & 24.9 & 2 & & \\
\hline & & Male-First Female Interaction & 10 & 5.7 & 2 & & \\
\hline & \multirow{3}{*}{ Peak Intensity (dB) } & Disturbance & 26 & 42.65 & 2 & \multirow{3}{*}{38.1} & \multirow{3}{*}{$<0.001$} \\
\hline & & Predation & 20 & 18.83 & 2 & & \\
\hline & & Male-First Female Interaction & 10 & 11.05 & 2 & & \\
\hline
\end{tabular}


of pulses $(U=53.5, \mathrm{p}=0.039)$ than male-first female signals, but the alpha values were higher than the Bonferroni corrected alpha value $(p=0.017)$.

\subsubsection{Comparing Signal Characteristics between Populations}

A Mann-Whitney $U$ test was used to examine variation in disturbance and malefirst female pre-mating signal characteristics between Alberta and Ontario females. Disturbance signals of Alberta females had significantly shorter chirp durations $(\mathrm{p}=$ $0.042)$, less number of pulses per chirp $(p=0.011)$, lower peak frequencies $(p<0.001)$, and higher sound pressure levels $(\mathrm{p}=0.004)$ than Ontario females (Table 2.9). There was no difference in pulse rates between the two populations $(p=0.14)($ Table 2.9).

Male-first female pre-mating signals of Alberta females had significantly shorter chirp durations $(p=0.039)$, fewer number of pulses per chirp $(p<0.001)$, slower pulse rates $(p=0.001)$, and higher amplitudes $(0.048)$ compared to Ottawa females (Table 2.9). There was no difference in peak frequencies between the two populations $(p=0.942)$ (Table 2.9).

\subsection{Discussion}

The present study characterized female Ips pini acoustic signals produced during physical disturbance, predation, and male-female pre-mating behavioural contexts, and provides novel details of the temporal, spectral, and transmission properties of the signals. In general, female Ips pini acoustic signals fell into two broad categories ("uninterrupted" and "interrupted" chirps), and all signals were comprised of broad frequency bandwidths, with frequency peaks in the high sonic (i.e. pre-mating signals) 
Table 2.9. Results from a Mann-Whitney $U$ comparison of temporal and spectral characteristics, of disturbance and male-first female signals, between Alberta and Ontario Ips pini females.

\begin{tabular}{|c|c|c|c|c|c|c|c|}
\hline Condition & Chirp Characteristics & Population & $\mathbf{N}$ & $\begin{array}{l}\text { Mean } \\
\text { Rank }\end{array}$ & $d f$ & $\boldsymbol{U}$ & $\mathbf{p}$ \\
\hline \multirow{10}{*}{ Disturbance } & \multirow{2}{*}{ Duration (sec) } & Alberta & 19 & 18.34 & 1 & \multirow{2}{*}{158.5} & \multirow{2}{*}{0.042} \\
\hline & & Ontario & 26 & 26.4 & 1 & & \\
\hline & \multirow{2}{*}{ Number of Pulses } & Alberta & 19 & 17.18 & 1 & \multirow{2}{*}{136.5} & \multirow{2}{*}{0.011} \\
\hline & & Ontario & 26 & 27.25 & 1 & & \\
\hline & \multirow{2}{*}{ Pulse Rate (\#/sec) } & Alberta & 19 & 19.58 & 1 & \multirow{2}{*}{182} & \multirow{2}{*}{0.14} \\
\hline & & Ontario & 26 & 25.5 & 1 & & \\
\hline & \multirow{2}{*}{ Frequency (kHz) } & Alberta & 19 & 13.37 & 1 & \multirow{2}{*}{64} & \multirow{2}{*}{$<0.001$} \\
\hline & & Ontario & 26 & 30.04 & 1 & & \\
\hline & \multirow{2}{*}{$\begin{array}{c}\text { Sound Pressure Level } \\
\text { (dB SPL) }\end{array}$} & Alberta & 5 & 9.0 & 1 & \multirow{2}{*}{0.00} & \multirow{2}{*}{0.004} \\
\hline & & Ontario & 6 & 3.5 & 1 & & \\
\hline \multirow{10}{*}{$\begin{array}{l}\text { Male-First Female } \\
\text { Interaction }\end{array}$} & \multirow{2}{*}{ Duration (sec) } & Alberta & 32 & 19.31 & 1 & \multirow{2}{*}{90} & \multirow{2}{*}{0.039} \\
\hline & & Ontario & 10 & 28.5 & 1 & & \\
\hline & \multirow{2}{*}{ Number of Pulses } & Alberta & 32 & 17.38 & 1 & \multirow{2}{*}{28} & \multirow{2}{*}{$<0.001$} \\
\hline & & Ontario & 10 & 34.7 & 1 & & \\
\hline & \multirow{2}{*}{ Pulse Rate (\#/sec) } & Alberta & 32 & 18 & 1 & \multirow{2}{*}{48} & \multirow{2}{*}{0.001} \\
\hline & & Ontario & 10 & 32.7 & 1 & & \\
\hline & \multirow{2}{*}{ Frequency (kHz) } & Alberta & 32 & 21.59 & 1 & \multirow{2}{*}{157} & \multirow{2}{*}{0.942} \\
\hline & & Ontario & 10 & 21.2 & 1 & & \\
\hline & \multirow{2}{*}{ Signal Amplitude (dB) } & Alberta & 32 & 23.59 & 1 & \multirow{2}{*}{93} & \multirow{2}{*}{0.048} \\
\hline & & Ontario & 10 & 14.8 & 1 & & \\
\hline
\end{tabular}


and ultrasonic (i.e. disturbance and predation) range. Specifically, there are six main results of this study, which relate to the main questions addressed in this study. The first is that signal features were substantially variable both within and between individuals, which suggests that these parameters are dynamic properties of the acoustic signals. The second major result is that signal characteristics (i.e. of disturbance signals) were significantly correlated with female size and weight measurements, indicating that signals may contain information about female quality. The third result is that there were significant differences in signal characteristics between behavioral contexts, indicating that signals are context-specific. Fourth, there were significant differences in signal characteristics between con-specific populations. The fifth main result is that, during male-female pre-mating interactions, females significantly decrease their signaling effort after the first 30 seconds of interaction, presumably after entrance into male nuptial chambers. The final result is that acoustic signals had both air-borne and substrate-borne vibration components, suggesting potentially a novel modality for communication in bark beetles. The details of these novel results are discussed in the sections below, with respect to potential signal function, evolution and receptor mechanisms.

Additionally, this study also tests the defensive "startling function" hypothesis of I. pini disturbance signals with their natural predators, Thanasimus dubius. To date, only one study has tested the defensive function of disturbance signals in bark beetles (Lewis and Cane 1990). The present study demonstrates that acoustic signals, during predation events were not effective in causing predators to release prey, and the results do not support the "startling function" hypothesis. These results accentuate the importance of 
testing (with natural predators) the widely accepted defensive function of disturbance signals in other bark beetle species, and are discussed in the final section below.

\section{Pine Engraver Acoustic Signals}

Initial observation of female I. pini signals showed substantial variation in the physical structure (i.e. shape and size) of the chirps. This variation in chirp types was not described previously by Swaby and Rudinsky (1976), and reflects the complex nature of the vertex-pronotum stridulatory mechanisms (Barr 1969). It is assumed that the individual pulses in chirps correspond to the striking of a single ridge on the pars stridens. However, unlike the gular-prosternal and the elytral-abdominal stridulatory mechanisms, where the plectrum is comprised of a single ridge or pair of pegs (respectively), and is scraped against the transverse ridges on the pars stridens, both the plectrum and pars stridens of the vertex-pronotal stridulatory mechanism is comprised of multiple transverse ridges, and both components of the stridulatory organ are theoretically capable of vibrating.

Regardless, despite this variation in the physical structure of signals, all signals were grouped into two broad categories: 'Uninterrupted' and 'Interrupted' chirps. There was no obvious patterning to the occurrence of interrupted chirps in any of the behavioural conditions, and there was considerable variation in the number and length of interruptions between chirps within females, suggesting that these interruptions were not caused by missing ridges on the stridulatory structures, and may be unintentionally produced by the females. Interrupted chirps have been observed in several bark beetles species, including 1 . pini, and were thought to be the result of the plectrum temporarily 
being dislodged from the pars stridens (Michael and Rudinsky 1972; Oester and Rudinsky 1978; Rudinsky and Ryker 1976; Ryker and Rudinsky 1976; Swaby and Rudinsky 1976). However, the functional significance (if any) of these interrupted chirps was not known for any species. In this study, the proportions of interrupted chirps were significantly higher during disturbance trials where the beetles were hand-held, suggesting that interruptions may be caused by experimenter interference during stridulation, and may not have any functional significance. Although interrupted chirps were also observed during predation and pre-mating trials, where there was no experimenter manipulation, it is still possible that interruptions in these chirps were caused by some obstruction during stridulation (e.g. predators' mandibles or males pushing back against the females during jostling behaviour), and may have no function. Further studies are needed to conclusively demonstrate this lack of function of interrupted signals.

Spectral analysis of Ips pini acoustic signals shows that female signals, in all behavioural conditions, were comprised of high sonic and ultrasonic frequency components (see Table 2.2). To date, spectral characteristics of bark beetle signals have only been reported in a few species, and in all of these reports, the authors have only made general comments about the frequency range of the signals (see Lewis and Cane 1992; Oester et al. 1978; Rudinsky and Michael 1972; Swaby and Rudinsky 1976; Vernoff and Rudinsky 1980; Wilkinson et al. 1967; Wilkinson 1962). For example, Oester et al. (1978) described the male Hylurgops rufipennis chirps as "broadband with most intense frequencies between $1-12 \mathrm{kHz}$, and less intense frequencies up to $18 \mathrm{kHz}$ ". In Ips pini, the high sonic and ultrasonic frequency components of pre-mating and 
disturbance signals reported in this study has important implications for 1) potential receptor mechanisms, and 2) providing some credibility to the hypothesis that bark beetles localize drought-stressed host-trees by exploiting their ultrasonic acoustic emissions (Haack et al. 1988; Mattson and Haack 1987).

In many invertebrates, high frequency air-borne signals are primarily received through tympanal ears (Yack and Dawson 2008). To date, tympanal hearing organs have been described in eight insect orders, and are known to have evolved independently at least 20 times across families (Fullard and Yack 1993; Yack and Dawson 2008; Yack and Hoy 2003). The high sonic and ultrasonic frequencies of Ips pini acoustic signals imply that these beetles may have a tympanal hearing mechanism capable of perceiving these signals. To date, tympanal ears have only been described in two coleopteran families (i.e. Scarabaeidae and Cicindelidae), and in both, they have been shown to function for detecting the ultrasonic cries of predatory bats (Forrest et al. 1995 and 1997; Spangler 1988; Yager and Spangler 1995 and 1997). Besides these examples, air-borne sound reception is not known for any other beetle species, and no study has investigated acoustic reception in bark beetles. This warrants the need for further neurophysiological, morphological, and behavioural investigations to determine if and/or how bark beetles perceive and respond to these ultrasonic frequencies (see Chapter 3).

Demonstrating reception to high sonic and ultrasonic frequencies in bark beetles would provide additional credibility to the hypothesis that bark beetles localize weakened host-trees by listening to their acoustic emissions. Several studies have shown that when trees experience during long periods of dehydration, the hydrogen molecules of the water columns in the xylem tissues cavitate, releasing ultrasonic sounds with frequencies 
ranging from 60 to $2000 \mathrm{kHz}$ (Haack et al. 1988; Mattson and Haack 1987; Pena and Grace 1986; Sandford and Grace 1985; Tyree and Dixon 1983). Mattson and Haack (1987) hypothesized that bark- and wood-boring insects may exploit these acoustic cues during host-plant localization. The ultrasonic frequencies in Ips pini signals, shown in this study, implies that bark beetles may be capable of hearing these frequencies, which provides indirect validity for Mattson and Haack's (1987) hypothesis.

\section{Variation in Signals Parameters within and between Females}

In this study, both within and between-female coefficient of variations (CV) were considerably high for all acoustic parameters. Previous studies on bark beetle acoustics did not examine this variability in signal parameters within and between individuals. Understanding this variability is important for understanding the type and strength of selection pressure on these acoustic signals. Using the advertisement calls of tree frogs (Hylidae), Gerhardt (1991) classified the acoustic parameters of signals as either static (highly stereotypic) or dynamic (highly variable). This classification was based on the $\mathrm{CV}$ of each parameter - static components of the signals had $\mathrm{CVs}<5 \%$, while dynamic features had CVs $>12 \%$ (Gerhardt 1991). All features of the I. pini disturbance and premating signals were classified as "dynamic" (see Table 2.6 and 2.7). Theory suggests that "dynamic" traits are usually associated with "open-ended" preference functions that exert directional selection pressures where extreme values of the traits are preferred, whereas "static" traits are associated with "unimodal" preference functions that exert stabilizing selection pressures where intermediate values are preferred (see Bentsen 2006; Gerhardt 1991; Ryan and Keddy-Hector 1992; Ryan and Rand 1993; Shaw and Herlihy 2000). 
Although male preferences for female signals is not known for I. pini, open-ended preferences for dynamic features of female signals are beneficial if these features provide honest indication of genetic and/or phenotypic quality (see Gerhardt 1991; Ryan and Keddy-Hector 1992; Shaw and Herlihy 2000). This study demonstrates that the temporal parameters of I. pini acoustic signals were correlated with female morphometrics (see below), albeit, it is not known whether these signals are costly to produce (i.e. increased predation, increased energy, and/or decreased longevity; see Kotiaho 2000; Zahavi 1975), and therefore honest indicators of female quality.

Shaw and Herlihy (2000) suggested that under conditions where heterospecific mating are likely, static features of acoustic signals (driven by unimodal preference function) can provide a mechanism for distinguishing sympatric species (species recognition), and preventing 'mis-matings'. Interestingly, none of the signal parameters in I. pini, including frequencies, were "static" (stereotypic), which indicates that these signals may not contain any information on species identity. In a laboratory cross-mating study, Lewis and Cane (1992) demonstrated that the acoustic signals of four closely related Ips species, although unique in their characteristics, were not effective in preventing forced heterospecific pairings, and suggested that acoustic signals may not serve species recognition function. Although highly variable traits can convey species identity information (Nevo and Capranica 1985), it is possible that species discrimination in bark beetles occurs during the flight phase of non-host selecting sex (before malefemale gallery entrance), where aggregation pheromones are used to localize conspecifics. Field studies, for example, show that the chemical compositions of aggregation pheromones are species-specific, and non-host selecting sex of several bark 
beetle species can discriminate between conspecific and heterospecific pheromones (Cognato et al. 1999; Dickens et al. 1984; Miller et al. 1996 and 1997; Mustaparta et al. 1985; Pureswaran et al. 2004; Teale et al. 1994; Tommeras et al. 1984). Therefore acoustic signals may not function for species recognition as this is likely accomplished through pheromones. Further bioacoustics studies on sympatric sound producing species are needed to determine whether signal characteristics are species-specific or show substantial overlap between heterospecifics.

\section{Signal Parameters and Female Size and Weight}

The relationship between signal parameters and morphology has never been examined for any bark beetles species. In this study, all temporal parameters of Alberta female disturbance signals were highly correlated with female size and weight. Peak frequencies, in contrast, were not related to female morphology, which is not surprising given that all female signals had fairly broad frequency bandwidths. Although

correlations were only examined for disturbance signals, pre-mating signals are likely to have similar correlations with size and weight, as both signals have similar temporal features (see below). These correlations suggest that female acoustic signals may convey information about size through the temporal characteristics, which may be important during male mate choice or even defense.

At present we can only speculate on the functional significance of these correlations. The pronotum of most bark beetle species is substantially large relative to the meso- and metanotum, and may play an important role during defense and/or gallery excavation. Future studies should examine a broader range of size measurements in $I$. 
pini (e.g. head size; mandible size). It is also not clear the importance of female size in $I$. pini. Studies have shown that male Ips pini size was correlated with offspring size and production (Reid and Roitberg 1995; Robertson and Roitberg 1998; Robertson 1998), and female choose males based on size. However, the effects of female size on reproductive success (i.e. number of viable eggs laid, offspring number, size and survival) have not been examined, and it is possible that female size may have similar effects, and males may choose females based on size. Acoustic signals may play an important role during male mate choice, where males use these signals to extract information about female size.

This relationship between acoustic signals and female morphometrics described in this study indicates a potential functional significance of these signals (i.e. pre-mating signals), and provides an insight into understanding the fundamental question - Why do bark beetles produce acoustic signals? Further studies should examine whether males discriminate between females, and whether this is correlated with acoustic signals, and in turn female size. This would not only indicate that acoustics signals convey information about female quality, but also that males are capable of perceiving these signals, and that their sensory mechanisms can discriminate fine temporal features of the signals.

\section{Comparing Signals Characteristics between Behavioural Context}

Swaby and Rudinsky (1976) demonstrated that female I. pini disturbance signals had significantly higher pulse rates than pre-mating, and female-female rivalry signals (see table 2.1). Besides these differences in pulse rates no other difference between disturbance and pre-mating signals were reported. In contrast, the present study shows that disturbance signals of Alberta females had significantly lower pulse rates than pre- 
mating signals, while the disturbance signals of Ontario females showed no significant difference to pre-mating signals (Table 2.8).

In addition to pulse rates, this study provides novel details of peak frequency differences between disturbance and pre-mating signals. Specifically, disturbance signals were significantly higher in peak frequencies (with peaks in the ultrasonic range) than pre-mating signals (with peaks in the high sonic range). Signals produced during predation events also had significantly higher peak frequencies (in the ultrasonic) than pre-mating signals. However, predation signals had significantly lower peak frequencies than disturbance signals. It is not clear from behavioural observations in this study how females alter the frequencies of their signals between disturbance and pre-mating. It is possible that females can change the frequencies of their signals by contracting or expanding their pronotum; assuming that the pronotum acts as a resonating chamber. Preliminary examinations under a light microscope revealed that there may be a small air space between plectrum (located on the pronotum), and the ventral-surface of the pronotum (personal observations). Swaby and Rudinsky (1976) also described the plectrum as a flexible thin plate. Therefore, it is alternatively possible that females can modulate the frequencies of their signals by increasing and decreasing this air space between the plectrum and the pronotum. Further investigations into the vertex-pronotum stridulatory mechanism are needed.

Regardless of the mechanism, it is clear from this study that these signals are context-specific; indicating that these signals may serve different functions (e.g. disturbance signals for defense, and pre-mating signals for courtship), and potential hearing organs must be capable of identifying and discriminating signal types. Given that 
the temporal features of female $I$. pini signals contain information about female size and weight, while the frequency component conveys information about signaling context, males receiving these signals can potentially extract multiple messages from female chirps (i.e. context, and female quality).

\section{Male-Female Pre-mating Interaction}

During pre-mating trials females placed near male entrance holes dug through the surrounding frass, entered, and started signaling. In this study, the signaling effort of both first and second females decreased with time, and this decrease was most significant after the first 30 seconds. This indicates that acoustic signaling in Ips pini primarily functions during the entrance phase of male-female encounters, and female signaling effort substantially decreases after admittance into male nuptial chamber. It is possible that during this phase of male-female interaction, the high signaling rate during pre-entrance may allow for quick assessment of species identity, which allows females to gain faster admittance into male nuptial chamber. Studies have demonstrated that females are most vulnerable to high levels of predation during mate search (Reid and Stamps 1997; Senger and Roitberg 1992); therefore, females benefit from entering into nuptial chambers faster. Given that peak frequencies of Alberta and Ontario females showed no difference, and frequencies were relatively less variable between females compared to temporal features of the signals, it is possible that peak frequencies may convey information on species identity.

In addition to species identity, pre-mating signals may also convey information about female quality. In this study, all females that successfully entered male nuptial 
chambers mated, and it is possible that during this entrance phase, males also assess female quality. Male I. pini may glean information on female quality (i.e. size and weight) through the temporal characteristics of female signals. To date, however, male mate choice has not been examined in the pine engravers. Given that 1) adult males risk predation and energetic cost during host colonization, 2) the sex ratio is female biased, and 3) population density of adults is negatively correlated with reproductive success, male mate choice is likely part of Ips pini mating system (Raffa and Dahlsten 1995; Raffa 2001; Robins and Reid 1997; Schenk and Benjamin 1969; Thomas 1961). Although mate choice was not tested in this study, it was noted that most males readily allowed signaling first and second females to enter, showing no apparent choosiness. There was also no difference in the signal characteristics or signaling effort between first and second females. It is possible that in Ips pini, males will indiscriminately accept and mate with the first 2 to 3 females, but become choosier with later females. Male choice with later females may depend on various factors including host-tree quality, population density of beetles in a given host, male size, and female quality (i.e. size and weight). Reid and Stamps (1997) demonstrated that female I. pini use an adjustable threshold mate choice tactic when choosing males. It is possible that males may also employ a similar threshold-based mate choice strategy. Further male mate choice studies are needed to determine the factors that influence the number of females that are accepted into the nuptial chambers, and whether males are choosier with later females. 


\section{Signal Transmission Properties}

Female stridulation during pre-mating trials simultaneously induces both airborne and substrate-borne vibrations. Substrate vibrations were transmitted through their natural substrate, the phloem layer of the tree, and given that all bark beetles spend most of their developing and adult lives inside the phloem layer, it is possible that bark beetles communicate through this modality. Communication through substrate vibrations is ubiquitous across plant-dwelling insects (Cocroft and Rodriguez 2005; Virant-Doberlet and Cokl 2004), but has never been examined in bark beetles. However, a recent study demonstrated the presence of substrate-borne vibrations in the mountain pine beetle, Dendroctonus ponderosae (Fleming 2009). In both studies, substrate vibrations occur simultaneously with air-borne vibrations. Although the peak frequencies of substrate vibrations were uncommonly high compared to those described in other invertebrates (Cocroft and Rodriguez 2005; Virant-Doberlet and Cokl 2004), it is not unusual. For example, the peak frequencies of the substrate vibrations in a cicada Okanagana rimosa, was shown to range between 6 to $10 \mathrm{kHz}$ (Stölting et al. 2002).

Theories in multiple signals suggest that different signals may convey different information ('multiple messages' hypothesis), or the same information ('redundant signals' hypothesis) (Hebets and Papaj 2005). Given that the frequencies and duration of air-borne and substrate-borne vibrations show substantial overlap, it is possible that these two components of Ips pini acoustic signals convey similar information ('redundant signals'). At present, however, the communicative function of substrate-borne vibrations in I. pini is not known, and warrants further investigations. Schmitz (1972) anecdotally observed that both males and females walked on their tibia when inside the gallery; a 
protibial spine allowed them to walk in the gallery. This observation, however, needs to be corroborated with further studies.

\section{Anti-predator Function of Disturbance Signals}

Bark beetle disturbance signals were hypothesized to have a "startling" function causing either a delay in predator attack, or an aversive physical stimulus resulting in the

predators releasing the prey (Barr 1969; Lewis and Cane 1990; Ryker 1988). The present study tests the "startling" hypothesis of Ips pini with one of their natural predators, Thanasimus dubius. Four predictions were addressed: 1) females should begin signaling immediately after predator attack; 2) predators will release signaling females at a higher proportion than non-signaling males; 3) signaling should increase prey handling time, resulting in a longer latency from prey seizure to prey death in predators attacking sound producing females compared to predators attacking non-signaling males; and 4) natural predators are capable of detecting disturbance signals. The results from behavioural trials and signal characterization provided limited support the "startling" hypothesis, and the details of the specific evidence and potential alternative hypotheses are discussed below. The first prediction that the onset of signaling should occur immediately after predator attack was not supported. Females on average had a latency of $14.5 \mathrm{sec}$ to start signaling following predator attack, and many females produced very few signals. In addition, the checkered beetles showed no apparent hesitation after signals were produced. This signaling behaviour of I. pini females during predation trials was different from the signaling behaviour reported for male mountain pine beetles, Dendroctonus ponderosae during human handling (disturbance) experiments (Fleming 2009). In $D$. 
ponderosae, males started signaling immediately upon experimenter attack, and signaling occurred continuously throughout the duration of the attack (Fleming 2009). Similar signaling behaviour was also observed in the red turpentine beetles, $D$. valens (personal observation). Conversely, during handling experiments with Ips pini, it was noted that there was variation in female signaling, where only some females readily signaled, while most produced considerably few chirps even with repeated physical stimulation. This difference between the genera (when attacked by humans) (Ips and Dendroctonus) was also noted by Wood (1961).

The second prediction that predator will release, from the grips of its mandibles, signaling females at a higher proportion than non-signaling males was also not supported. None of the observed predators lost grip of their prey after grasping them with their mandible. This was in contrast to Lewis and Cane (1990), who showed that signaling females of Ips calligraphus were dropped significantly more often than non-signaling males by a natural predator, Thanasimus dubius. It is possible that this difference between the present and previous study was due to the relatively low sample size $(\mathrm{N}=9$ for female prey; and $\mathrm{N}=\mathbf{8}$ for male prey) of the present study. However, this is unlikely, as in the previous study, the proportion of I. calligraphus females dropped was low (10/53 females dropped), and the data may not have been independent as each predator was used more than once, and only 7 out of 25 predators dropped their female prey (Lewis and Cane 1990).

Related to the prey releasing prediction was the third prediction that signaling should increase prey handling time, resulting in a longer latency from prey seizure to prey death in predators attacking females compared to those attacking non-signaling 
males. This prediction was also not supported based on two evidences: 1) there was no difference in the time from prey seizure to prey death between predators attacking males and females; and 2) as indicated above, prey releasing was not observed in any of the predators. Lewis and Cane (1990) also showed no difference in the time from prey seizure to prey death between predators attacking males and females, Ips calligraphus, and noted that all offered prey were eventually consumed by their predators.

The startling function of $I$. pini disturbance signals relies heavily on the fourth prediction that the predators are capable of perceiving these signals. This prediction was only indirectly tested in the present study, and evidence was inconclusive. The signals recorded during disturbance, and predation events had broad frequency bandwidths, with frequency components that ranged from as low as $10 \mathrm{kHz}$ to well over $85 \mathrm{kHz}$ (Table 2.2), albeit, predation signals had significantly lower peak frequencies, and were composed of multiple narrow band frequency peaks, as opposed to few broad band frequency peaks observed in disturbance signals. Although broad frequency bandwidths are typical characteristics of disturbance signals (Masters 1980), they are not exclusive to this context. Indeed, the pre-mating signals of both Alberta and Ontario females also had fairly broad frequency bandwidths. Nevertheless, the broad frequency bandwidth in Ips pini signals allow them to be perceived by a variety of predators and parasitoids, which, in nature, includes clerid beetles (i.e. Thanasimus dubius, and Enoclerus lecontei) (Coleoptera: Cleridae), clown beetles (Histeridae), darkling beetles (Tenebrionidae), bark-gnawing beetles (trogossitidae), robber flies (Diptera: Asilidae), and the parasitic wasp, Tomicobia tibialis, (Hymenoptera: Pteromalidae) (Aukema et al. 2004; Boone et al. 2009; Dahlsten et al 2003; Lanier et al. 1972; Raffa and Dahlsten 1995; Senger and 
Roitberg 1992). However, neither auditory nor vibration perception has not been demonstrated for any of the invertebrate predators listed above.

In the present study, Thanasimus dubius showed no obvious behavioural response to the acoustic signals, suggesting that these signals may not function to startle predators. Although, the startling function of "disturbance" signals was only tested with one type of predator, and it is possible that these signals are directed towards other predators who may respond differently, Thanasimus dubius are considered primary predators of I. pini, and are a major cause of mortality in adult males and females, during host-plant colonization and mate localization (Raffa 2001). It is reasonable to argue that any antipredation signals are likely to be directed towards $T$. dubius, as they impose significant predation pressure. The lack of behavioural response in T. dubius to I. pini acoustic signals, suggests that the I. pini "disturbance" signals may not have any anti-predation function. However, I. pini are also targets of other predators, most notably, Tomicobia tibialis, which are capable of reducing female reproductive potential by up to $50 \%$ (Sengar and Roitberg 1992), and further tests with other invertebrate predators are needed to conclusively rule out anti-predator function disturbance signals.

Ips pini are also prey of the downy woodpecker (Dendrocopos villosus), and the hairy woodpecker (D. pubescens), as trees inoculated by I. pini showed increased signs of woodpecker (Picidae) foraging (Schenk and Benjamin 1969; Six et al. 2002). Ramp (1965), showed that the auditory range of the hairy woodpecker had an upper limit reaching $18.5 \mathrm{kHz}$, which overlaps the lower frequency limit of I. pini disturbance signals $(16-18 \mathrm{kHz})$ recorded in this study. Given that the sound intensities of Alberta and Ontario disturbance signals ranged from $63.5-72.6$ and $24.1-27.0 \mathrm{~dB}$ SPL at $1 \mathrm{~cm}$, 
respectively, these signals can be detected by avian predators, and warrants further studies with avian predators.

Based on evidence indicating that in Ips pini, acoustic signaling does not follow predator attack (prediction 1), signaling does not affect prey handling (prediction 2), signals are ineffective in startling predators and causing momentary hesitation and/or obstruction in predator attacks (prediction 3), and only weak indirect evidence to support prediction 4 (predators are capable of hearing signals), it is unlikely that the "disturbance" signals of Ips pini functions for startling predators. Although, further tests with other predators (i.e. avian predators) are needed to conclusively reject this startling hypothesis, it is also important to consider alternative hypotheses, which may not be mutually exclusive.

First, it is possible that the sounds produced during disturbance and predation trials were incidental, and may not have any functional significance. Masters (1980) suggested that when the movements involved in stridulation and the struggling behaviour (e.g. erratic up and down head movements in I. pini) are closely coupled, acoustic signals can be caused by the incidental scraping of the plectrum against the pars stridens during struggles. These incidental signals usually have irregular temporal structures, and signaling patterns (Masters 1980). The present study provides some evidence that lends support to the "incidental signal" hypothesis: 1) the struggling movements (i.e. vigorous leg and head movements) were similar for both males and females; 2) there was considerable variation in the temporal shape and structure of female disturbance signals (see Fig 2.7); and 3) females did not readily produce chirps during both disturbance and predation trials, and on average, females had a delay $14 \mathrm{sec}$ to initiate signaling after 
predator attack; suggesting a dissociation between signaling and predation events. In addition, on several occasions, pine engraver females that had fallen ventral-side up produced spontaneous chirps while struggling to turn dorsal-side up, and the vigorous leg and head movements, during this context, were similar to the struggling movements during predation events (personal observation). Interestingly, in contrast to I. pini, the disturbance signaling of Dendroctonus ponderosae (Fleming 2009) and D. valens (personal observation) had a more rhythmic temporal pattern in their disturbance signals. This can be attributed to the decoupling of the movements involved in stridulation (i.e. elytral-abdominal mechanism in Dendroctonus), and the movements involved in struggling (see Masters 1980).

Second, female "disturbance" signals may function to mediate spacing and territoriality between con-specifics. Several studies have noted that, in many bark beetle species, including Ips pini, radiating female tunnels between galleries rarely collided with each other, and in some cases, tunnels nearing collision showed a sudden change in direction away (see Byers 1989 and 2007; personal observation). Although the mechanism involved in spacing within the phloem layer is not known, acoustic signals have been hypothesized as a possible mechanism. It is possible that, in I. pini, these so called "disturbance" signals are produced by tunneling females to announce their presence to neighboring females, which may be transmitted through the phloem substrate vibrations. Future behavioural playback studies are needed to test the phonotaxis behaviour of tunneling females inside the phloem layer to determine whether "disturbance" signals play a role in spacing behaviour. 
Third, these signals may function as "alarm calls" to alert con-specific males, of intruding egg predators. Reid and Roitberg (1994) have suggested that during oviposition, males provide defense against egg predators, and showed that predation events were higher in galleries where males had been removed. However, it is not known how males, that are usually guarding the entrance to the nuptial chamber, detect and defend against egg predators. It is possible that these female "disturbance" signals may function to alert males of the presence of predators.

The present study is one of only a few studies (Buchler et al. 1981; Eisner et al. 1974; Lewis and Cane 1990; Masters 1979) that have tested the function of "disturbance" signals in beetles with their natural predators. In most of the beetles examined, acoustic signals are followed by the secretion of some noxious chemicals, and were hypothesized to function as aposematic signals (Buchler et al. 1981; Eisner et al. 1974; Masters 1979). Bark beetles, however, do not secrete any chemicals when handled, or have any apparent physical defenses. Therefore, their disturbance signals were hypothesized to be deimatic signals that temporarily startled predators (Lewis and Cane 1990). The results from this study provides little support for this widely accepted "startling" function of bark beetle disturbance signals, and accentuate the need for further empirical tests with other natural predators and the consideration of testing possible alternative hypotheses. In addition, the present study highlights the importance of testing the many suggested hypotheses of disturbance signals in other beetles, including other species of bark beetles. Such studies are invaluable, and can elucidate the functional and evolutionary significance of disturbance signals, not only in bark beetles, but Coleoptera in general. 


\section{Conclusion}

In conclusion, the present study characterized the acoustic signals of female pine engraver bark beetles, Ips pini, and provides novel details of their spectral and transmission properties, and allows us to develop hypotheses on their functional significance. Firstly, all female acoustic signals had broad frequency bandwidths, but disturbance signals had peak frequencies ( 22 to $27 \mathrm{kHz}$ ) that were significantly higher than that of pre-mating signals $(11-13 \mathrm{kHz})$; indicating that signals were context-specific, and potential receptor mechanisms (i.e. tympanal hearing organ) may be capable of distinguishing between broad frequency bands. Secondly, acoustic signals were substantially correlated with female size and weight, indicating that the temporal features of these signals contains information about female quality, which may be important for male mate choice. Thirdly, acoustic signals had both air-borne and substrate-borne vibratory components, suggesting possibly multi-modal communication system in bark beetles. Lastly, this study tests the "startling" function of female disturbance signals, and showed that disturbance signals were not effective in startling natural predators, and may not have any anti-predator function. These novel findings on the characteristics and transmission properties of Ips pini acoustic signals have important implications for understanding the functional significance of bark beetle acoustic signals, and allows for developing hypotheses about potential receptor mechanisms. This study accentuates the need for further investigation into bark beetle acoustic communication, which has important applications in conservation biology and forest pest management. 


\section{Chapter 3}

\section{Acoustic communication in Ips pini: Putative acoustic receptors and the central nervous system}

\subsection{Introduction}

Acoustic communication is believed to be widespread in bark beetles (Scolytinae), as stridulatory organs have been documented in numerous species across genera (see Barr 1969), and sound production in different behavioural contexts has been described in several species (see Ryker 1988). Early studies in the Douglas fir beetles, Dendroctonus pseudotsugae, demonstrated a direct association between male and female acoustic signaling and the release of anti-aggregation pheromones (see Rudinsky and Michael 1972; Rudinsky et al. 1973; Rudinsky 1969). Barr (1969) and Wilkinson et al. (1967) conducted ablation experiments in Ips confusus and Ips calligraphus, respectively, and demonstrated that acoustic signaling was important for gaining admittance into male initiated nuptial chambers, as males rarely accepted non-signaling females. These early studies demonstrate that, 1) bark beetles are highly acoustic insects, 2) acoustic signals in bark beetles are communicative, and 3) these signals are somehow received and processed by the receiver. Furthermore, acoustic studies in Ips pini (chapter 2), and Dendroctonus ponderosae (Fleming 2009) have shown that signals may be transmitted through both air and the solid phloem substrate (multi-modal signaling). Given that acoustic communication in prevalent across Scolytinae, it is surprising that no study to date has examined the receptor mechanisms involved in perceiving these acoustic signals in any bark beetle species. 
Acoustic receptor mechanisms have been described in numerous insect species across taxa, and have been extensively studied in select model organisms (see review by Yack and Dawson 2008). There are several comprehensive reviews on the various types of receptor mechanisms found in insects (see Yack and Dawson 2008 and references therein). In general, all types of acoustic receptors are highly specialized and sensitive mechanoreceptors (Yack 2004). The differences between receptor types, however, lies partly in their external and internal morphology, and the properties of acoustic stimuli to which they are receptive. Essentially there are three properties of acoustic signals that are considered relevant for insect "hearing": 1) the near-field component of air-borne vibrations; 2) the far-field component of air-borne vibrations; and 3) vibrations transmitted through solid substrates (substrate-borne vibrations) (see Bradbury and Vehrencamp 1998).

A sound source emitting air-borne vibrations creates mechanical disturbances (or displacement) in the air molecules directly surrounding the source, which in turn displaces neighboring particles (Bradbury and Vehrencamp 1998). The variation in pressure (energy), caused by air particle displacement, propagates through the air medium, and is perceived as "sound" (Bradbury and Vehrencamp 1998). These vibrations transmitted through the air medium have two basic components: 1) the displacement (or velocity) component of the air-particles; and 2) the pressure wave (energetic) component (Bradbury and Vehrencamp 1998). The region where the particle velocity component is larger, and out of phase with the pressure component, is called the "acoustic near-field"; which is considered to be less than one wavelength from the sound source (Bradbury and Vehrencamp 1998). One of the most extensively studied near-field 
acoustic receptors capable of detecting air-particle displacement is the "Johnston's organ", which is located on the second antennal segment (the pedicel) of many insects (see Yack and Dawson 2008).

Unlike the displacement of air particles, which can move only short distances, the pressure wave components can propagate for much longer distances (Bradbury and Vehrencamp 1998). The region in space where the pressure component is greater, and in phase with the particle velocity component, is called the "acoustic far-field"; which is considered to be greater than one wavelength from the sound source (Bradbury and Vehrencamp 1998). The most extensively studied pressure sensitive hearing organ is the tympanal hearing organ (Hoy and Robert 1996). Tympanal hearing organs (or tympanal ears) have been described in eight insect orders, and are known to have evolved independently at least 20 times across families (see Fullard and Yack 1993; Hennig et al. 2004; Mason and Faure 2004; Yack 2004; Yack and Dawson 2008; Yager 1999).

The vibrating source, when in contact with a solid substrate (surface), can also transmit vibrations through that substrate. Vibrations transmitted through a solid substrate can be detected as either changes in displacement, velocity, or acceleration. In insects, the "subgenual organs", found in the tibia of some insects, and functions as an accelerometer, remains the most studied solid-borne vibration receptor to date (Yack and Dawson 2008). Other receptors used for detecting substrate-vibrations include the Johnston's organ, campaniform sensilla, and trichoid sensilla (Yack and Dawson 2008).

To identify acoustic receptor organs, and determine their functional significance, Yack and Fullard (1993) described three systematic approaches: 1) identifying and describing the external morphology of putative areas where potential receptor systems 
may be located;2) conducting neurophysiological experiments to determine whether receptor organs are capable of detecting biologically relevant signals; and 3) behavioural and ablation studies to determine whether signal reception mediates adaptive behavioural response.

Therefore, as a first step in identifying receptor organs, the primary objective of this chapter is to use the pine engraver bark beetle, Ips pini, as a model organism to describe the external features of putative regions of the body that may function for acoustic reception. Specific focus will be on: 1) the antenna, 2) the tibia of the thoracic legs, and 3) the lateral margin of the thorax. This will provide a starting point for future investigations into acoustic reception in Ips pini, as well as in other bark beetle species.

Another approach to identifying receptor mechanisms is to conduct extracellular nerve recordings on nerves associated with the putative receptor organs to determine whether these organs are capable of detecting acoustic vibrations (Yack and Fullard 1993). To identify these associated nerves, it is imperative to have an understanding of the anatomical features of the central nervous system. To date, the gross anatomy of the CNS has only been described in two bark beetle species, the Douglas fir beetles, Dendroctonus pseutodsugae (Atkins and Chapman 1957) and the mountain pine beetle, D. ponderosae (Fleming, 2009). The secondary objective of this chapter is to characterize the morphology of Ips pini central nervous system, as a preliminary to future histological, neurophysiological, and comparative studies. The main focus of this study is to provide general descriptions of structures where possible receptor organs may be found, and the gross morphology of the CNS. 


\subsection{Materials and Methods}

\subsubsection{Animals}

Pine engraver beetles, Ips pini (Say), were collected at the Herbert's Corner site (Carleton University Forest A, Ottawa, Ontario, Canada), and at the Central Experimental Farm Arboretum (Ministry of Agriculture and Agri-Food Canada (AAFC), Ottawa, Ontario, Canada). Beetles were collected using various 8,12 or 16-funnel Lindgren traps (Contech Enterprises Inc., Victoria, British Columbia, Canada), baited with two I. pini attractant lures, ipsdienol, and lanierone (Contech Enterprises Inc, Victoria, British Columbia, Canada). Lindgren funnel traps were randomly hung on branches of mostly red pine trees (Pinus resinosa; one trap per tree), but also some white pine (P. strobes), and one jack pine ( $P$. banksiana) tree. Traps were hung so that the base of the collecting jar was $\sim 1 \mathrm{~m}$ above the ground.

\subsubsection{Dissection}

Prior to dissections, live beetles were fixed and preserved in Chauthani and Callahan (C \& C) fixative solution (Chauthani and Callahan 1966), and kept refrigerator, at $5^{\circ} \mathrm{C}$, for at least 24 hours; beetles were injected at the posterior tip of the abdomen. Prior to dissection, the elytra, hind wings, and thoracic legs were removed, and beetles were pinned, with minutin pins, in a Petri dish lined with Sylgard 184 (Dow Corning, Midland, MI, U.S.A.). The brain and subesophageal ganglion were exposed using an established dorsal dissection approach, and the thoracic and abdominal nerves were exposed using a ventral approach (see Fleming 2009). Light microscopic images of the CNS were taken both before and after staining with Janus Green B (Yack 1993). All 
drawings of the CNS were made by Karen Wang using a drawing tube (Wild Heerbrug Leitz, Leica 10446993, Heerbrug, Germany).

\subsubsection{Light Microscopy}

The external and internal (i.e. CNS) morphology of adult beetles of both sex was observed and photographed using a light microscope (Olympus SZX12, Tokyo, Japan) equipped with a camera (Zeiss AxioCam MRc5, 1.4 megapixels, $1388 \times 1040$, Oberkochen, Germany). Images of external features were taken from freshly sacrificed beetles. Images of the brain, subesophageal, thoracic and abdominal ganglia, and their major nerve roots were taken during dissections (see above).

\subsubsection{Scanning Electron Microscopy}

Adult males and females, Ips pini, preserved in 90\% ethanol, were prepared for scanning electron microscopy (SEM). The pro-thorax and head of beetles were careful separated from the rest of the body. The head was then separated from the pro-thorax with an insect pin. A medial cut was then made to separate the head into halves, and each half of the head was mounted on an aluminum stub, lateral-side up to expose the antenna; the body was also mounted lateral side up to expose the lateral margin of the meso- and meta-thorax. All specimens were then double coated with gold-palladium (Hummer VII SEM Sputtering System, Anatech Ltd., Alexandria, VA) prior to imaging. Micrographs were taken using a variable pressure scanning electron microscope (Tescan Vega II XMU, Czech Republic). 


\subsubsection{Nomenclature}

Snodgrass (1935) and Faucheux (1994) were used as primary references for determining the nomenclature and associating abbreviations of both external (i.e. antennae, thoracic legs) and internal (i.e. ganglia and nerve roots) structures. Both references were used as primary sources to be consistent with previous work on bark beetle anatomy (e.g. Atkins and Chapman 1957).

The follow is a list of abbreviations used in the figures.

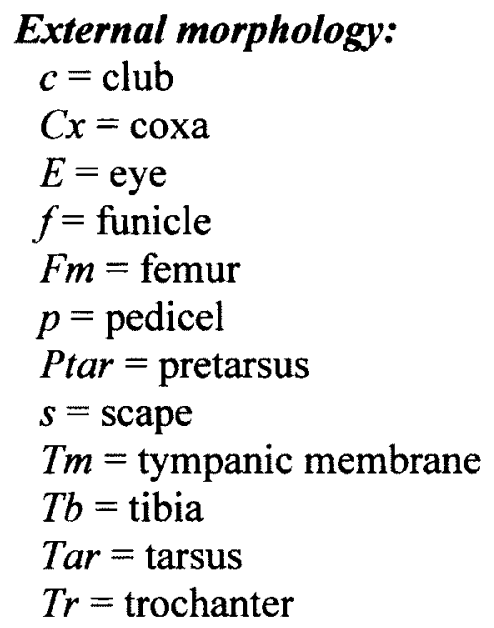

Internal morphology:

AbdGng = abdominal ganglion

$A b d N v=$ abdominal nerve

$A n t N v=$ antennal nerve

$B r=$ brain

$B r l=$ protocerebrum

$B r 2=$ deutocerebrum

$\mathrm{Br} 3=$ tritocerebrum

CoeCon $=$ circumoesophageal connectives

Con $=$ connectives

Eso $=$ esophagus

Gngl = prothoracic ganglion

Gng2 = mesothoracic ganglion

Gng3 = metathoracic ganglion

Gng $I N v I=$ prothoracic nerve 1

Gng2Nv $(I \& I I)=$ mesothoracic nerves 1 and 2

Gng3Nv $(I-I I I)=$ metathoracic nerves 1 to 3

$L b N v=$ labial nerve 
$M d N v=$ mandibular nerve

Mth = mouth

$M x N v=$ maxillary nerve

$O p L=$ optic lobe

$O p N v=$ optic nerve

PoGng = posterior ganglion

SoeGng = suboesophageal ganglion

\subsection{Results and Discussion}

\subsubsection{External Morphology of Ips pini}

Antennae

The antennae of males and females were composed of four segments: scape $(s)$, pedicel $(p)$, funicle $(f)$, and club (c) (Fig. 3.1). Observations of males and females showed no apparent sexual dimorphism in antennal morphology. Previous study by Michael Faucheux (1994) also showed no sexual dimorphism in antennal morphology. The scape was the longest part of antenna, which extended from a socket located directly below the compound eye. The scape increased in diameter distally, and was comprised of several hair-like mechanoreceptors, sensilla chaetica (described previously in Ips pini; Faucheux 1994) (Fig. 3.1). These mechanoreceptors were extended perpendicularly to the long axis of the scape. The pedicel also increased in diameter distally, and was comprised of sensilla chaetica (see Faucheux 1994). Following the pedicle was the funicle, which was comprised of four segments. The first segment extends from a socket on the distal end of the pedicle, and increased in diameter distally. The proximal part of this first segment was considerably narrower relative to other parts of the funicle (Fig. 3.1). Segments two to 

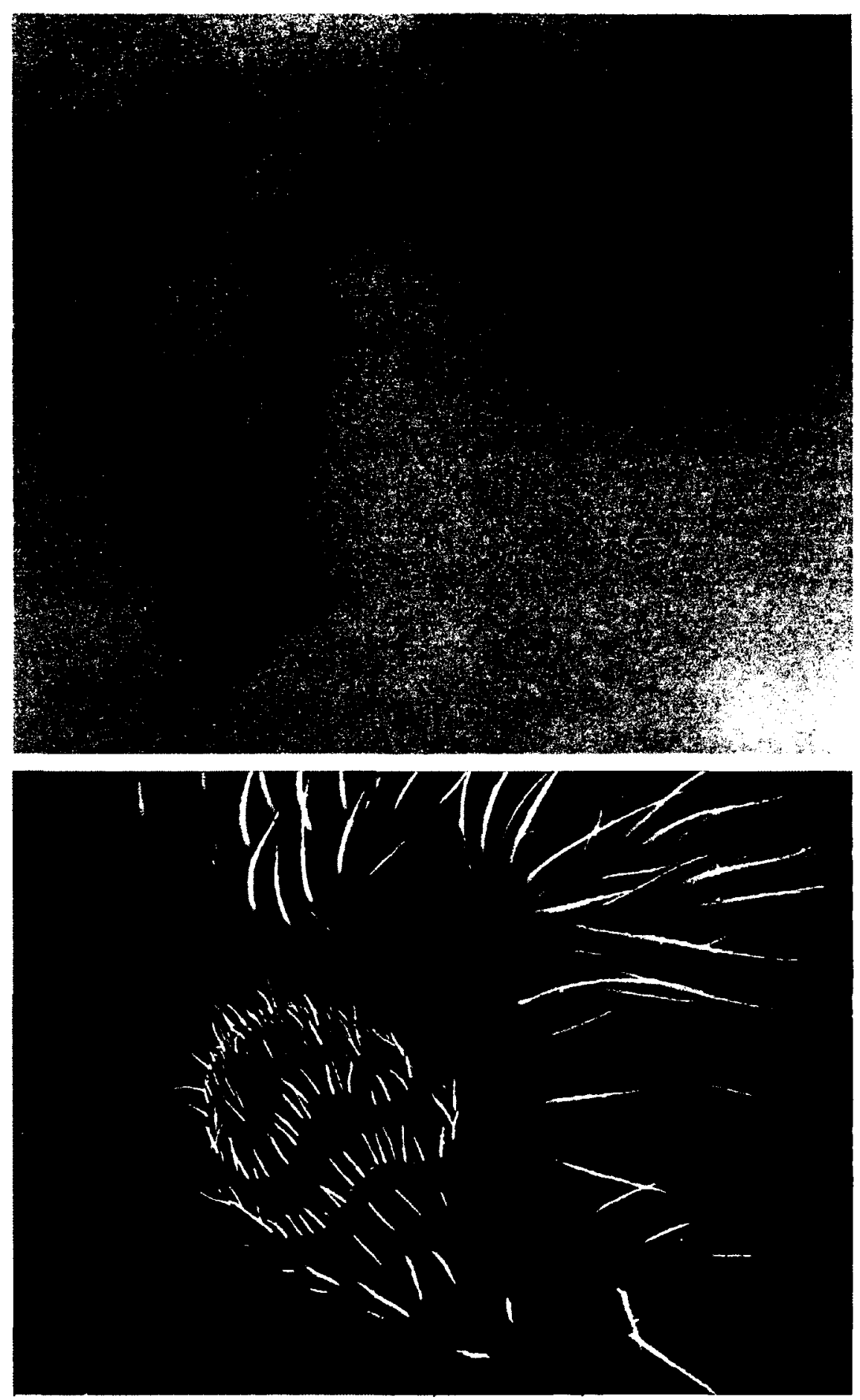

Figure 3.1. External morphology of Ips pini antennae. A) Adult male antennae were composed of four regions: scape $(s)$, pedicel $(p)$, funicle $(f)$, and antennal club $(c)$. The funicle is comprised of four segments. Scale bar $=200 \mu \mathrm{m}$. B) Scanning electron micrograph of female antenna showing hair-like chemical receptors found only on the antennal club, and longer mechanoreceptors, sensilla chaetica, found on the scape, pedicel (indicated by arrow), funicle, and the antennal club. Scale bar $=100 \mu \mathrm{m}$. 
four of the funicle were structurally similar, and were comprised of sensilla chaetica. The last segment of the antenna was the club, a flat, oval shaped structure comprised of several hair-like chemo- and mechanoreceptors organized into three distinct bands or "sensory fields" (see Faucheux 1994). In bark beetles, including I. pini, six types of hairlike sensilla have been described on the antennal club: chaetica, fluted cones, long basiconica, short basiconica, trichodea II, and trichodea III (see Faucheux 1989). Electrophysiological experiments (see Dickens and Payne 1978) have demonstrated that many of these receptor types function for olfactory perception.

In many bark beetle species (including some for which sounds have not been described), the antennal pedicel is a distinct "bowl-like" structure (see Payne et al. 1973). It is possible that the antennal pedicel of Ips pini (and other bark beetles) have increased innervations of chordotonal organs, and may function as a Johnston's organ. The Johnston's organ detects movements of the flagellum or funicle, and functions as gravity detectors, proprioceptors, air current detectors (during flight), and/or air-particle movement detectors (for hearing) (Hallberg 1981; Jeram and Pabst 1996). Johnston's organs have previously been described in several beetle species, including several weevils, which have similar antennal morphology to that seen in Ips pini (Bendele 1986; Frings and Lollis 1971; Schneider 1964; Skilbeck and Anderson 1996). In most of these beetles, however, the authors have only shown the presence of several scolopidia in the antennal pedicel (e.g. Skilbeck and Anderson 1996), but the functions of these scolopidia has not been examined for most beetles. An exception is the whirligig beetles (Gyrinidae), where the Johnston's organ has been shown to function for detecting 
vibrations transmitted through the water surface in the context of prey localization (Bendele 1986; Kolmes 1983).

In most bark beetles, communication during male-female pre-mating interactions occurs at very close distances $(\sim 1 \mathrm{~cm})$ (Barr 1969; Swaby and Rudinsky 1976; Wilkinson et al. 1967). In I. pini for example, stridulation occurs during periods of male-female jostling, and female mandible scraping and biting of male elytra (Schmitz 1972; Swaby and Rudinsky 1976; personal observation). During these close and tactile interactions, it is possible that vibrations from acoustic signals can be perceived as air-particle displacement (in the near-field) through a Johnston's organ in the antennal pedicel. Furthermore, previous study (chapter) has demonstrated that Ips pini acoustic signals can also be transmitted through the phloem substrate, and it is possible that I. pini males and females may detect these substrate vibrations by placing their antennas against the phloem walls inside the galleries. Future studies should first determine whether the antennal pedicel of Ips pini males and females are innervated with chordotonal organs, and the arrangement of these organs using histology. Extracellular electrophysiological studies in combination with ablation experiments can then be used to determine antennal sensitivity to acoustic signals, and whether these signals are detected as air-particle movements or substrate-borne vibrations.

In addition to possible Johnston' organ in Ips pini, the sensilla chaetica on the scape and pedicel may also function as air-particle displacement detectors analogous to the trichoid sensilla described in the larvae of Barathra brassicae (Lepidoptera, Noctuidae) (Markl and Tautz 1975). These hair-like receptors have been described in several Scolytinae species, including Dendroctonus frontalis (Dickens and Payne 1977), 
D. ponderosae (Whitehead 1980), D. valens (Chen et al. 2010), Ips confusus (Borden 1968; Borden and Wood 1966), I. pini (Faucheux 1994), I. sexdentatus (Faucheux 1989), I. typographus (Faucheux 1989; Hallberg 1982; Henderson and Wadhams 1981), Scolytus multistriatus (Borg and Norris 1971), S. scolytus (Henderson and Wadhams 1981; Wadhams et al. 1982), and Trypodendron lineatum (Moeck 1968). Cross sections of the hair shafts showed that these setae are solid and circular with a narrow central lumen containing an electron dense material (Borg and Norris 1971; Hallberg 1982; Moeck 1968). At the basal part of the hair, is a sensory process that terminates as a tubular body; indicative of a mechanoreception function (see Borg and Norris 1971; Hallberg 1982; McIver 1975; Moeck 1968; Payne et al. 1973). Histological experiments on Scolytus multistriatus, and Trypodendron lineatum have show that sensilla chaetica are innervated by a single scolopidium containing a single bipolar sensory nerve that terminates at the base of the seta, and are stimulated by the mechanical movement of the hair shaft (Borg and Norris 1971; Moeck 1968)

Scanning and transmission electron microscopy has shown that these sensilla come in three types based on the external morphology of the hair shaft: 1) un-branched; 2) unilaterally branched; and 3) bilaterally branched (Faucheux 1994; Henderson and Wadhams 1981). In I. pini, the bilaterally branched types are primarily found on the scape, pedicel, and funicle, while the unilaterally and un-branched types are found primarily on the antennal club (Faucheux 1994). The function of these three types, however, has not been investigated, and it is not known whether these hair types vary in their biophysical properties (e.g. weight, thickness, and/or movement). It is possible that variation in biophysical properties between different hair types may allow them to be 
sensitive to different mechanical stimuli. According to Henderson and Wadhams (1981), single cell recordings from bilaterally branched sensilla chaetica in Scolytus scolytus (Wadhams and Angst unpublished data), have shown the presence of cells that only respond to air flow, and it is possible that these receptors may also respond to near-field properties of sound. To date, no histological and electrophysiological studies have examined the internal architecture, and the biophysical and physiological properties of sensilla chaetica in Ips pini.

\section{Thoracic Legs}

There was no apparent sexual dimorphism between males and females in leg morphology, and all six legs were similar in structure. The trochanter of metathoracic legs, however, was considerably elongated in both males and females (Fig. 3.2). The femur, tibia and tarsus of all legs were comprised of several hair-like sensilla (Fig. 3.2). In Dendroctonus ponderosae, cross sections of hair-like sensilla on the prothoracic tibia showed a single dendrite ending in a tubular body at the base of the hairs; the hair shaft, however, lacked a lumen (Whitehead 1981). It is possible that these hairs may have a mechano-sensory function.

The diameter of the tibia increased distally, and the anterior surface and lateral margins were comprised of several ridges and spines. This increase in diameter may indicate a possible subgenual organ in the tibia of the thoracic legs for detecting substrate vibrations. To date, subgenual organs have not been examined or described for any coleopteran species (Virant-Doberlet and Cokl 2004). However, there is behavioural 
A

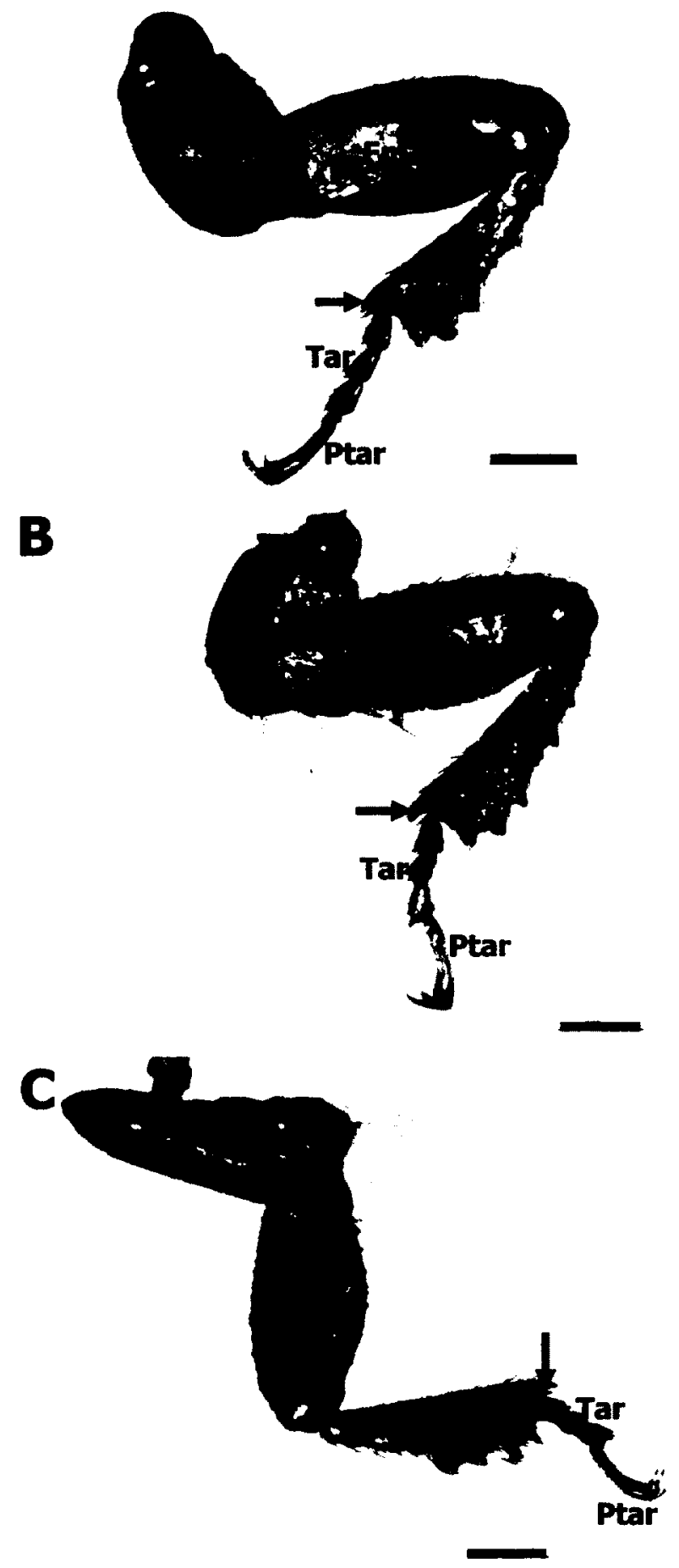

Figure 3.2. External morphology of Ips pini male pro-thoracic A), meso-thoracic B), and meta-thoracic C) legs; black arrow indicates the protibial spine (see text). Coxa $(C x)$;

femur $(F m)$; pretarsus (Ptar); tibia (Tb); tarsus (Tar); trochanter (Tr). All scale bars $=200$ $\mu \mathrm{m}$. 
evidence to suggest that some beetles can detect and communicate with substrate vibrations (e.g. Tenebrionidae beetles; Slobodchikoff and Spangler 1979). In Ips pini, Schmitz (1972) observed that both males and females walked on their tibia using their protibial spine when inside the galleries (Fig. 3.2). Although this observation needs to be corroborated with further behavioural studies using the phloem sandwich methodology, it is possible that chordotonal organs in the tibia, possibly near tibial spines that are in contact with the phloem substrate, can be used to detect solid-borne vibrations through the phloem. Other possible substrate-vibration receptors include possible campaniform sensilla and/or femoral chordotonal organs. In general, there is a lack of histological and electrophysiological studies in coleopteran species; partly due to the highly sclerotized exoskeleton of many beetles making such studies difficult. These studies are definitely worth conducting in bark beetles to investigate substrate-borne vibratory communication and reception. Given that many bark beetles spend the majority of their life cycle inside the phloem layer of trees, it is possible that substrate vibrations play an important role in bark beetle communication. Future histological studies should determine the presence of chordotonal and/or campaniform sensilla in Ips pini tibia and/or femur.

Neurophysiological studies should also record from I. pini leg nerves (see gross morphology of the central nervous system below) to determine whether vibrations are perceived through the legs.

\section{Lateral Margins of the Meso- and Metathorax}

Preliminary observations of Ips pini abdomen and thorax under a light microscope revealed a relatively large and fairly transparent structure on the lateral margin of the 
meta-thorax (Fig. 3.3). Further observations with light and scanning electron microscopes indicated that this structure was located anterior to the first abdominal segment, near a relatively enlarged first abdominal spiracle, and was surrounded by much thicker cuticle (Fig. 3.3). Slight mechanical force, with an insect pin, applied to this transparent structure, indicated that this area was fairly thin and flexible, suggesting a considerable decrease in sclerotization of the cuticle at this region. It is possible that this structure may function as a tympanum to detect the high frequency sounds of Ips pini acoustic signals.

Most tympanal hearing organs are composed of three key structures: 1) tympanal membrane, a thinned region of cuticle surrounded by much thicker cuticle; 2) tracheal air-sacs, a large air-filled chamber formed by the enlargement of surrounding trachea, and located directly behind the tympana; and 3) one or more chordotonal organs that innervate the tympanum directly or indirectly, and are sensitive to vibrations of the tympanum (see Hoy and Robert 1996; Yack and Dawson 2008; Yack 2004). In Ips pini, the thin tympanum-like structure was located adjacent to an enlarged abdominal trachea, which indicates that there may be a tracheal air-sac located behind this membrane. Further microscopy studies in combination with cobalt backfilling techniques (to characterize nerve projections) should first determine the presence of tracheal air-sacs behind the putative tympanum, and innervating nerves. These studies should be followed by future histological and electrophysiological studies.

\subsubsection{Anatomy of the Central Nervous System of Ips pini}

Prior to conducting neurophysiological studies on putative receptor organs, it is important to identify and demonstrate nerves innervating these structures. In order to identify these 
A
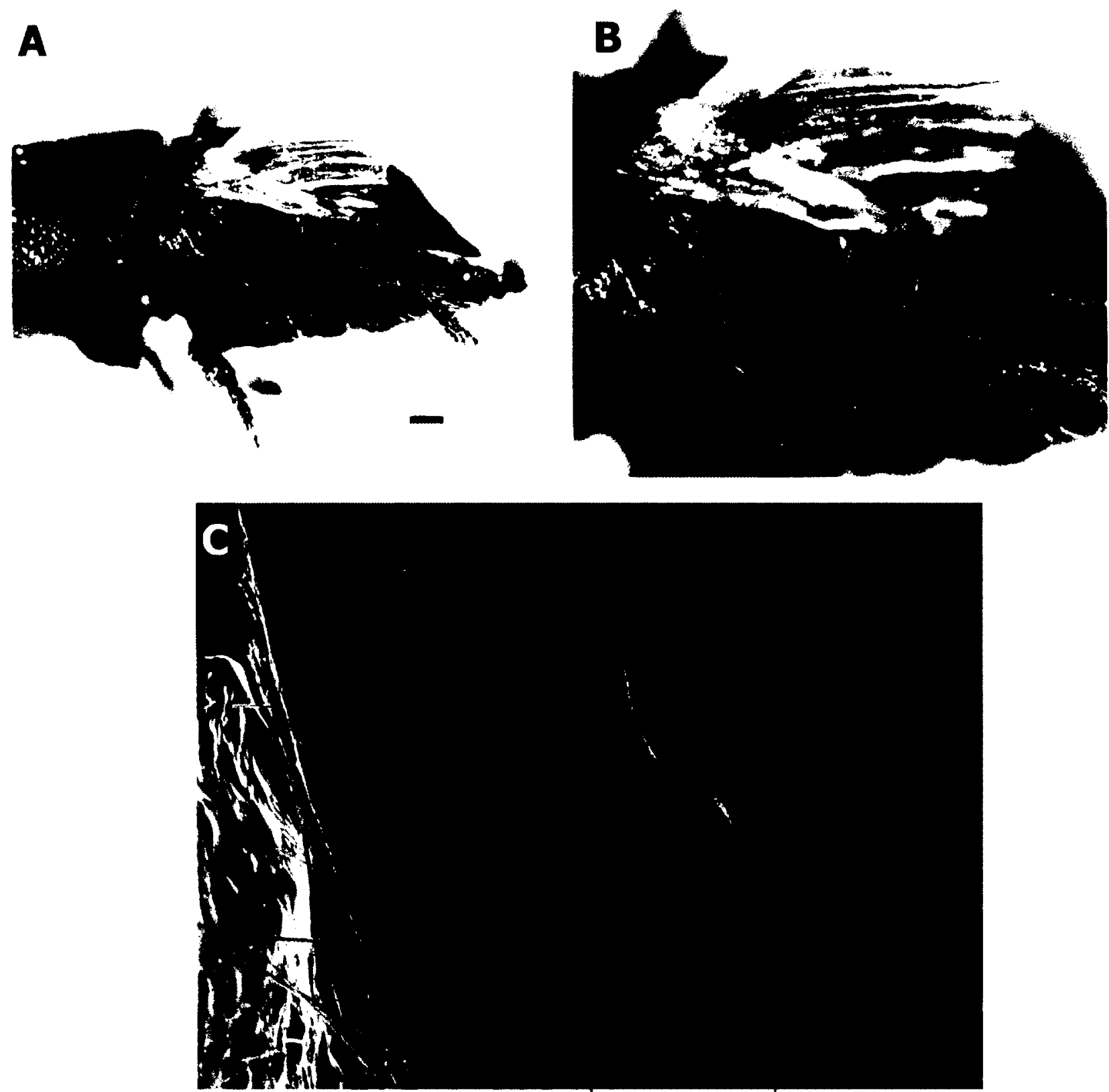

Figure 3.3. External morphology of putative tympanal structure on the proximal lateral margin of Ips pini meta-thorax. A \& B) Light micrograph of the lateral thoracic margin of male 1 . pini showing the position of the tympanum $(\mathrm{Tm})$ on the proximal lateral margin of the metathorax. Scale bars $=200 \mu \mathrm{m}$. C) Scanning electron micrograph of proximal lateral margin of female metathorax showing the proposed tympanum $(T m)$. Scale bar $=$ $100 \mu \mathrm{m}$. 
nerves, it is first important to characterize the general architecture of the central nervous system (CNS). To date, the CNS has not been examined in any bark beetle species of the genus Ips. In this study, the CNS of Ips pini consisted of four main structures: 1) brain $(B r) ; 2)$ suboesophageal ganglion (SoeGng); 3) pro-thoracic ganglion (GngI); and 4) posterior ganglion (PoGng) or the "thoracic-abdominal complex" (Fig. 3.4). The posterior ganglionic mass was formed by the fusion of the mesothoracic (Gng2), metathoracic (Gng3), and abdominal ganglia (AbdGng) (Figs. 3.4 and 3.7). The brain and suboesophageal ganglion were connected by two thick circumoesophageal connectives (CoeCon) (Figs. 3.5 and 3.6). The subpesophageal and prothoracic ganglia were connected by relatively thinner connectives (Con) (Fig. 3.4). The prothoracic and posterior ganglia were also connected by a pair of connectives (Figs. 3.4 and 3.7).

The brain was located dorsal to the esophagus (Eso; Fig 3.6), and consisted of a large protocerebrum $(B r l)$ (Fig 3.5). The deuto- and tritocerebrum were located slightly ventral-posterior to the protocerebrum, and were relatively smaller, and harder to distinguish (Figs 3.5 and 3.6). The lateral-anterior part of the protocerebrum connected with the optic lobe $(O p L)$ proper; whose nerves $(O p N v)$ innervated the compound eye $(E)$ of the beetle (Fig 3.5). The most conspicuous nerve extending from the brain, specifically from the deutocerebrum, was the antennal nerve (AntNv) (Fig 3.6). Two circumoesophageal connectives extending ventral-posterior from the tritocerebrum, along either side of the esophagus, innervated the suboesophageal ganglion, which was located directly ventral to the esophagus (Fig. 3.6). Three major nerve roots were observed on the suboesophageal ganglion: 1) Mandibular nerve $(M d N v) ; 2)$ maxillary nerve $(M x N v)$; and 
3) labial nerve ( $L b N v)$ (Fig 3.6). Both the brain and the suboesophageal ganglion were located in the head of the beetle.

The prothoracic ganglion was located ventral-posterior in the prothorax, and was connected to the suboesophageal ganglion by a pair of connectives (the ventral nerve cord) (Figs 3.6 and 3.7). A pair of connectives extended posteriorly from the prothoracic ganglion, and innervated the posterior ganglionic mass; located at the junction between the pro- and mesothorax. This ganglionic mass was the result of a high degree of fusion of the mesothoracic, metathoracic, and abdominal ganglia (Fig 3.7). The peripheral innervations of the thoracic and abdominal nerves were not further investigated. However, it was observed that the prothoracic nerve (GnglNvI), the second mesothoracic nerve (Gng2NvII), and the long metathoracic nerve (Gng3NvIII) innervated the pro-, meso-, and meta-thoracic legs, respectively (Fig 3.7). Interestingly, the fused posterior ganglion was located close to the putative tympanum structure described in this study (above; Fig. 3.3). Future studies should focus on the metathoracic nerves 1 and 2, Gng3NvI and Gng3NvIl respectively (Figs. 3.6 and 3.7), as observations showed that these nerves were innervating structures closed to the abdomen.

The gross morphology of Ips pini central nervous system (CNS) was comparable to the CNS morphology described in Dendroctonus pseudotsugae (Atkins and Chapman 1957), and D. ponderosae (Fleming 2009). The consolidation of the meso-metathoracic and abdominal ganglia, observed in all three bark beetle species was also observed in the Australian scolytid beetle, Hylurgus ligniperda, and has been considered to be characteristic of the family Scolytinae (Calder 1989). Edmonds (1974) hypothesized that the shortening of the ventral nerve cord and the high degree of ganglionic consolidation 


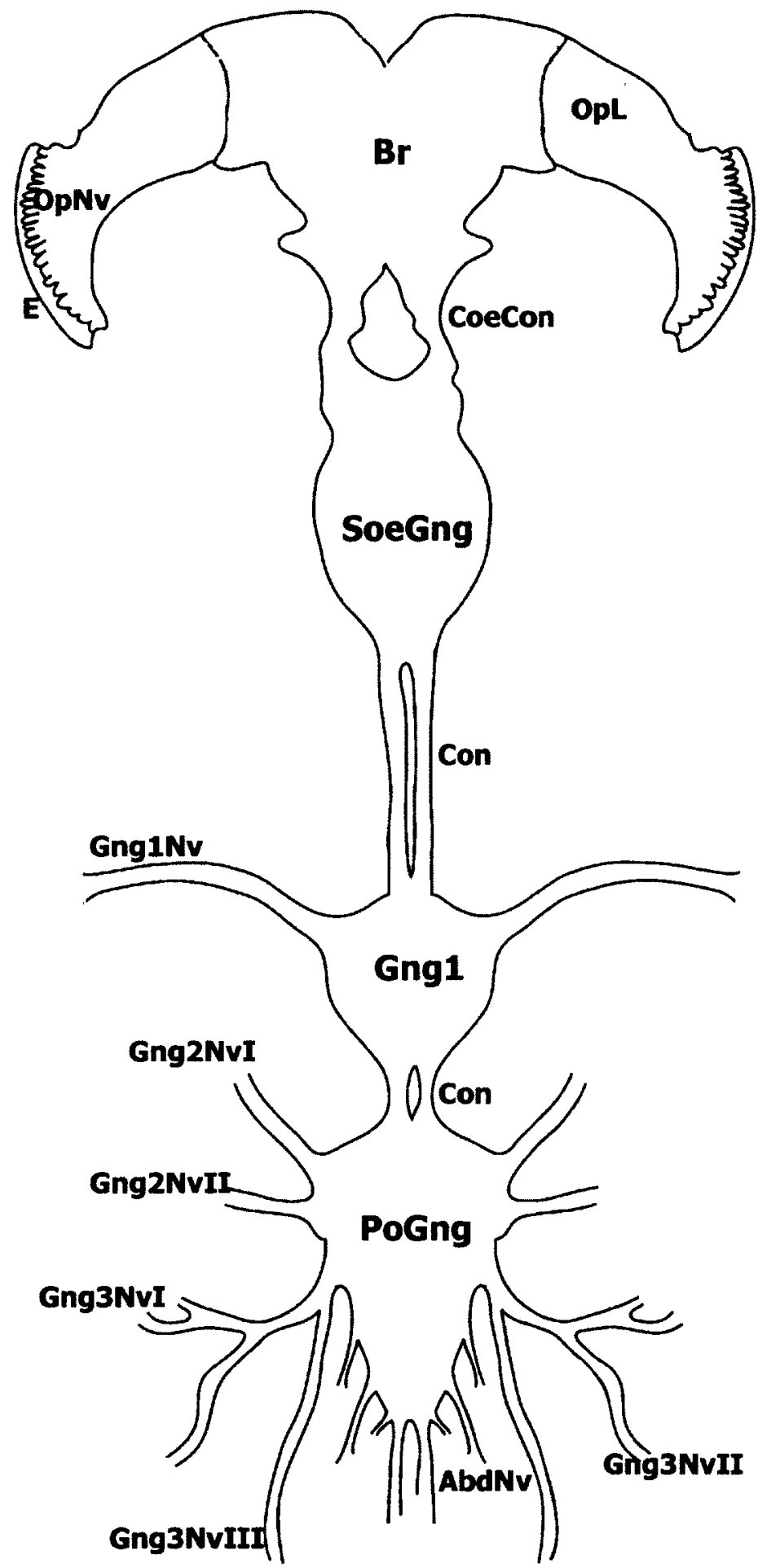

Figure 3.4. Schematic illustration of Ips pini central nervous system (CNS) highlighting the major thoracic and abdominal nerves. The CNS of Ips pini had four major ganglionic mass: the brain $(B r)$, the suboesophageal ganglion (SoeGng), the prothoracic ganglion $(G n g l)$, and the posterior ganglion (PoGng). There were no apparent differences between males and females. Illustration by Karen Wang. 

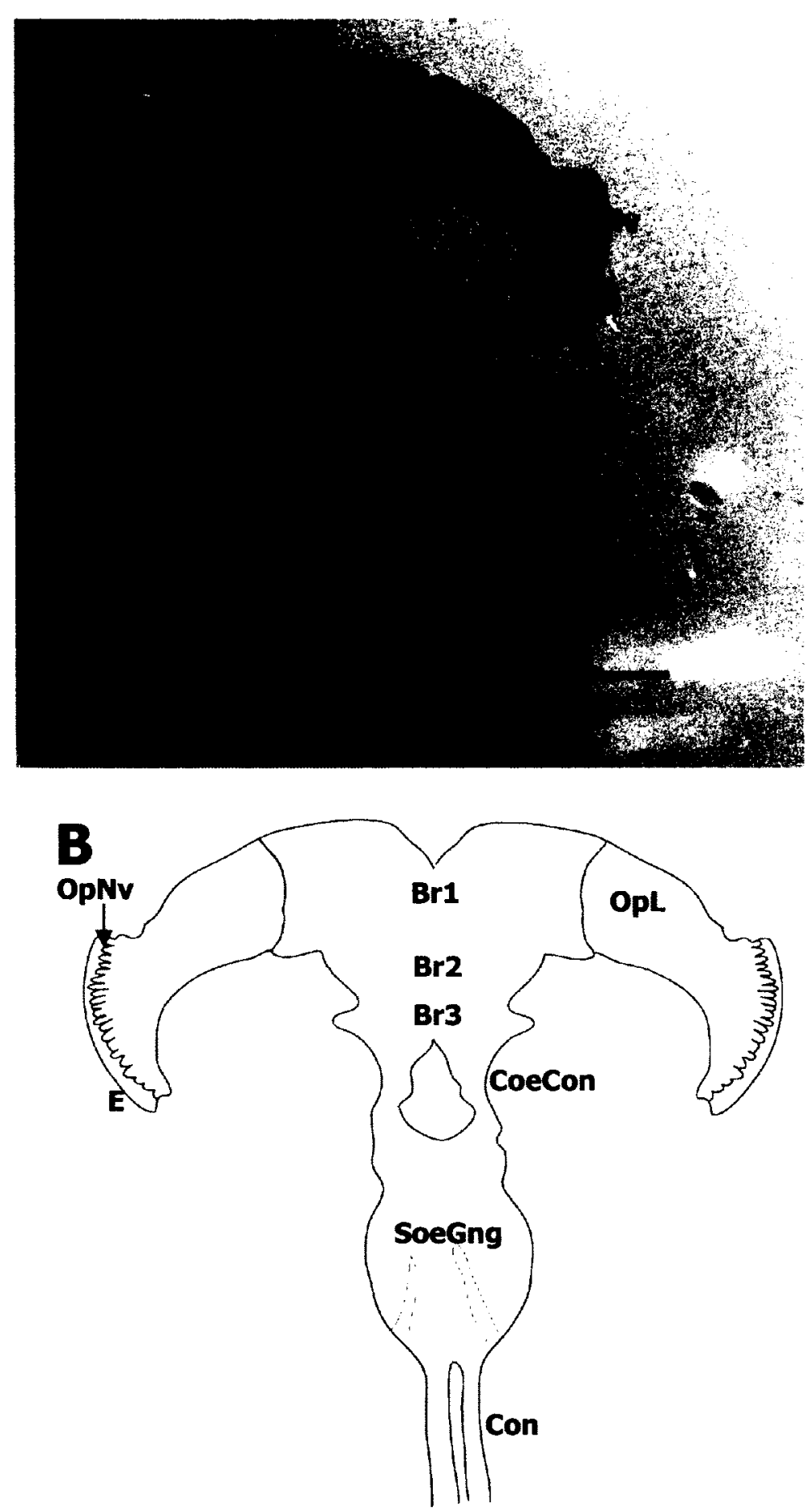

Figure 3.5. Dorsal view of the brain and suboesophageal ganglion of Ips pini. A) Ips pini brain stained with Janus Green B. Brain $(B r)$, eye $(E)$, circumoesophageal connectives (CoeCon), connectives (Con), optic lobe $(O p L)$, optic nerve $(O p N v)$, and suboesophageal ganglion (SoeGng). Scale bar $=200 \mu \mathrm{m}$. B) Schematic illustration of the dorsal brain and suboesophageal ganglion of Ips pini. Deutocerebrum $(B r 2)$, protocerebrum $(B r 1)$, and tritocerebrum $(B r 3)$. Photo credit: Senthurran Sivalinghem; Illustration by Karen Wang. 

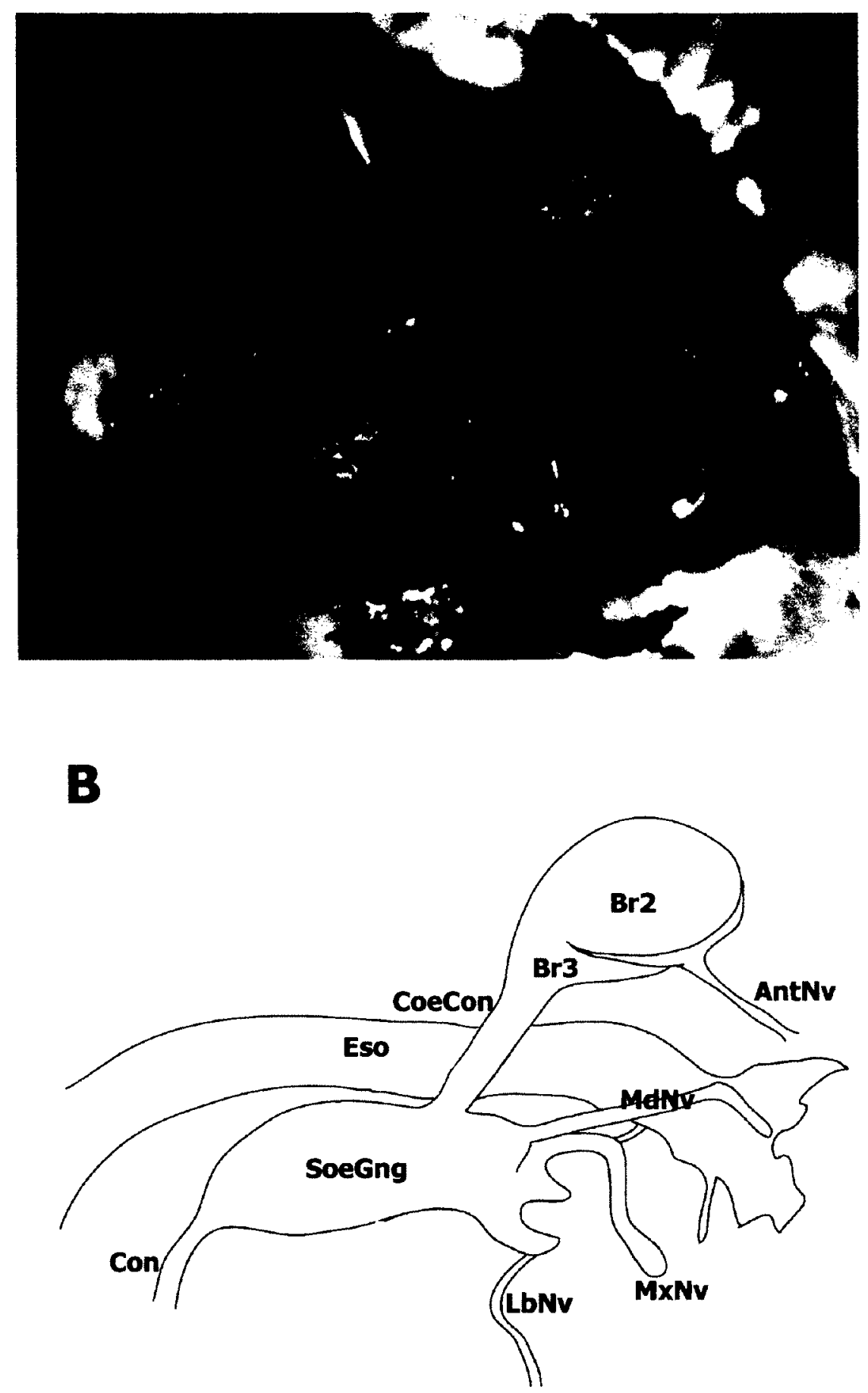

Figure 3.6. Lateral view of Ips pini head, showing the brain, esophagus, and suboesophageal ganglion. A) Ips pini brain ( $\mathrm{Br} 2$ and $\mathrm{Br} 3$ ), esophagus (Eso), and suboesophageal ganglion (SoeGng) stained with Janus Green B. Scale bar $=200 \mu \mathrm{m}$. B) Schematic illustration of the brain and suboesophageal ganglion of Ips pini. Antennal nerve $(A n t N v)$, labial nerve $(L b N v)$, mandibular nerve $(M d N v)$, maxillary nerve $(M x N v)$. Photo credit: Senthurran Sivalinghem; Illustration by Karen Wang. 


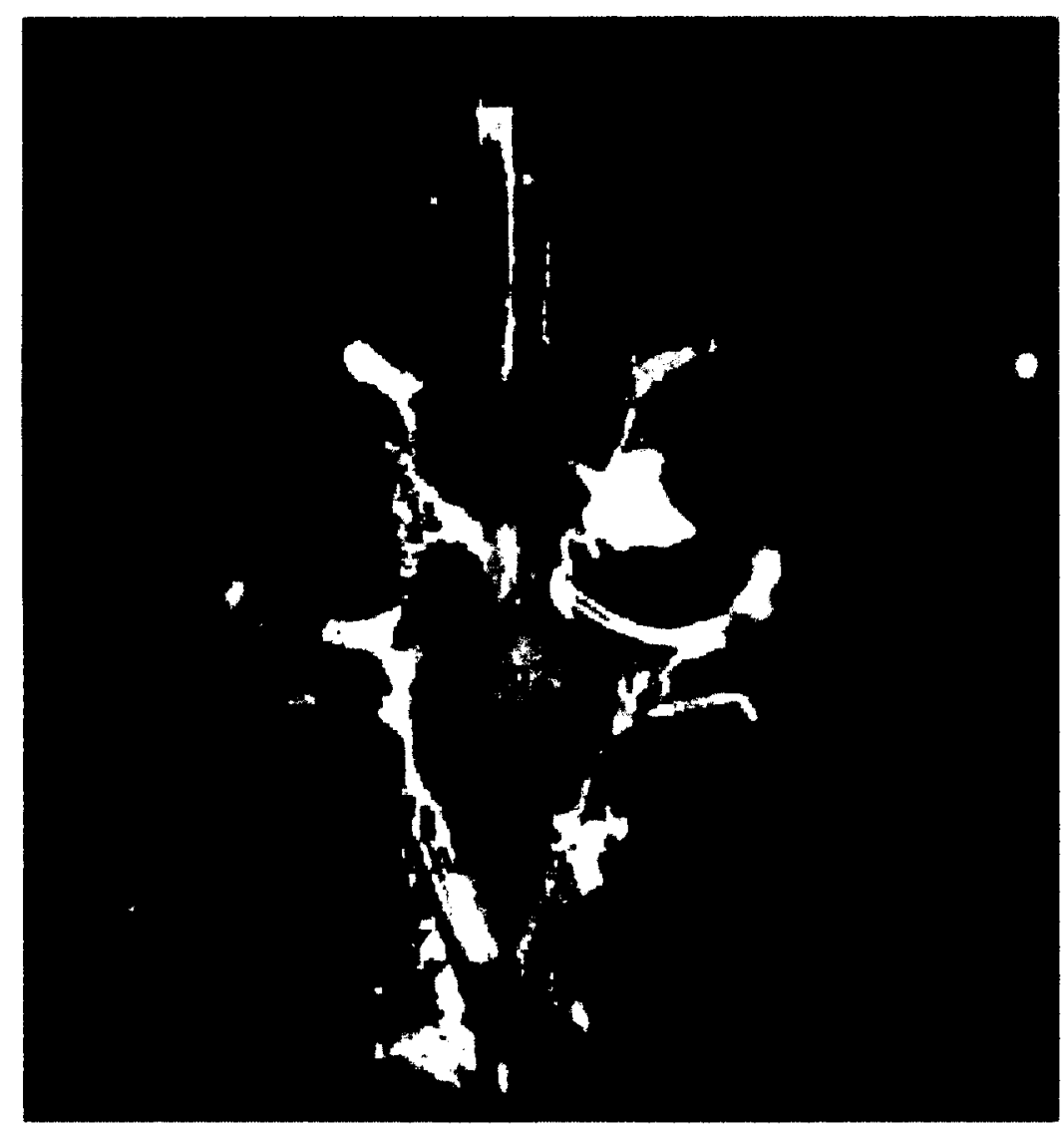

B

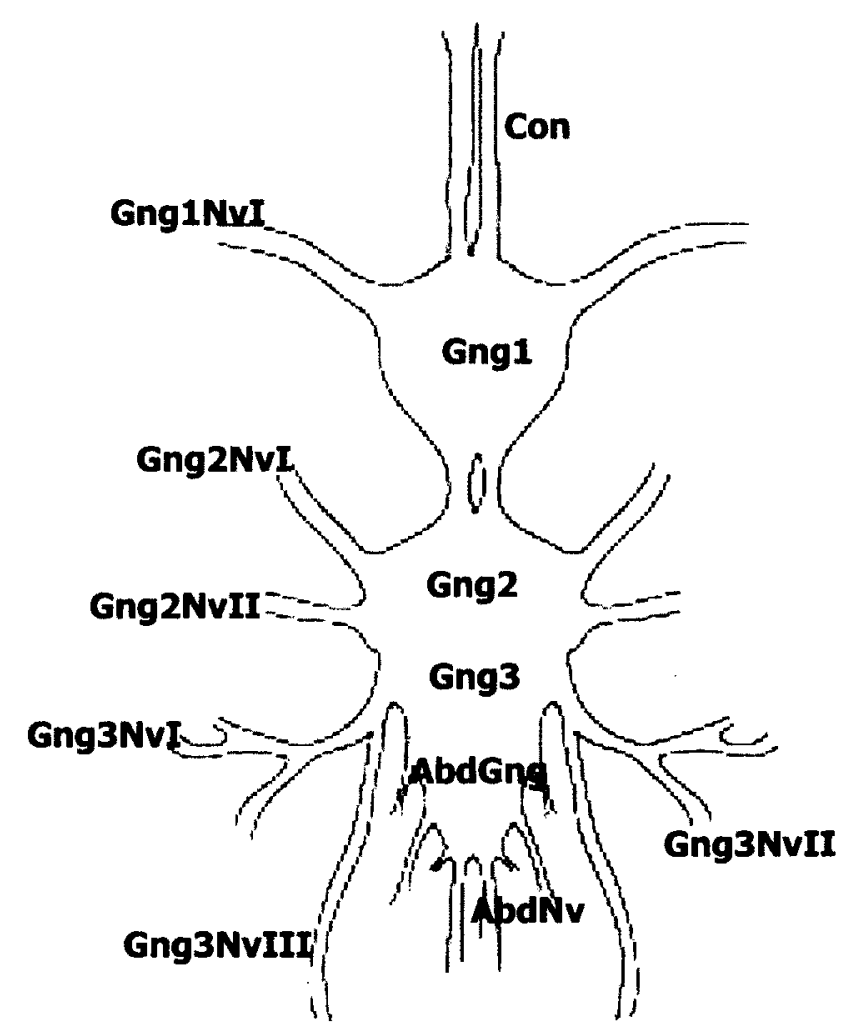

Figure 3.7. Dorsal view of the thoracic and abdominal ganglia of Ips pini. A) Ips pini thoracic and abdominal ganglia and associated major nerve roots; stained with Janus Green B. Scale bar $=200 \mu \mathrm{m}$. B) Schematic illustration of the dorsal thoracic and abdominal ganglia and their associated nerve roots. Abdominal ganglion ( $A b d G n g$ ), abdominal nerve $(A b d N v)$, prothoracic ganglion (Gngl), prothoracic nerve (GnglNvI), mesothoracic ganglion (Gng2), mesothoracic nerves 1 and 2 (Gng2NvI and II, respectively), metathoracic ganglion (Gng3), metathoracic nerves 1 to 3 (Gng 3NvI to III). Photo credit: Senthurran Sivalinghem; Illustration by Karen Wang. 
in the dung beetle, Coprophanaeus lancifer (Scarabaeidae) was due to a general trend towards smaller body sizes, which is an adaptation for digging. Heath and Evans (1990) further demonstrated in ground beetles (Carabidae), a positive relationship between body length, and the length of the ventral nerve cord, and the number of abdominal ganglia (indicating a higher degree of ganglionic consolidation). They argue that, in smaller beetles, more consolidation would result in faster coordination of adjacent and nonadjacent thoracic and abdominal segments (through a more central ganglion).

In theory, the fusion of ganglia are usually accompanied by some form of behavioural specialization or adaptation, as consolidation can result in changes to synaptic connections, and formation (see Niven et al. 2008). For example, the fusion between the metathoaracic and first abdominal ganglion was shown to have occurred early in insect evolution, and has been hypothesized to have been important for the development of flight (see Niven et al. 2008). To date, gross morphology of the CNS has only been examined in sound producing bark beetles, and further examination in nonacoustic beetles are needed to determine the prevalence of ganglionic fusion in Scolytinae, which may provide some insight into the significance of ganglionic fusion for acoustic communication.

\section{Conclusion}

This chapter described the external morphology of putative locations of acoustic receptor mechanisms in the pine engraver bark beetle, Ips pini. This study also characterized the gross morphology of I. pini central nervous system (CNS).

Observations of the antennal showed an enlarged pedicle, which may contain increased 
innervations of chordotonal organs, and may be the location of a possible Johnston's organ. Observations of the thoracic legs showed that the tibia increased in diameter distally, and was covered with dense seta, and several spines and ridges. It is possible that any chordotonal organs (e.g. subgenual organs) and/or campaniform sensilla near leg joints and/or near tibial ridges that are in contact with the phloem substrate may function for perceiving substrate-vibrations. The present study also described a putative tympanal structure on the proximal lateral margins of the meta-thorax. This structure was adjacent to an enlarged spiracle of the first abdominal segment, and it is possible that is it associated with an enlarged tracheal air-sac. Further microscopic (with backfilling techniques), histological, and electrophysiology studies are needed to conclusively identify the presence of these putative receptors mechanisms, and to characterize their external and internal structure.

To identify nerves innervating these possible receptor mechanisms, and to conduct neurophysiological experiments, it is first important to describe the architecture of the CNS. The gross morphology of I. pini the CNS showed four distinct structures: 1) brain; 2) suboesophageal ganglion; 3) prothoracic ganglion; and 4) posterior ganglionformed as a result of consolidation of the meso-metathoracic and abdominal ganglia. This gross CNS anatomy was similar to those described in other bark beetles species, and may be characteristic in all species in the family Scolytinae. The posterior ganglion was located adjacent to the putative tympanal structure, and afferent nerves from the tympanal structure may project to this ganglion, which warrants the need for future backfilling studies. Furthermore, further electrophysiological studies are also needed to determine 
leg nerve responses to substrate vibrations. This study provides a starting point for future investigations into acoustic receptor mechanisms in Ips pini. 


\section{Chapter 4}

\section{General Discussion}

Despite nearly two decades (in the 1970s and 1980s) of research in bark beetle bioacoustics (see Chapter 1 and Table 1.1), this mode of communication remains one of the least understood and largely under-appreciated forms of communication in this group of beetles. Compared to the vast amount of empirical investigations in bark beetle chemical/pheromone ecology and sensory physiology, acoustic communication has received relatively little attention (see Ryker 1988). To understand communication in any organisms, it is important to investigate four main questions: 1) what are the characteristics of the signals; 2 ) how are these signals transmitted from the sender to the intended receiver; 3) what is the functional significance of these signals; and 4) how are these signals received and processed in the nervous system. Given that previous literature in bark beetle acoustics provides little to no information on the details of the signal characteristics, transmission properties of the signals, functional significance of signals, and the receptor mechanisms, the overall goal of this research was to use a model species, the pine engraver bark beetle, Ips pini, to start to address these questions, and to provide a basis upon which future studies can further investigate.

Female Ips pini were previously shown to produce acoustic signals through a vertex-pronotal stridulatory mechanism (see Barr 1969) during handling, male-female pre-mating, and female-female "rivalry" interactions (Swaby and Rudinsky 1976). This early study (Swaby and Rudinsky 1976) described some temporal characteristics of the signals (i.e. chirp duration, number of pulses, and pulse rate), and showed significant 
variations in these characteristics between behavioural conditions (see Table 2.1). Besides this temporal analysis and a general statement on the frequency bandwidth of the chirps (see Chapters 1 and 2), no further characteristics of the signals were examined.

In chapter two of this thesis, characterization of female signals during handling disturbance and male-female pre-mating conditions demonstrated that acoustic signals in both conditions were largely comprised of high sonic and ultrasonic frequency components (see Table 2.2). Ultrasonic frequencies were also shown in the disturbance and pre-mating signals of Dendroctonus ponderosae (Fleming 2009), and in preliminary observations of disturbance signals in $D$. valens (personal observation). Previous literature on bark beetle acoustics has largely ignored spectral characteristics of the signals or only provide vague and general statements of the frequency range (e.g. Oester et al. 1978; Rudinsky and Michael 1972; Vernoff and Rudinsky 1980; Wilkinson et al. 1967; Wilkinson 1962), and further studies describing the spectral and intensity characteristics of other species across genera are needed. Given that pine engravers live sympatrically with $D$. valens (in Ontario, and parts of British Columbia), D. ponderosae (in western North America), and other sound producing bark beetle species (e.g. Ips calligraphus), it would be interesting to compare the frequencies of different sympatric species to determine the degree of overlap between them. A high degree of frequency overlap may indicate that these signals are probably shaped by the signaling environment (see Endler 1992 and 1993), whereas little overlap may indicate species-specific signals.

In addition to frequency characteristics, chapter two also demonstrated that the temporal and spectral features of $I$. pini acoustic signals were highly variable between females, between behavioural conditions, and between conspecific populations. In theory, 
features of acoustic signals that are highly variable between individuals are usually associated with "open-ended" preference functions, where extreme values of the traits are preferred (Gerhardt 1991; Shaw and Herlihy 2000). Given that signal parameters were also correlated with female size and weight (see Table 2.7), it is possible that males may use these signals to determine female size during mate choice. Before determining whether males use acoustic signals to assess female size, it is important for future studies to first determine whether males reject signaling females, and whether female size is related to reproductive success (e.g. number of viable eggs laid, and offspring size and number). As discussed in chapter two, it is possible that male mate choice in I. pini will depend on several factors including host-tree quality, population density on a given host tree, quality of the male, and female quality. Addressing the importance of acoustic signals during male mate choice is fundamental to understanding the function of acoustic communication in Ips pini.

Highly dynamic properties of the acoustic signals can also be influenced by the local environment (i.e. local predators, temperature, and humidity), which can lead to population differences in signal characteristics (see Nevo and Capranica 1985). Indeed, comparing the signals of Alberta and Ontario females showed substantial variation in the temporal and frequency characteristics of the chirps. Further research is needed to determine the environmental factors influencing I. pini signal characteristics, and whether signal variation between populations is directional. Understanding these variations in signals within and between conspecific populations is important for gaining insights into the mechanisms of signal divergence and the evolution of reproductive isolation. 
Recordings during pre-mating trials indicated that Ips pini acoustic signals had both air-borne and solid-borne vibratory components. Although these results do not demonstrate substrate-vibratory communication, considering that most bark beetle species, including I. pini, spend the majority of their life cycle inside galleries on the phloem substrate, it is very possible that they do communicate using substrate-borne vibrations. There are three specific questions that follow-up studies should address before determining whether bark beetles communicate using solid-borne vibrations. First, what are the details of the vibratory signal characteristics? Descriptions of substrate vibration in chapter two are incomplete, and several details (e.g. signal intensity, vibration type) of signals were not analyzed. Understanding the details of these signals can provide insights into the properties of the signals that are important, and the processing demands of receptor mechanisms. Second, how are vibrations transmitted to the phloem? Given that communication between males and females occurs inside galleries, vibrations can theoretically be transmitted through the legs, the elytra, and/or the pronotum. Substrate vibrations can also be induced by the air-borne sounds themselves (similar to those described in Okanagana rimosa; Stölting et al. 2002). Third, what are the transmission properties of the phloem substrate and how effectively are vibratory signals transmitted? Understanding this is crucial for determining possible functions of vibratory signals. For example, if these signals can be transmitted over longer distances, then it is possible that they can play a role during spacing of galleries. The phloem layer, however, can vary in the amount of water content, and density both between and within trees, and it would be interesting to determine how these properties affect transmitted signals. These properties of the phloem can also affect air-borne sounds (i.e. baffling and/or reverberations of 
signals). Depending on the reflective properties of the phloem substrate, there can be echoes inside the galleries.

The implied functions of bark beetle signals have not been previously tested (but see Lewis and Cane 1990). For example, the disturbance signals of bark beetles were hypothesized to function as defensive startling signals that either caused predators to drop beetles from their mouth or to momentarily delay attacks, allowing the beetles to escape. In chapter two, this startling hypothesis was tested in $I$. pini using their primary natural predators, the red-bellied checkered beetles, Thanasimus dubius. Evidence from predation trials suggested that disturbance signals may not function to startle predators, and may be incidentally caused by the struggling head movements. These results, however, are not conclusive, and further studies are needed to test some of the alternative defensive functions of these disturbance signals. Alternative functions include acoustic mimicry (possibly ultrasonic signals of mice; see Portfors 2007), warning or aposematic signals, and alarm signals to recruit conspecifics inside galleries (i.e. females recruiting males). I. pini, however, does not secrete noxious chemical substance when handled or have any apparent physical weaponry (albeit, the exoskeleton of these beetles can function as armors against predators), and during predation trials, their primary predators showed no obvious hesitation when attacking signaling females. Further tests with other predators, specifically avian predators (e.g. woodpeckers) are also needed.

The underlying implication of many of the hypotheses stated above and in the previous chapters is that these acoustic signals are somehow perceived by the intended receivers. One of the long term objectives of this research in bark beetle acoustics is to determine these receptor mechanisms, and to understand how acoustic signals are 
received and processed in the nervous system. In chapter three, three putative regions where receptor mechanisms may be located were identified: 1) possible Johnston's organ in the antennal pedicel; 2) possible vibration receptors on the tibia of prothoracic legs; and 3) putative tympanum on the lateral margins of the metathorax. Although further histological and electrophysiological experiments are needed to determine whether these putative structures can function for hearing, these preliminary observations provide a starting point for further investigations.

In conclusion, this thesis used the pine engraver bark beetle, Ips pini, to address the four main questions (see above) important for understanding communication in bark beetles. Specifically, this thesis provided detailed characterization of the temporal, frequency, and intensity features of female I. pini signals, which provides insights into possible functions and allows for developing new hypotheses. This thesis also described the transmission properties of the acoustic signals, tested the startling function hypothesis of disturbance signals, and described the external morphology of putative acoustic receptor mechanisms, which sets the groundwork for future research into signal transmission, function, and reception. This study provides significant contributions towards understanding acoustic communication in bark beetles, and illustrates the need for further research into this form of communication in one of the most notorious pest organisms in North America. These studies can have vast implications understanding the behavioural and evolutionary ecology of bark beetles, which has applications in conservation biology, forest and pest management, and international environmental policy making. 


\section{References}

Alexander, R. D., Moore, T. E. and Woodruff, R. E. (1963). The evolutionary differentiation of stridulatory signals in beetles (Insecta: Coleoptera). Animal Behaviour 11, 111-115.

Anderson, R. F. (1948). Host selection by the pine engraver. Journal of Economic Entomology 41, 596-602.

Andersson, M. N., Larsson, M. C. and Schlyter, F. (2009). Specificity and redundancy in the olfactory system of the bark beetle Ips typographus: Single-cell responses to ecologically relevant odors. Journal of Insect Physiology 55, 556-567.

Angst, Max. E. and Lanier, Gerald, N. (1979). Electroantennogram responses of two populations of Ips pini (Coleoptera: Scolytidae) to insect-produced and host tree compounds. Journal of Chemical Ecology 5, 131-140.

Atkins, M. D. and Chapman, J. A. (1957). Studies on nervous system anatomy of the Douglas fir beetle, Dendroctonus pseudotsugae Hopk. (Scolytidae). The Canadian Entomologist 89, 80-86.

Arrow, G. J. (1942). The orgin of stridulation in beetles. Proceedings of the Royal Entomological Society of London (A) 17, 83-86.

Aukema, B. H. and Raffa, K. F. (2004). Does aggregation benefit bark beetles by diluting predation? Links between a group-colonisation strategy and the absence of emergent multiple predator effects. Ecological Entomology 29, 129-138.

Barr, B. A. (1969). Sound production in scolytidae (Coleoptera) with emphasis on genus Ips. Canadian Entomologist 101, 636-678.

Bendele, H. (1986). Mechanosensory cues control chasing behavior of whirligig beetles (Coleoptera, Gyrinidae). Journal of Comparative Physiology A-Sensory Neural and Behavioral Physiology 158, 405-411.

Bentsen, C. L., Hunt, J., Jennions, M. D. and Brooks, R. (2006). Complex multivariate sexual selection on male acoustic signaling in a wild population of Teleogryllus commodus. American Naturalist 167, E102-E116.

Bentz, B. J., Regniere, J., Fettig, C. J., Hansen, E. M., Hayes, J. L., Hicke, J. A., Kelsey, R. G., Negron, J. F. and Seybold, S. J. (2010). Climate Change and Bark Beetles of the Western United States and Canada: Direct and Indirect Effects. Bioscience 60, 602-613. 
Boone, C. K., Six, D. L., Krauth, S. J. and Raffa, K. F. (2009). Assemblage of Hymenoptera arriving at logs colonized by Ips pini (Coleoptera: Curculionidae: Scolytinae) and its microbial symbionts in western Montana. Canadian Entomologist 141, 172-199.

Borden, J. H. (1968). Antennal morphology of Ips confusus (Coleoptera: Scolytidae). Annals of the Entomological Society of America 61, 10-\&.

Borden, J. H. and Wood, D. L. (1966). Antennal receptors and olfactory response of Ips confusus (Coleoptera: Scolytidae) to male sex attractant in laboratory. Annals of the Entomological Society of America 59, 253-\&.

Borg, T. K. and Norris, D. M. (1971). Ultrastructure of sensory receptors on antennae of Scolytus multistriatus (marsh). Zeitschrift Fur Zellforschung Und Mikroskopische Anatomie 113, 13-\&.

Bradbury, J. W. and Vehrencamp, S. L. (1998). Principles of animal communication. Sinauer Associates.

Broughton, W. B. (1963). Methods in bioacoustic terminology. In: Acoustic behaviour of animals. (Ed R.G. Busnel). pp 3-24. Elsevier, Amsterdam,

Buchler, E. R., Wright, T. B. and Brown, E. D. (1981). On the functions of stridulation by the passalid beetles Odontotaenius disjunctus (Coleoptera: Passalidae). Animal Behaviour 29, 483-486.

Byers, J. A. (1989). Chemical ecology of bark beetles. Cellular and Molecular Life Sciences 45, 271-283.

Byers, J. A. (2007). Simulation of mating disruption and mass trapping with competitive attraction and camouflage. Environmental Entomology 36, 1328-1338.

Calder, A. A. (1989). The alimentary canal and nervous system of Curculionoidea (Coleoptera): Gross morphology and systematic significance. Journal of Natural History 23, 1205-1265.

Carisio, L., Palestrini, C. and Rolando, A. (2004). Stridulation variability and morphology: an examination in dung beetles of the genus Trypocopris (Coleoptera, Geotrupidae). Population Ecology 46, 27-37.

Chen, H. B., Zhang, Z., Wang, H. B. and Kong, X. B. (2010). Antennal morphology and sensilla ultrastructure of Dendroctonus valens LeConte (Coleoptera: Curculionidae, Scolytinae), an invasive forest pest in China. Micron 41, 735-741. 
Claridge, L. C. (1968). Sound production in species of Rhynchaenus (= Orchestes) (Coleoptera: Curculionidae). Transactions of the Royal Entomological Society of London 120, 287-299.

Cocroft, R. B. and Rodriguez, R. L. (2005). The behavioral ecology of insect vibrational communication. Bioscience 55, 323-334.

Cognato, A. I., Seybold, S. J. and Sperling, F. A. H. (1999). Incomplete barriers to mitochondrial gene flow between pheromone races of the North American pine engraver, Ips pini (Say) (Coleoptera: Scolytidae). Proceedings of the Royal Society of London Series B-Biological Sciences 266, 1843-1850.

Dahlsten, D. L., Six, D. L., Erbilgin, N., Raffa, K. F., Lawson, A. B. and Rowney, D. L. (2003). Attraction of Ips pini (Coleoptera: Scolytidae) and its predators to various enantiomeric ratios of ipsdienol and lanierone in California: Implications for the augmentation and conservation of natural enemies. Environmental Entomology 32, 11151122 .

Dickens, J. C. and Payne, T. L. (1977). Bark beetle olfaction: Pheromone receptor system in Dendroctonus frontalis. Journal of Insect Physiology 23, 481-489.

Dickens, J. C. and Payne, T. L. (1978). Structure and function of sensilla on antennal club of southern pine beetle, Dendroctonus frontalis (Zimmerman) (Coleoptera: Scolytidae). International Journal of Insect Morphology \& Embryology 7, 251-265.

Dickens, J. C., Payne, T. L., Ryker, L. C. and Rudinsky, J. A. (1984). Single cell responses of the Douglas-fir beetle, Dendroctonus pseudotsugae Hopkins (Coleoptera, Scolytidae), to pheromones and host odors. Journal of Chemical Ecology 10, 583-600.

Dobzhansky, T. H. (1937). Genetics and the origin of species. Columbia University Press, New York.

Drosopoulos, S. and Claridge, M. F. (2006) Insect sounds and communication: physiology, behaviour, ecology, and evolution. CRC Press.

Edmonds, W. D. (1974). Internal anatomy of Coprophanaeus lancifer (L) (Coleoptera: Scarabaeidae). International Journal of Insect Morphology and Embryology 3, 257-272.

Eisner, T., Aneshansley, D. J., Eisner, M., Rutowski, R., Chong, B. and Meinwald, J. (1974). Chemical defense and sound production in Australian Tenebrionid beetles (Adelium spp.). Psyche 81, 189-208.

Erbilgin, N., Nordheim, E. V., Aukema, B. H. and Raffa, K. F. (2002). Population dynamics of Ips pini and Ips grandicollis in red pine plantations in Wisconsin: Withinand between-year associations with predators, competitors, and habitat quality. Environmental Entomology 31, 1043-1051. 
Erbilgin, N. and Raffa, K. F. (2000). Effects of host tree species on attractiveness of tunneling pine engravers, Ips pini, to conspecifics and insect predators. Journal of Chemical Ecology 26, 823-840.

Faucheux, M. J. (1989). Morphology of the antennal club in the male and female bark beetles Ips sexdentatus Boern and Ips Typographus (L) (Coleoptera, Scolytidae). Annales Des Sciences Naturelles-Zoologie Et Biologie Animale 10, 231-243.

Faucheux, M. J. (1994). Distribution and abundance of antennal sensilla from 2 populations of the pine engraver, Ips pini (Say) (Coleoptera, Scolytidae). Annales Des Sciences Naturelles-Zoologie Et Biologie Animale 15, 15-31.

Fleming, A. J. (2009). Acoustic communication in the Mountain Pine Beetle, Dendroctonus ponderosae Hopk. (Coleoptera: Scolytidae): Characterization of signals and anatomy. M.Sc. Thesis. Carleton University. Ottawa, ON.

Forrest, T. G., Farris, H. E. and Hoy, R. R. (1995). Ultrasound acoustic startle response in scarab beetles. Journal of Experimental Biology 198, 2593-2598.

Forrest, T. G., Read, M. P., Farris, H. E. and Hoy, R. R. (1997). A tympanal hearing organ in scarab beetles. Journal of Experimental Biology 200, 601-606.

Gara, R.I., Millegan, D.R. AND Gibson, K.E. (1999). Integrated pest management of Ips pini (Coleoptera: Scolytidae) populations in southeastern Montana. Journal of Applied Entomology 123, 529-534.

Gerhardt, H. C. (1991). Female mate choice in treefrogs: Static and dynamic acoustic criteria. Animal Behaviour 42, 615-635.

Gries, G., Bowers, W. W., Gries, R., Noble, M. and Borden, J. H. (1990). Pheromone production by the pine engraver Ips pini following flight and starvation. Journal of Insect Physiology 36,819-824.

Haack, R. A., Blank, R. W., Fink, F. T. and Mattson, W. J. (1988). Ultrasonic acoustical emissions from sapwood of Eastern white pine, Northern red oak, red maple, and paper birch: Implications for bark- and wood-feeding insects. Florida Entomologist 71, 427-440.

Hallberg, E. (1981). Johnston's organ in Neodiprion sertifer (Insecta: Hymenoptera). Journal of Morphology 167, 305-312.

Hallberg, E. (1982). Sensory organs in Ips typographus (Insecta, Coleoptera): Finestructure of antennal sensilla. Protoplasma 111, 206-214. 
Heath, R. V. and Evans, M. E. G. (1990). The relationship between ventral nerve cord, body size, and phylogeny in ground beetles (Coleoptera, Carabidae). Zoological Journal of the Linnean Society 98, 259-293.

Hebets, E. A. and Papaj, D. R. (2005). Complex signal function: developing a framework of testable hypotheses. Behavioral Ecology and Sociobiology 57, 197-214.

Henderson, N. C. and Wadhams, L. J. (1981). Morphology of the antennal club of Scolytus scolytus (F) and S. multistriatus (Marsham) (Coleoptera: Scolytidae). Zeitschrift Fur Angewandte Entomologie-Journal of Applied Entomology 92, 477-487.

Hennig RM, Franz A, and Stumpner A. (2004). Processing of auditory information in insects. Microscopy Research and Technique 63, 351-374.

Herms, D. A., Haack, R. A. and Ayres, B. D. (1991). Variation in semiochemical mediated pre-predator interaction in Ips pini (Scolytidae) and Thanasimus dubius (Cleridae). Journal of Chemical Ecology 17, 515-524.

Hirschberger, P. (2001). Stridulation in Aphodius dung beetles: Behavioral context and intraspecific variability of song patterns in Aphodius ater (Scarabaeidae). Journal of Insect Behavior 14, 69-88.

Hoy, R. R. and Robert, D. (1996). Tympanal hearing in insects. Annual Review of Entomology 41, 433-450.

Huber, D.P.W., Borden, J. H. and Statstny, M. (2001). Response of the pine engraver, Ips pini (Say) (Coleoptera: Scolytidae), to conophthorin and other angiosperm bark volatiles in the avoidance of non-hosts. Agricultural and Forest Entomology 3, 225-232.

Hyder, D. E. and Oseto, C. Y. (1989). Structure of the stridulatory apparatus and analysis of the sound produced Smicronyx fulvus and Smicronyx sordidus (Coleoptera, Curculionidae, Erirrhininae, Smicronychini). Journal of Morphology 201, 69-84.

Jefferies, D. and Fairhurst, C. P. (1982). Stridulatory organs of the elm bark beetles Scolytus multistriatus Marsham and Scolytus scolytus Fabricius. Journal of Natural History 16, 759-762.

Jeram, S. and Pabst, M. A. (1996). Johnston's organ and central organ in Nezara viridula (L.) (Hymenoptera, Pentatomidae). Tissue and Cell 28, 227-235.

Kasper, J. and Hirschberger, P. (2005). Stridulation in Aphodius dung beetles: Songs and morphology of stridulatory organs in North American Aphodius species (Scarabaeidae). Journal of Natural History 39, 91-99.

Kegley, S.J., Livingston, R.L. and Gibson, K.E. (1997). Pine engraver Ips pini (Say), in the western United States. USDA Forest Service Forest Insect Pest Leaflet 
Kirkendall, L. R. (1983). The evolution of mating systems in bark and ambrosia beetles (Coleoptera, Scolytidae and Platypodidae). Zoological Journal of the Linnean Society 77, 293-352.

Klepzig, K. D., Moser, J. C., Lombardero, F. J., Hofstetter, R. W. and Ayres, M. P. (2001). Symbiosis and competition: Complex interactions among beetles, fungi and mites. Symbiosis 30, 83-96.

Klepzig, K. D. and Six, D. L. (2004). Bark beetle-fungal symbiosis: Context dependency in complex associations. Symbiosis 37, 189-205.

Kolmes, S. A. (1983). Ecological and sensory aspects of prey capture by whirligig beetle Dineutes discolor (Coleoptera, Gyrinidae). Journal of the New York Entomological Society 91, 405-412.

Kotiaho, J. S. (2000). Cost of sexual traits: a mismatch between theoretical considerations and empirical evidence. Biological Review 76, 365-376.

Kurz, W. A., Dymond, C. C., Stinson, G., Rampley, G. J., Neilson, E. T., Carroll, A. L., Ebata, T. and Safranyik, L. (2008). Mountain pine beetle and forest carbon feedback to climate change. Nature 452, 987-990

Lande, R. (1982). Rapid origin of sexual isolation and character divergence in a cline. Evolution 36, 609-627.

Lanier, G. N., Birch, M. C., Schmitz, R. F. and Furniss, M. M. (1972). Pheromones of Ips pini (Coleoptera: Scolytidae) - Variation in response among three populations. Canadian Entomologist 104, 1917-1923.

Lewis, E. E. and Cane, J. H. (1990). Stridulation as a primary antipredator defence of a beetle. Animal Behaviour 40, 1003-1004.

Lewis, E. E. and Cane, J. H. (1992). Inefficacy of courtship stridulation as a premating ethological barrier for Ips bark beetles (Coleoptera, Scolytidae). Annals of the Entomological Society of America 85, 517-524.

Lissemore, F. M. (1997). Frass clearing by male pine engraver beetles (Ips pini; Scolytidae): Paternal care or paternity assurance? Behavioral Ecology 8, 318-325.

Lyal, C. H. C. and King, T. (1996a). Elytro-tergal stridulation in weevils (Insecta: Coleoptera: Curculionoidea). Journal of Natural History 30, 703-773.

Mankin, R. W., Moore, A., Samson, P. R. and Chandler, K. J. (2009). Acoustic characteristics of Dynastid beetle stridulations. Florida Entomologist 92, 123-133. 
Markl, H. and Tautz, J. (1975). Sensitivity of hair receptors in caterpillars of Barathra brassicae L (Lepidoptera: Noctuidae) to particle movement in a sound field. Journal of Comparative Physiology 99, 79-87

Mason AC, and Faure PA. (2004). The physiology of insect auditory afferents. Microscopy Research and Technique 63, 338-350.

Masters, M. W. (1979). Insect disturbance stridulation: Its Defensive role. Behavioral Ecology and Sociobiology 5, 187-200.

Mattson, W. J. and Haack, R. A. (1987). The role of drought in outbreaks of planteating insects. BioScience 37, 110-118.

Masters, M. W. (1980). Insect disturbance stridulation: Characterization of airborne and vibrational components of the sound. Journal of Comparative Physiology A:

Neuroethology, Sensory, Neural, and Behavioral Physiology 135, 259-268.

Mayr, E. (1963). Animal species and evolution. Harvard University Press, Cambridge, MA.

McIver, S. B. (1975). Structure of Cuticular Mechanoreceptors of Arthropods. Annual Review of Entomology 20, 381-397.

Michael, R. R. and Rudinsky, J. A. (1972). Sound production in Scolytidae: specificity in male Dendroctonus beetles. Journal of Insect Physiology 18, 2189-2201.

Michelson, A. (1966). On the evolution of tactile stimulatory actions in longhorned beetles (Cerambycidae, Coleoptera). Zeitschrift für Tierpsychologie 23, 257-266.

Miller, D. R., Borden, J. H. and Slessor, K. N. (1996). Enantiospecific pheromone production and response profiles for populations of pine engraver, Ips pini (Say) (Coleoptera: Scolytidae), in British Columbia. Journal of Chemical Ecology 22, 21572172.

Miller, D. R., Gibson, K. E., Raffa, K. F., Seybold, S. J., Teale, S. A. and Wood, D. L. (1997). Geographic variation in response of pine engraver, Ips pini, and associated species to pheromone, lanierone. Journal of Chemical Ecology 23, 2013-2031.

Miller, P. L. (1971). A note on stridulation in some cerambycid beetles and its possible relation to ventilation. Journal of Entomology (A): General Entomology 46, 63-68.

Moeck, H. A. (1968). Electron microscopic studies of antennal sensilla in ambrosia beetle Trypodendron lineatum (Olivier) (Scolytidae). Canadian Journal of Zoology 46, 521-556. 
Mustaparta, H., Angst, M. E. and Lanier, G. N. (1977). Responses of single receptor cells in pine engraver, Ips pini (Say) (Coleoptera: Scolytidae) to its aggregation pheromone, ipsdienol, and aggregation inhibitor, ipsenol. Journal of Comparative Physiology 121, 343-347.

Mustaparta, H., Angst, M. E. and Lanier, G. N. (1979). Specialization of olfactory cells to insect-produced and host-produced volatiles in the bark beetle Ips pini (Say) Coleoptera, Scolytidae. Journal of Chemical Ecology 5, 109-123.

Mustaparta, H., Tommeras, B. A., Beckstrom, P. and Lanier, G. N. (1982). Specificities of pheromone receptor cells in inter-populational hybrids of Ips pini. Acta Physiologica Scandinavica, 38-38.

Mustaparta, H., Tommeras, B. A. and Lanier, G. N. (1985). Pheromone receptor cell specificity in inter-populational hybrids of Ips pini (Coleoptera, Scolytidae). Journal of Chemical Ecology 11, 999-1007.

Nevo, E. and Capranica, R. R. (1985). Evolutionary origin of ethological reproductive isolation in cricket frogs, Acris. Evolutionary Biology 19, 147-214.

Niven, J. E., Graham, C. M. and Burrows, M. (2008). Diversity and evolution of the insect ventral nerve cord. Annual Review of Entomology 53, 253-271.

Oester, P. T. and Rudinsky, J. A. (1979). Acoustic behavior of three sympatric species of Ips (Coleoptera, Scolytidae) co-habiting Sitka spruce. Zeitschrift Fur Angewandte Entomologie-Journal of Applied Entomology 87, 398-412.

Oester, P. T. and Rudinsky, J. A. (1975). Sound production in Scolytidae: Stridulation by "silent" Ips bark beetles. Zeitschrift für Angewandte Entomologie 79, 421 - 427.

Oester, P. T., Rudinsky, J. A. and Ryker, L. C. (1981). Olfactory and acoustic behavior of Pseudohylesinus nebulosus (Coleoptera, Scolytidae) on Douglas-fir bark. Canadian Entomologist 113, 645-650.

Oester, P. T., Ryker, L. C. and Rudinsky, J. A. (1978). Complex male premating stridulation of the bark beetle Hylurgops rugipennis (Mann.). The Coleopterists' Bulletin 32, 93-98.

Paterson, H. E. H. (1985). The recognition concept of species. In Species and speciation. (Ed E. Vrba). Pp 415-431. Transvaal Museum Monographs. Pretoria, South Africa.

Payne, T. L., Moeck, H. A., Wilson, C. D., Coulson, R. N. and Humphreys, W. J. (1973). Bark beetle olfaction II: Antennal morphology of sixteen species of Scolytidae (Coleoptera). International Journal of Insect Morphology and Embryology 2, 177-192. 
Pena, J. and Grace, J. (1986). Water relations and ultrasound emissions of Pinus sylvestris L. before, during, and after a period of water stress. New Phytologist 103, 515524.

Portfors, C. V. (2007). Types and functions of ultrasonic vocalizations in laboratory rats and mice. Journal of the American Association for Laboratory Animal Science 46, $28-34$.

Pureswaran, D. S., Gries, R. and Borden, J. H. (2004). Antennal responses of four species of tree-killing bark beetles (Coleoptera: Scolytidae) to volatiles collected from beetles, and their host and nonhost conifers. Chemoecology 14, 59-66.

Pureswaran, D. S., Gries, R., Borden, J. H. and Pierce, H. D. (2000). Dynamics of pheromone production and communication in the mountain pine beetle, Dendroctonus ponderosae Hopkins, and the pine engraver, Ips pini (Say) (Coleoptera:

Scolytidae). Chemoecology 10, 153-168.

Raffa, K. F. (2001). Mixed messages across multiple trophic levels: the ecology of bark beetle chemical communication systems. Chemoecology 11, 49-65.

Raffa, K. F., Aukema, B. H., Bentz, B. J., Carroll, A. L., Hicke, J. A., Turner, M. G. and Romme, W. H. (2008). Cross-scale drivers of natural disturbances prone to anthropogenic amplification: The dynamics of bark beetle eruptions. Bioscience 58, 501517.

Raffa, K. F. and Berryman, A. A. (1983). The role of host plant resistance in the colonization behavior and ecology of bark beetles (Coleoptera, Scolytidae). Ecological Monographs 53, 27-49.

Raffa, K. F. and Dahlsten, D. L. (1995). Differential responses among natural enemies and prey to bark beetle pheromones. Oecologia 102, 17-23.

Ramp, W. K. (1965). The auditory range of a hairy woodpecker. The Condor 67, 183185.

Reid, M.L. (1992). Female mate choice and male parental care in a bark beetle (Ips pini, Coleoptera: Scolytidae). Ph. D. thesis, Simon Fraser University, Burnaby, B.C.

Reid, M. L. and Roitberg, B. D. (1994). Benefits of prolonged male residence with mates and brood in pine engravers (Coleoptera, Scolytidae). Oikos 70, 140-148.

Reid, M. L. and Roitberg, B. D. (1995). Effects of body size on investment in individual broods by male pine engravers (Coleoptera, Scolytidae).Canadian Journal of ZoologyRevue Canadienne De Zoologie 73, 1396-1401.

Reid, M. L. and Stamps, J. A. (1997). Female mate choice tactics in a resource-based mating system: Field tests of alternative models. American Naturalist 150, 98-121. 
Robertson, I. C. (1998). Paternal care enhances male reproductive success in pine engraver beetles. Animal Behaviour 56, 595-602.

Robertson, I. C. and Roitberg, B. D. (1998). Duration of paternal care in pine engraver beetles: why do larger males care less? Behavioral Ecology and Sociobiology 43, 379 386.

Robins, G. L. and Reid, M. L. (1997). Effects of density on the reproductive success of pine engravers: is aggregation in dead trees beneficial? Ecological Entomology 22, 329334.

Rudinsky, J. A. (1962). Ecology of Scolytidae. Annual Review of Entomology 7, 327348 .

Rudinsky, J. A. (1969). Masking of aggregation pheromone in Dendroctonus pseudotsugae Hopk. Science 166, 884-885.

Rudinsky, J. A. (1979). Chemoacoustically induced behavior of Ips typographus (Col, Scolytidae). Zeitschrift Fur Angewandte Entomologie-Journal of Applied Entomology 88, 537-541.

Rudinsky, J. A., Kline, L. N. and Diekman, J. D. (1975). Response inhibition by 4 analogues of $\mathrm{MCH}$, and anti-aggregative pheromone of Douglas-fir beetle (Coleoptera, Scolytidae). Journal of Economic Entomology 68, 527-528.

Rudinsky, J. A. and Michael, R. R. (1972). Sound production in Scolytidae: chemostimulus of sonic signals by Douglas-fir beetle. Science 175, 1386-1390.

Rudinsky, J. A. and Michael, R. R. (1973). Sound production in Scolytidae: stridulation by female Dendroctonus beetles. Journal of Insect Physiology 19, 689-705.

Rudinsky, J. A. and Michael, R. R. (1974). Sound production in scolytidae: rivalry behavior of male Dendroctonus beetles. Journal of Insect Physiology 20, 1219-1230.

Rudinsky, J. A., Morgan, M., Libbey, L. M. and Michael, R. R. (1973). Sound Production in Scolytidae: 3-Methyl-2-Cyclohexen-1-One Released by the Female Douglas Fir Beetle in Response to Male Sonic Signal. Environmental Entomology 2, 505510 .

Rudinsky, J. A., Morgan, M. E., Libbey, L. M. and Putnam, T. B. (1974). Antiaggregative rivalry pheromone of mountain pine beetle (Coleoptera, Scolytidae), and a new arrestant of southern pine beetle (Coleoptera, Scolytidae). Environmental Entomology 3, 90-98. 
Rudinsky, J. A., Oester, P. T. and Ryker, L. C. (1978a). Gallery initiation and male stridulation of polygamous spruce bark beetle Polygraphus rufipennis. Annals of the Entomological Society of America 71, 317-321.

Rudinsky, J. A. and Ryker, L. C. (1976). Sound production in Scolytidae: rivalry and pre-mating stridulations of male Douglas-fir beetle. Journal of Insect Physiology 22, 997-1003.

Rudinsky, J. A., Ryker, L. C., Michael, R. R., Libbey, L. M. and Morgan, M. E. (1976). Sound production in Scolytidae: female sonic stimulus of male pheromone release in 2 Dendroctonus beetles. Journal of Insect Physiology 22, 1675-1681.

Rudinsky, J. A. and Vallo, V. (1979). Ash bark beetles Leperisinus fraxini and Hylesinus oleiperda: Stridulatory organs, acoustic signals and pheromone production. Zeitschrift Fur Angewandte Entomologie-Journal of Applied Entomology 87, 417-429.

Rudinsky, J. A., Vallo, V. and Ryker, L. C. (1978b). Sound production in Scolytidae: attraction and stridulation of Scolytus mali (Col, Scolytidae). Zeitschrift Fur Angewandte Entomologie-Journal of Applied Entomology 86, 381-391.

Ryker, L. C. (1988). Acoustic studies of Dendroctonus bark beetles. Florida Entomologist 71, 447-461.

Ryker, L. C., Libbey, L. M. and Rudinsky, J. A. (1979). Comparison of volatile compounds and stridulation emitted by the Douglas-fir beetle from Idaho and Western Oregon populations (Coleoptera, Scolytidae). Environmental Entomology 8, 789-798.

Ryker, L. C. and Rudinsky, J. A. (1976a). Sound production in Scolytidae: acoustic signals of male and female Dendroctonus valens LeConte. Zeitschrift Fur Angewandte Entomologie-Journal of Applied Entomology 80, 113-118.

Ryker, L. C. and Rudinsky, J. A. (1976b). Sound production in Scolytidae: aggressive and mating behavior of mountain pine beetle. Annals of the Entomological Society of America 69, 677-680.

Salle, A. and Raffa, K. F. (2007). Interactions among intraspecific competition, emergence patterns, and host selection behaviour in Ips pini (Coleoptera :

Scolytinae). Ecological Entomology 32, 162-171.

Sanford, A. P. and Grace, J. (1985). The measurement and interpretation of ultrasound from woody stem. Journal of Experimental Botany 36, 298-311.

Sasakawa, M. and Sasakawa, T. (1981). Stridulatory organs of the minute pine bark beetle, Cryphalus fulvus Niijima (Coleoptera: Scolytidae), and role of male sound in the aggregation behavior. The Entomological Society of Japan 49, 461-469. 
Sasakawa, M. and Yoshiyasu, Y. (1983). Stridulatory organs of the Japanese pine bark beetle (Coleoptera: Scolytidae). The Entomological Society of Japan 51, 493-501.

Sauvard, D. (2004). General biology of bark beetles. Dordrecht: Kluwer Academic Publishers.

Schenk, J. A. and Benjamin, D. M. (1969). Notes on biology of Ips pini in central Wisconsin jack pine forests. Annals of the Entomological Society of America 62, 480-\&.

Schmitt, M. (1994). Stridulation in leaf beetles (Coleoptera, Chrysomelidae). In Novel Aspects of the biology of Chrysomelidae. (Eds. P.H. Jolivet, M.L. Cox \& E. Petitpierre), pp 319-325. Kluwer Academic Publishers, Dodrecht, Holanda.

Schmitt, M. and Traue, D. (1990). Morphological and bioacoustical aspects of stridulation in Criocerinae (Coleoptera, Chrysomelidae). Zoologischer Anzeiger 225, 225-240.

Schmitz, R. F. (1972). Behavior of Ips pini during mating, oviposition, and larval development (Coleoptera: Scolytidae). Canadian Entomologist 104, 1723-\&.

Schneider, D. (1964). Insect Antennae. Annual Review of Entomology 9, 103-122.

Senger, S.E. and Roitberg, B.D. (1992). Effects of parasitism by Tomicobia tibialis Ashmead (Hymenoptera: Pteromalidae) on reproductive parameters of female pine engravers, Ips pini (Say). Canadian Entomologist 124, 509-513.

Seybold, S. J., Teale, S. A., Wood, D. L., Zhang, A. J., Webster, F. X., Lindahl, K. Q. and Kubo, I. (1992). The role of lanierone in the chemical ecology of Ips pini (Coleoptera, Scolytidae) in California. Journal of Chemical Ecology 18, 2305-2329.

Shaw, K. L. and Herlihy, D. P. (2000). Acoustic preference functions and song variability in the Hawaiian cricket Laupala cerasina. Proceedings of the Royal Society of London Series B-Biological Sciences 267, 577-584.

Six, D. L., Vander Meer, M., DeLuca, T. H. and Kolb, P. (2002). Pine engraver (Ips pini) colonization of logging residues created using alternative slash management systems in Western Montana. Western Journal of Applied Forestry 17, 96-100.

Skilbeck, C. A. and Anderson, M. (1996). The ultrastructure, morphology and distribution of sensilla on the antennae of the adult parasitoid Aleochara bilineata Gyll. and Aleochara bipustulata L. (Coleoptera: Staphylinidae). International Journal of Insect Morphology and Embryology 25, 261-280. 
Slobodchikoff, C. N. and Spangler, H. G. (1979). Two types of sound production in Eupsophulus castaneus (Coleoptera: Tenebrionidae). The Coleopterists Bulletin 33:239243.

Snodgrass, R. E. (1935). Principles of insect morphology. McGraw-Hill Book Co., Inc., New York \& London.

Spangler, H. G. (1988). Hearing in tiger beetles (Cicindelidae). Physiological Entomology 13, 447-452.

Stamps, J. A., Krishnan, V. V. and Reid, M. L. (2005). Search costs and habitat selection by dispersers. Ecology 86, 510-518.

Steed, B. E. and Wagner, M. B. (2004). Importance of log size on host selection and reproductive success of Ips pini (Coleoptera : Scolytidae) in ponderosa pine slash of northern Arizona and western Montana. Journal of Economic Entomology 97, 436-450.

Stolting, H., Moore, T. E. and Lakes-Harlan, R. (2002). Substrate vibration during signaling in the cicada Okanagana rimosa. Journal of Insect Science 2, 1-7.

Swaby, J. A. and Rudinsky, J. A. (1976). Acoustic and olfactory behavior of Ips pini (Say) (Coleoptera: Scolytidae) during host invasion and colonization. Zeitschrift Fur Angewandte Entomologie-Journal of Applied Entomology 81, 421-432.

Swedenborg, P. D., Jones, R. L. and Ryker, L. C. (1989). Stridulation and associated behavior of the native elm bark beetle Hylurgopinus rufipes (Eichhoff) (Coleoptera, Scolytidae). Canadian Entomologist 121, 245-252.

Symonds, M. R. E. and Elgar, M. A. (2004a). Species overlap, speciation and the evolution of aggregation pheromones in bark beetles. Ecology Letters 7, 202-212.

Symonds, M. R. E. and Elgar, M. A. (2004b). The mode of pheromone evolution: evidence from bark beetles. Proceedings of the Royal Society of London Series BBiological Sciences 271, 839-846.

Teale, S. A., Hager, B. J. and Webster, F. X. (1994). Pheromone based assortative mating in bark beetles. Animal Behaviour 48, 569-578.

Teale, S. A., Webster, F. X., Zhang, A. and Lanier, G. N. (1991). Lanierone: A new pheromone component from Ips pini (Coleoptera: Scolytidae) in New York. Journal of Chemical Ecology 17, 1159-1176

Thomas, J. B. (1961). The life history of Ips pini (Say) (Coleoptera: Scolytidae). The Canadian Entomologist 93, 384-390. 
Tommeras, B. A., Mustaparta, H. and Gregoire, J. C. (1984). Receptor cells in Ips tyographus and Dendroctonus micans specific to pheromones of the reciprocal genus. Journal of Chemical Ecology 10, 759-769.

Tyree, M. T. and Dixon, M. A. (1983). Cavitation events in Thuja occidentalis L.? Ultrasonic acoustic emissions from the sapwood can be measured. Plant Physiology 72 , 1094-1099.

Vernoff, S. and Rudinsky, J. A. (1980). Sound production and pairing behavior of Leperisinus californicus (Swaine), and Leperisinus oregonus (Blackman) (Coleoptera, Scolytidae), attacking Oregon ash. Zeitschrift Fur Angewandte Entomologie-Journal of Applied Entomology 90, 58-74.

Virant-Doberlet, M. and Cokl, A. (2004). Vibrational communication in insects. Neotropical Entomology 33, 121-134.

Wadhams, L. J., Angst, M. E. and Blight, M. M. (1982). Response of the olfactory receptors of Scolytus scolytus (F) (Coleoptera: Scolytidae) to the stereoisomers of 4Methyl-3-Heptanol. Journal of Chemical Ecology 8, 477-492.

Wallin, K. F. and Raffa, K. F. (2000). Influences of host chemicals and internal physiology on the multiple steps of postlanding host acceptance behavior of Ips pini (Coleoptera : Scolytidae). Environmental Entomology 29, 442-453.

Wessel, A. (2006). In Insect sounds and communication: physiology, behaviour, ecology, and evolution. (Ed. S. Drosopoulos and M.F. Claridge). CRC Press.

Whitehead, A. T. (1981). Ultrastructure of sensilla of the female mountain pine beetle, Dendroctonus ponderosae Hopkins (Coleoptera, Scolytidae). International Journal of Insect Morphology \& Embryology 10, 19-28.

Wilkinson, R. C., McClelland, W.T. and Ostmark, E.O. (1967). Stridulation and behavior in two southeastern Ips bark beetles. The Florida Entomologist 50, 185-195.

Wilkinson, R. C. (1962). Stridulating organs in three southern Ips bark beetles. The Florida Entomologist 45, 42-44.

Wood, S.L. (1982) Great Basin Naturalist Memoirs, Number 6: The Bark and Ambrosia Beetles of North and Central America (Coleoptera: Scolytidae), a Taxonomic Monograph. Brigham Young University, Provo, Utah.

Wood. D.L. (1961). Stridulation in the genus Ips De Geer. The Pan-pacific Entomologist 37, 187-188.

Yack, J. E. (2004). The structure and function of auditory chordotonal organs in insects. Microscopy Research and Technique 63, 315-337. 
Yack, J. E. and Dawson, J. (2008). Insect Ears. In: The Senses: A Comprehensive Reference. (Eds. Hoy, R.R., Shepherd, G.M., Basbaum, A.I., Kaneko, A., and Westheimer, G.) Vol. 3, pp.35-54.

Yack, J.E. and Fullard, J. H. (1993). What is an insect ear? Annals of the Entomological Society of America 86, 677-682.

Yack, J. E. and Hoy, R. R. (2003). Insect Ears. In: The Encyclopedia of Insects (Eds. Resh, V.H. and Cardé, R.). pp. 498-505. Academic Press, San Diego, CA.

Yager, D. D. (1999). Structure, development, and evolution of insect auditory systems. Microscopy Research and Technique 47, 380-400.

Yager, D. D. and Spangler, H. G. (1995). Characterization of auditory afferents in the tiger beetle, Cicindela marutha Dow. Journal of Comparative Physiology a-Sensory Neural and Behavioral Physiology 176, 587-599.

Yager, D. D. and Spangler, H. G. (1997). Behavioral response to ultrasound by the tiger beetle Cicindela marutha Dow combines aerodynamic changes and sound production. Journal of Experimental Biology 200, 649-659.

Yandell, K. L. (1984). Sound production of Dendroctonus ponderosae, Hopkins, (Coleoptera: Scolytidae): a comparison of population from 3 host pines in Oregon. Zeitschrift Fur Angewandte Entomologie-Journal of Applied Entomology 97, 180-187.

Zahavi, A. (1975). Mate selection - A selection for a handicap. Journal of Theoretical Biology 53, 205-214. 